Leandro Augusto da Silva

\title{
Classificação de Nódulos Mamográficos Utilizando um Comitê de Redes Neurais Artificiais
}

Dissertação apresentada à Escola Politécnica da Universidade de São Paulo para obtenção do Título de Mestre em Engenharia. 
Leandro Augusto da Silva

\section{Classificação de Nódulos Mamográficos Utilizando um Comitê de Redes Neurais Artificiais}

Dissertação apresentada à Escola Politécnica da Universidade de São Paulo para obtenção do Título de Mestre em Engenharia.

Área de concentração:

Sistemas Eletrônicos

Orientador:

Prof. Dr.

Emilio Del Moral Hernandez 


\section{FICHA CATALOGRÁFICA}

Silva, Leandro Augusto da

Classificação de Nódulos Mamográficos Utilizando um Comitê de Redes Neurais Artificiais. São Paulo, 2005. 94 p.

Dissertação (Mestrado) - Escola Politécnica da Universidade de São Paulo. Departamento de Sistemas Eletrônicos.

1-Redes Neurais 2-Reconhecimento de Padrões 3-Processamento de Imagens 4-Diagnóstico por Imagens 5-Mamografia 6-Neoplasias Mamárias I. Universidade de São Paulo. Escola Politécnica. Departamento de Sistemas Eletrônicos. Departamento de Sistemas Eletrônicos. II. T. 
aos meus pais Cirilo e Vera pelo apoio, compreensão e carinho... 


\section{Apoio}

Este projeto foi financiado por:

Conselho de Desenvolvimento Científico e Tecnológico (CNPq).

E contou com os recursos adquiridos através do:

Projeto SIIAM (Sistemas Informacionais Integrados para Análise Multisensorial).

Ao orgão financiador, sem o qual este projeto não seria realizado e ao Projeto SIIAM, sem o qual não poderíamos contar com os equipamentos do laboratório, nossos agradecimentos. 


\section{Agradecimentos}

Gostaria de agradecer à Universidade de São Paulo, à Escola Politécnica e ao Laboratório de Sistemas Integráveis.

Agradeço ao meu orientador Prof. Dr. Emilio Del Moral Hernandez pela oportunidade de realizar esse trabalho e ao aprendizado dado na realização do mestrado sempre desempenhando o papel de orientador no sentido mais puro da palavra, com paciência nas extensas discussões e sempre buscando as melhores soluções e estratégias para resolver os inúmeros desafios surgidos ao longo do mestrado.

Agradeço também o professor Rangaraj Mandayam Rangayyan da Universidade de Calgary, quem colaborou e apoiou esse trabalho e sempre que presente no Brasil, discutia o desenrolar do projeto com sugestões e críticas que ajudaram no desenvolvimento da pesquisa. Agradeço também a professora Roseli de Deus Lopes e o professor Ademar Ferreira pelas críticas, dicas e contribuições.

Agradeço também o grande amigo e companheiro nessa jornada, Humberto Rodrigo Sandmann que sempre estava disposto a ouvir e discutir idéias, além de sempre ter boas sugestões para os problemas enfrentados nessa pesquisa.

Também aquelas pessoas que me ajudaram indiretamente: Paula Khater, Vinícius Maeda, Márcio Binatto e Marcel Macedo.

Por fim, agradeço aos meus pais, quem sempre acreditaram que a educação é o melhor investimento que pode ser dado ao filho. 


\section{Resumo}

Este trabalho apresenta uma nova estratégia computacional para classificar nódulos mamográficos, que podem ser identificados por radiologistas nos exames de mamografia, em benignos ou malignos.

Para a realização dos experimentos computacionais, foram utilizados 57 regiões suspeitas de câncer (ROIs) encontrados pelo radiologista nos exames de mamografia. Das 57 ROIs, 37 foram identificadas como nódulos benignos e 20 identificadas como nódulos malignos, após o exame de biópsia.

Com base nestas 57 ROIs são aplicadas técnicas de processamento de imagens para extrair determinadas características que possibilitam classificar um nódulo como benigno ou maligno. Estas características são separadas em três conjuntos: três características de forma, quatorze características de textura e três características de nitidez da borda.

A estratégia computacional usada para classificar esses três conjuntos de características foi o classificador Máquina de Comitê. A Máquina de Comitê é formado por um grupo de classificadores, usados para resolver uma tarefa difícil. Os membros do comitê são tipicamente Redes Neurais Artificiais. Nesse trabalho foram usados Perceptrons de Múltiplas Camadas (MLP) como classificador da Máquina de Comitê. O resultado da classificação é dado pela combinação das respostas de cada classificador. Experimento envolvendo alteração na configuração da Máquina de Comitê também foi realizado. A precisão da classificação foi avaliada utilizando o cálculo da área sob a curva Receiver Operating Characteristics (ROC), designada por $A_{z}$.

O resultado de $A_{z}$ apresentado pela Máquina de Comitê é comparado com o resultado de outros classificadores neurais, como MLPs e Perceptrons de Camada Simples (SLP). Os resultados são apresentados pela média e desvio padrão de 20 experimentos.

Para concluir se o resultado apresentado por um classificador é melhor que o outro, foram realizados testes de hipóteses utilizando a distribuição de Student $t$. 


\section{Abstract}

This work addresses a new approach using a committee machine to classify masses found in mammograms as benign or malignant. The characteristics sets used in the classification are: Three shape factors, three measures of edge sharpness, and fourteen texture features. They were used for the classification of 37 regions of interest (ROIs) related to benign masses and 20 ROIs of malignant tumors.

The committee machine is a group of classifiers used to resolve a difficult task. Committee members are typically neural networks. In this work, we used a group of multi-layer perceptrons (MLPs) as a committee machine classifier. The classification results were realized by combining the responses of these classifiers. Experiments involving change in the learning algorithm of the committee machine also were conducted. The classification accuracy was evaluated using the area $A_{z}$ under the receiver operating characteristics (ROC) curve.

The $A_{z}$ result for the committee machine was compared with the $A_{z}$ results obtained using MLP and single-layer perceptron (SLP) neural networks. In almost all cases, the committee machine outperformed the MLP and SLP. For a better understanding about the results of the experiments we carried out the hypothesis test using the Student's t-Distribution and it showed that the Committee Machine classifier has better results than MLP and SLP classifiers. 


\section{Sumário}

\section{Lista de Figuras}

\section{Lista de Tabelas}

\section{Lista de Abreviaturas}

\section{Convenções e Lista de Símbolos}

1 Introdução 1

1.1 O Problema Câncer de Mama . . . . . . . . . . . . . . . . . . . 1

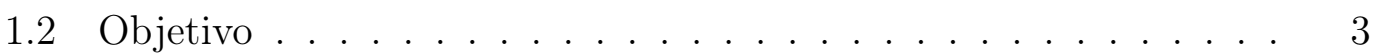

1.3 Motivação . . . . . . . . . . . . . . . . . . . . . . 4

1.4 Metodologia ...................... . . 4

1.5 Estrutura do Texto . . . . . . . . . . . . . . . . 5

2 Câncer de Mama $\quad 6$

2.1 Definição do Câncer de Mama . . . . . . . . . . . . . . . . . 6

2.2 Incidência do Câncer de Mama no Brasil e no Mundo . . . . . . . 7

2.3 Mamografia . . . . . . . . . . . . . . . . . 10

2.4 Diagnóstico Auxiliado por Computador ou CAD . . . . . . . . . . 14

$\begin{array}{llr}3 & \text { Extração das Características } & 17\end{array}$

3.1 Base de Imagens Usadas para o Trabalho . . . . . . . . . . . . . 17 
3.2 Procedimento Clínico de um Radiologista . . . . . . . . . . . . . . 17

3.3 Características de Forma da Borda do Nódulo . . . . . . . . . . . 22

3.4 Características de Textura . . . . . . . . . . . . . . 24

3.5 Características de Nitidez da Borda do Nódulo . . . . . . . . . . . 27

4 Classificador Utilizando uma Arquitetura de Rede Neural Artificial do tipo Máquina de Comitê $\quad 31$

4.1 Breve Histórico sobre as Redes Neurais Artificiais . . . . . . . . . 31

4.2 Conceitos Básicos sobre as Redes Neurais Artificiais . . . . . . . . 33

4.3 Aplicações das Redes Neurais . . . . . . . . . . . . . . . . 35

4.4 Máquinas de Comitê . . . . . . . . . . . . . . . 36

4.4.1 Reforço por Filtragem . . . . . . . . . . . 38

4.4 AdaBoost . . . . . . . . . . . . . . . 38

4.4.3 Arquitetura Neural $R N_{N T E}$ - Perceptrons de Múltiplas Camadas ..................... . . 45

5 Área Sob a Curva ROC - $A_{z} \quad 49$

5.1 Métrica de Análise de Desempenho na Medicina . . . . . . . . . . 49

5.2 Métrica de Desempenho para Classificador Automático Aplicado na Medicina ...................... 51

6 Experimentos Realizados e Análise $\quad 56$

6.1 Base de Dados Utilizada nos Experimentos . . . . . . . . . . 56

6.2 Método de Análise de Desempenho - Área Sob a Curva ROC ou $A_{z} 60$

6.3 Resultados Obtidos . . . . . . . . . . . . . . . 63

6.4 Configuração dos Classificadores para a Obtenção dos Resultados 64

6.5 Análises Realizadas . . . . . . . . . . . . . . . . . . . . 69 
6.5.1 O problema da Dimensionalidade . . . . . . . . . . . 69

6.5.2 Análise dos Resultados com o Teste de Hipóteses . . . . . 71

$\begin{array}{llr}7 & \text { Conclusão e Trabalhos Futuros } & 81\end{array}$

Anexo A - Teste de Hipóteses utilizando a distribuição de Student $t$

Referências Bibliográficas

Apêndice A - Tabela da Distribuição de Student $t$. 


\section{Lista de Figuras}

2.1 Incidência do câncer de mama no mundo. . . . . . . . . . . . . . 8

2.2 Incidência de câncer no Brasil em 2005. . . . . . . . . . . . . . . . . 9

2.3 Ilustração do aparelho de raios-x. . . . . . . . . . . . . . . . . . . 11

2.4 Exemplos de aquisições de imagens feitas em um exame de raios-x. . . 12

2.5 Diagrama esquemático do sistema CAD . . . . . . . . . . . 16

3.1 Ilustração das 37 ROIs benignas. . . . . . . . . . . . . . . . 18

3.2 Ilustração das 20 ROIs malignas. . . . . . . . . . . . . . . . . 19

3.3 Nódulo benigno com contorno circunscrito. . . . . . . . . . . . . . . . 21

3.4 Nódulo maligno com contorno espiculado. . . . . . . . . . . . . . 21

3.5 Nódulo benigno com contorno espiculado. . . . . . . . . . . . . . . 21

3.6 Nódulo maligno com contorno circunscrito. . . . . . . . . . . . . . . . 22

3.7 Nódulo demonstrando a parte côncava e convexa do contorno. . . . . . 23

3.8 Faixa de pixels do contorno do nódulo. . . . . . . . . . . . . . . 27

3.9 Linhas perpendiculares traçadas em torno do contorno do nódulo. . . . 28

3.10 Ilustração de deferentes contornos do nódulo. . . . . . . . . . . . . . 30

4.1 Ilustração de neurônio biológico e neurônio artificial. . . . . . . . . . . . 34

4.2 Ilustração dos pesos probabilísticos. . . . . . . . . . . . . . . 40

4.3 Ilustração da arquitetura Máquina de Comitê. . . . . . . . . . . . . . 42

4.4 Resumo do Algoritmo AdaBoost . . . . . . . . . . . . . . 43

4.5 Desempenho do erro de generalização do AdaBoost. . . . . . . . . . . 44 
4.6 Desempenho do erro de generalização do aprendizado de retropropagação do erro. . . . . . . . . . . . . . . . . . . . . . . . . . 4 45

4.7 Ilustração do MLP. . . . . . . . . . . . . . . . . . . . . . . . . . . . 46

4.8 Exemplo da função sigmóide. . . . . . . . . . . . . . . . . . . . . . 47

5.1 Exemplo de resultados de um diagnóstico. . . . . . . . . . . . . . . 50

5.2 Exemplo da curva ROC. . . . . . . . . . . . . . . . . . . . . . 54

6.1 Gráfico 3D das características $\left[F_{c c}, S I, C\right] \ldots \ldots \ldots$

6.2 Gráfico 3D das características $[C V, A$, contraste $] . \ldots \ldots$. . . . . . 58

6.3 Ilustração do teste da Máquina de Comitê. . . . . . . . . . . . . . . . 61

6.4 Análise dos resultados de classificação da Máquina de Comitê para a construção da curva ROC . . . . . . . . . . . . . . . . . . . . . 62

6.5 Ilustração da curva ROC e do $A_{z} \ldots \ldots$. . . . . . . . . . . 63

6.6 Curvas de Aprendizagem para as características $\left[F_{c c}, S I, C\right] \ldots \ldots 7$

6.7 Curvas de Aprendizagem para as características de textura. . . . . . . 67

6.8 Curvas de Aprendizagem para as características $[C V, A$, contraste $]$. . . 68

6.9 Efeito do problema da dimensionalidade. (Fonte (CAMPOS, 2001)) . . 70

6.10 Comparação entre o classificador Máquina de Comitê configurado "sem $w$ continuado" e "com $w$ continuado". . . . . . . . . . . . . . . . . . 74

6.11 Resultados da comparação entre o classificador Máquina de Comitê configurado "sem $w$ continuado" e o classificador MLP. . . . . . . . . . . 75

6.12 Resultados da comparação entre o classificador Máquina de Comitê configurado "sem $w$ continuado" e o classificador SLP. . . . . . . . . . . . 76

6.13 Resultados da comparação entre o classificador Máquina de Comitê configurado "com $w$ continuado" e o classificador MLP. . . . . . . . . . . 77

6.14 Resultados da comparação entre o classificador Máquina de Comitê configurado "com $w$ continuado" e o classificador SLP. . . . . . . . . . . . 78

6.15 Todos os resultados de comparações. . . . . . . . . . . . . . . . . . 80 
A.1 Valores dos percentis $\left(t_{p}\right)$ da distribuição de Student $t$ com $\nu$ graus de liberdade (área sombreada $=p$ ). Fonte: (SPIEGEL, 1993). . . . 94 


\section{Lista de Tabelas}

2.1 Tendência mundial do câncer de mama. . . . . . . . . . . . . 7

5.1 Tabela de Contingência. . . . . . . . . . . . . . . . . . . 51

6.1 Tabela de resultados. . . . . . . . . . . . . . . . . . . . . . 64

6.2 Número de especialistas usado no comitê. . . . . . . . . . . . . . 66 


\section{Lista de Abreviaturas}

CAD Diagnóstico Auxiliado por Computador em inglês Computer Aided Diagnosis

MLP Perceptrons de Múltiplas Camadas em inglês Multi-Layer Perceptron

SLP Perceptron de Única Camada em inglês Single Layer Perceptron

ROC do inglês Receiving Operating Curve

ROI do inglês Region of Interest

CC Crânio Caudal

MLO Médio Lateral Oblíquo

C compacidade ou compactness

$\boldsymbol{F}_{\boldsymbol{c c}}$ concavidade fracionária (ou fractional concavity em inglês)

SI grau de "espicularidade" (ou spiculation index em inglês)

A descontinuidade (ou Acutance em inglês)

contraste do inglês contrast

CV coeficiente de variação (ou coefficient of variation em inglês

AdaBoost algoritmo de reforço adaptativo em inglês, adaptive boosting

PAC Provavelmente Aproximadamente Correta em inglês, Probably Approximately Correct 


\section{Convenções e Lista de Símbolos}

Na notação das fórmulas, as seguintes convenções foram utilizadas:

- letras maiúsculas são conjuntos, exemplo: $D, X, Y$;

- letras minúsculas são elementos de conjunto, exemplo: $x, y$;

- subscrito diferencia um elemento de um conjunto, exemplo: $x_{i}, y_{i}$ e $w_{i}$;

- em uma algoritmo: a variável ne significa cada iteração e NTE o número máximo de iteração;

- função de um vetor $\mathbf{x}: f(\mathbf{x})$;

- matriz de pesos sinapticos: $w$;

- cardinalidade do conjunto de treinamento: $N$. 


\section{Introdução}

\subsection{O Problema Câncer de Mama}

O câncer de mama é o tipo de câncer que se manifesta com maior freqüência entre as mulheres brasileiras (INCA, 2002), nas quais a maior incidência ocorre em mulheres entre 35 e 50 anos. Nos países desenvolvidos, principalmente, observa-se um aumento constante na incidência de câncer de mama, na maioria dos casos, em mulheres de meia idade (NCI, 2004).

Desde o início das pesquisas sobre o câncer de mama, a melhor maneira para a cura da doença é uma rápida detecção. A detecção precoce pode ser conseguida através do exame de mamografia, que é uma forma particular de radiografia capaz de registrar imagens da mama com a finalidade de diagnosticar a presença ou ausência de estruturas que possam indicar a doença. Com esse tipo de exame pode-se detectar o tumor antes que ele se torne palpável. No entanto, a avaliação do exame de mamografia e o diagnóstico, que é realizado por um radiologista, requer bastante habilidade.

Estudos têm mostrado que apenas $20 \%$ a 30\% de nódulos mamográficos identificados pelo radiologista, considerados suspeitos e submetidos ao exame de biópsia, são malignos (HERMANN et al., 1987; HALL et al., 1988; JACOBSON; EDEIKEN, 1990; ARAUJO, 2000).

O exame de biópsia consiste numa pequena cirurgia destinada a retirar um 
pedaço do nódulo suspeito, ou mesmo o nódulo inteiro, para que este seja analisado. Conforme o caso, isso pode ser feito através de uma biópsia aspirativa por agulha fina ${ }^{1}$. Um erro no diagnóstico dado pelo radiologista (falso positivo que é submeter à biópsia um nódulo suspeito de câncer, o qual se constata não ser câncer), acarreta em um excessivo custo ao sistema de saúde e traumatismo ao paciente.

Por estes motivos, vários pesquisadores estão desenvolvendo sistemas que auxiliam o radiologista no diagnóstico do câncer evitando o exame desnecessário de biópsia. Estes sistemas são conhecidos como CAD (Diagnóstico Auxiliado por Computador em inglês, Computer-Aided-Diagnosis).

Os sistemas CAD auxiliam o radiologista no diagnóstico, atuando em uma região suspeita de câncer, pré-identificada no exame de mamografia pelo radiologista. Assim, quando o radiologista identificar uma região suspeita de câncer é feita uma marcação (manualmete) do nódulo não palpável suspeito de ser câncer. A região que envolve a marcação é chamada de região de interesse, ROI (em inglês, Regions of Interest).

São utilizadas técnicas de processamento de imagens para detectar e extrair determinadas características do nódulo marcado manualmente pelo radiologista (as ROIs). A partir destas características extraídas, são aplicadas técnicas de inteligência computacional, que as classificam em benignas ou malignas.

Entre as diversas técnicas utilizadas na extração de características dos nódulos nas ROIs, algumas se destacam, como filtros de Wavelets (FERRARI et al., 2001), crescimento de região (SHEN et al., 1994), transformada H-dome (HALKIOTIS; MANTAS; BOTSIS, 2002) e transformada de Wathershed (SANTOS, 2002).

As Redes Neurais Artificiais (RNA) são um exemplo de técnica de inteligên-

\footnotetext{
${ }^{1}$ É um método diagnóstico, que retira células para estudos ao microscópio, para detectar a exata natureza de um nódulo.
} 
cia computacional que vem sendo utilizada para a classificação das características extraídas (HALKIOTIS; MANTAS; BOTSIS, 2002; YU; GUAN, 2000; ANDRE; RANGAYYAN, 2003). Para isto, diversas arquiteturas de RNA como o Perceptron de Múltiplas Camadas (MLP em inglês Multi-Layer Perceptron) (HALKIOTIS; MANTAS; BOTSIS, 2002; YU; GUAN, 2000; ANDRE; RANGAYYAN, 2003) e Perceptron de Única Camada (SLP em inglês Single Layer Perceptron) (ANDRE; RANGAYYAN, 2003) são aplicadas na tentativa de uma melhor classificação de nódulos.

\subsection{Objetivo}

O objetivo do presente trabalho é apresentar uma nova proposta de classificação de características extraídas das ROIs utilizando redes neurais artificiais. Dessa maneira, pretende-se melhorar os resultados de discriminação entre nódulo benigno e nódulo maligno, utilizando-se um comitê de Redes Neurais de arquiteturas de Perceptrons de Múltiplas Camadas. Essa arquitetura é a conhecida como Máquina de Comitê, a qual baseia-se em um princípio freqüentemente usado em engenharia: "dividir e conquistar" (HAYKIN, 1999; DUDA; HART; STORK, 2000; SCHAPIRE, 1999; HU; HWANG, 2001).

Para medir a capacidade do classificador em discriminar um nódulo maligno ou benigna é utilizado o método conhecido como área sob a curva ROC (em inglês Receiver Operating Characteristics), designada por $A_{z}$ (WOODS; BOWYER, 1997; DELEO; CAMPBELL, 1995; DELEO, 2002). A curva ROC também pode ser utilizada para comparar resultados entre classificadores. Neste trabalho é mostrado o resultado da área sob a curva ROC $\left(A_{z}\right)$ para o classificador Máquina de Comitê e para os classificadores MLP e SLP (utilizados para a comparação).

Diversas investigações na combinação das características utilizadas (extraídas 
das ROIs) são realizadas de modo a verificar qual a combinação das características para a qual o classificador apresenta melhor resultado de discriminação.

\subsection{Motivação}

A motivação deste trabalho é a sua relevância científica e social na detecção precoce do câncer de mama. O desenvolvimento de um classificador capaz de fornecer resultados com alto valor de $A_{z}$ permitirá ao radiologista aumentar a sua aferição no diagnóstico, evitando-se assim erros que acarretam em falsos diagnósticos, comprometem o paciente psicologicamente e acarretam em gastos desnecessários ao sistema de saúde.

\subsection{Metodologia}

Para a realização dos experimentos de classificação, foi utilizado um conjunto de características (features) extraídas de regiões suspeitas de câncer de mama identificadas nas imagens de mamografia. Os valores destas características para as ROIs são fornecidos pela Universidade de Calgary. Assim, este conjunto de valores de características é dividido em dois novos conjuntos, onde um conjunto é utilizado como exemplo para o treinamento do classificador e o outro conjunto é utilizado para o teste do classificador. O resultado da classificação do conjunto de teste é avaliado utilizando o método da área sob a curva ROC ou $A_{z}$. O resultado do classificador Máquina de Comitê é comparado com o resultado do classificador MLP e SLP. Para verificar se existe diferença significativa entre os resultados apresentados pelos classificadores, foi realizado o teste de hipóteses utilizando a distribuição de Student t. 


\subsection{Estrutura do Texto}

Além da introdução (Capítulo 1), que visa melhorar a compreensão do trabalho, compõem a dissertação as seguintes partes:

Capítulo 2: este capítulo descreve os problemas do câncer de mama e os fatores de risco associados ao aumento na frequência da doença, as particularidades físicas do mamógrafo e as aquisições necessárias de cada mama. Descreve-se também neste capítulo, os sistemas conhecidos como CAD, desenvolvidos utilizando técnicas de processamento de imagens e de inteligência computacional.

Capítulo 3: as técnicas de processamento de imagens utilizadas para a extração de características de regiões suspeitas de câncer (ROIs) do exame da mamografia são apresentadas neste capítulo.

Capítulo 4: é apresentado o classificador utilizando uma rede neural artificial do tipo Máquina de Comitê.

Capítulo 5: este capítulo apresenta o método de avaliação de desempenho, utilizado neste trabalho, conhecido como área sob a curva ROC denominado de $A_{z}$.

Capítulo 6: os experimentos e análises dos resultados de classificação das características extraídas das ROIs são apresentados neste capítulo. De maneira ilustrativa, é explicado também neste capítulo o procedimento para o cálculo de $A_{z}$. Descrevem-se também, os resultados obtidos e as configurações dos classificadores utilizados. As análises sobre o problema da dimensionalidade e o teste de hipóteses utilizando a distribuição de Student também são abordados neste capítulo.

Capítulo 7: são discutidas as conclusões sobre os resultados obtidos nos experimentos realizados e apresentam-se os trabalhos futuros. 


\section{Câncer de Mama}

\subsection{Definição do Câncer de Mama}

O câncer de mama é um tumor maligno causado pela multiplicação exagerada e desordenada de células do tecido da mama. O tumor é chamado de maligno quando as células do tecido têm a capacidade de gerar metástases, ou seja, espalhar-se para outras regiões do corpo. Se estas células chamadas malignas entrarem na circulação sangüínea podem chegar a outras partes do corpo, invadindo tecidos e órgãos originando novos tumores e, conseqüentemente, levando uma pessoa ao óbito. Por outro lado, os tumores chamados benignos não possuem a capacidade de gerar metástases. Os tumores benignos têm um crescimento mais lento e não ultrapassam um certo tamanho, além de não se espalharem por outros órgãos. Os tumores benignos não são cancerígenos (SAUDE, 2004).

Pode-se perceber que tanto na formação do tumor maligno quanto do tumor benigno, inicia-se com um crescimento de células. Esse crescimento de células forma uma massa, cuja identificação em estágio inicial pode ajudar na cura da doença. A identificação desta massa pelo especialista recebe alguns nomes que são sinônimos, como: massa mamária, lesão na mama ou nódulo não palpável. Neste trabalho adotamos a última definição, nódulo de mama não palpável, mas algumas vezes, simplificaremos para nódulo. 


\subsection{Incidência do Câncer de Mama no Brasil e no Mundo}

O câncer de mama é o segundo mais freqüente tipo de câncer em todo o mundo e tem se tornado um grave problema para a saúde pública de todos os países pela sua alta incidência, morbidade, mortalidade e pelo seu elevado custo no tratamento. A sua incidência é maior na América do Norte e no Norte da Europa; intermediária no restante da Europa e na América do Sul, e menor na Ásia e nos países menos desenvolvidos (veja Figura 2.1) (PARKIN, 2000; PAULINELLI et al., 2003). E como mostrado por Parkin (PARKIN, 2000), a tendência para a incidência do câncer de mama em todo o mundo é aumentar (veja Tabela 2.1).

No Brasil, o câncer de mama é o tipo de câncer que se manifesta com maior freqüência, sendo este o maior causador de mortes nessa população. O número de casos vem aumentando a cada ano (INCA, 2004) (veja na Figura 2.2 a projeção para 2005).

\begin{tabular}{|l|r|r|r|r|}
\hline & \multicolumn{4}{|c|}{$\begin{array}{c}\text { Número de mortes } \\
\text { (em milhões) }\end{array}$} \\
\hline & $\mathbf{2 0 0 0}$ & $\mathbf{2 0 1 0}$ & $\mathbf{2 0 2 0}$ & $\mathbf{2 0 5 0}$ \\
\hline Mundo & 1050 & 1250 & 1480 & 1970 \\
\hline Regiões mais desenvolvidas & 580 & 640 & 690 & 710 \\
\hline Regiões menos desenvolvidas & 470 & 610 & 690 & 710 \\
\hline África & 60 & 80 & 100 & 230 \\
\hline Ásia (Japão) & 30 & 30 & 30 & 30 \\
\hline Ásia (outros) & 320 & 420 & 520 & 750 \\
\hline Europa & 350 & 370 & 390 & 380 \\
\hline América do Sul & 90 & 130 & 170 & 290 \\
\hline América do Norte & 200 & 230 & 270 & 330 \\
\hline Oceania & 10 & 20 & 20 & 30 \\
\hline
\end{tabular}

Tabela 2.1: Tendência mundial do câncer de mama.

Tendências para incidência do câncer de mama em todo o mundo para os próximos anos. Fonte: (PARKIN, 2000)

A maior incidência do câncer ocorre em mulheres entre 35 e 50 anos de idade 


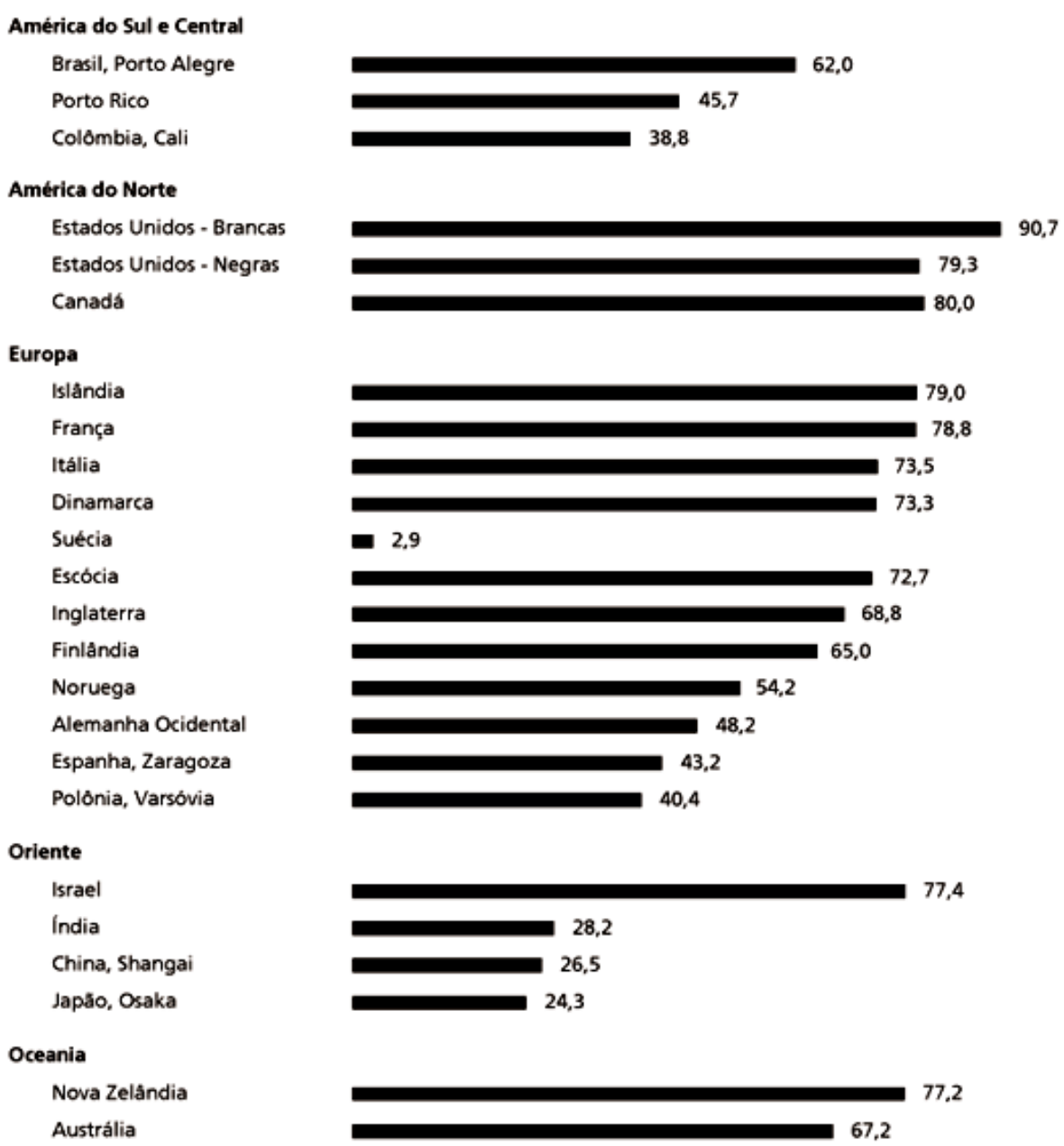

Figura 2.1: Incidência do câncer de mama no mundo.

Variação internacional na incidência do câncer de mama entre mulheres, de 1988 a 1993, por 100000 mulheres por ano. Fonte: (PAULINELLI et al., 2003)

(ARAUJO, 2000). Nos países desenvolvidos, principalmente, observa-se um aumento constante na incidência de câncer de mama em mulheres de meia idade (NCI, 2004).

O aumento do número de pacientes com câncer de mama no Brasil é semelhante à de países desenvolvidos, onde a urbanização levou ao aumento de fatores de risco do câncer de mama, como a idade tardia da primeira gravidez. Outros fatores associados que têm aumentado o risco de desenvolver câncer de mama são: 


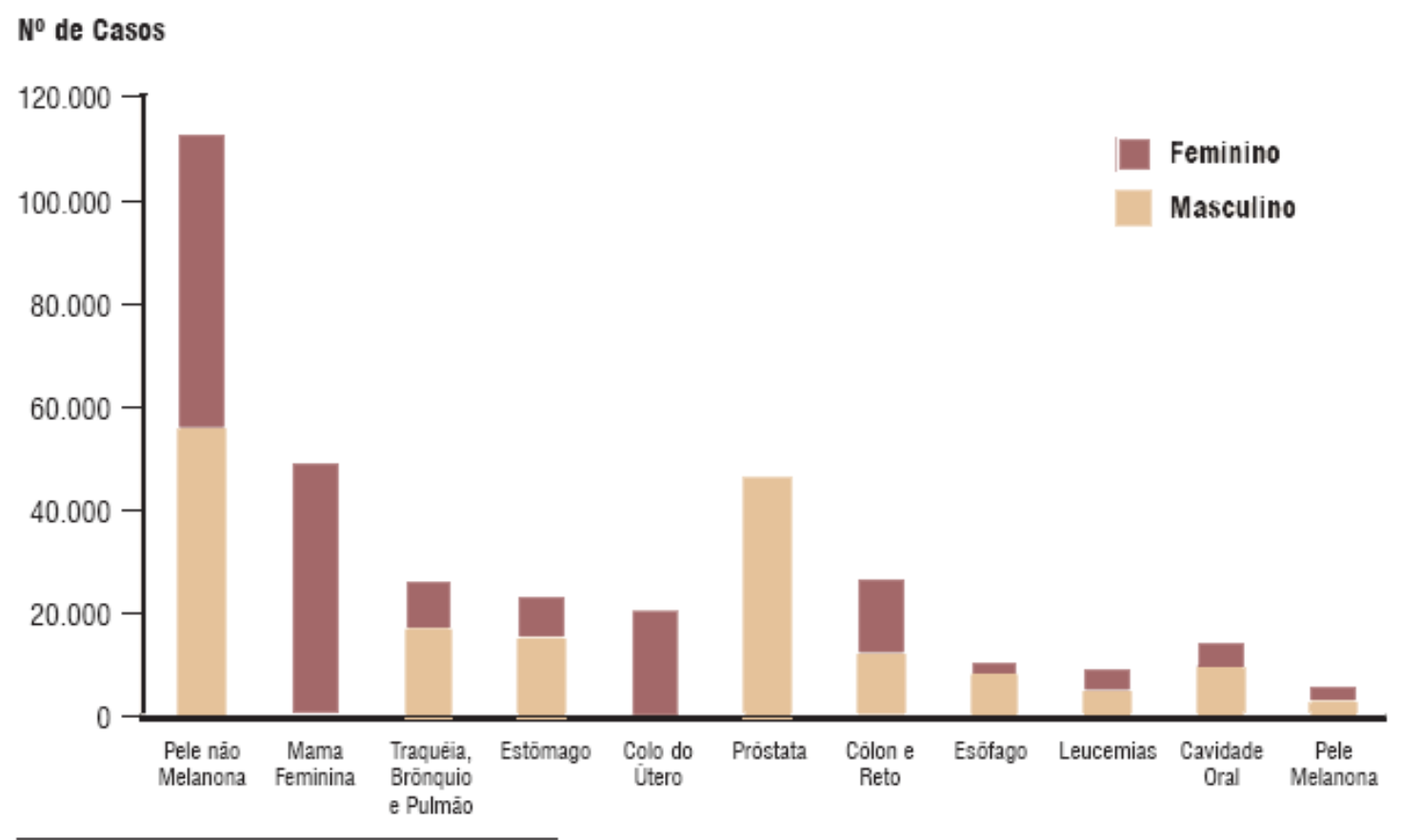

Fonte: MS/Instituto Nacional de Cancer - INCA

Figura 2.2: Incidência de câncer no Brasil em 2005.

Tipos de câncer mais incidentes, estimados para 2005 na população brasileira. Fonte:

(INCA, 2004).

- menarca precoce (antes dos 11 anos);

- menopausa tardia (após os 55 anos);

- não ter filhos (nuliparidade);

- ciclos menstruais menores que 21 dias;

- mãe ou irmã com história de câncer de mama na pré-menopausa;

- dieta rica em gordura animal;

- dieta pobre em fibras;

- obesidade (principalmente após a menopausa);

- ausência de atividade sexual;

- cor branca. 
Estes são os principais fatores que favorecem o surgimento do câncer de mama.

Desde a origem da doença de câncer de mama, ainda desconhecida, a melhor maneira para a cura da doença é uma rárida detecção.

A elevada incidência e a mortalidade por câncer de mama no Brasil e em países desenvolvidos, como o Canadá, têm levado a estratégias visando à detecção precoce do câncer de mama.

No Brasil, existe o programa Viva Mulher que é um programa nacional de controle ao câncer do colo do útero e da mama, cujo objetivo é controlar o câncer de mama através da deteç̧ão precoce evitando a mortalidade e as repercussões físicas, psíquicas e sociais. Na província canadense de Alberta, existe também um programa para a detecção precoce do câncer de mama, que é o Alberta Program for the Early Detection of Breast Cancer. Programas semelhantes a estes existem em outros países do continente americano e também no continente europeu. Estes são programas para a detecção precoce do câncer de mama.

O exame de mamografia é uma maneira para a detecção precoce do câncer de mama, permitindo diagnosticar o tumor maligno antes mesmo que ele se torne palpável. Na seção seguinte, será descrito em detalhes o exame de mamografia.

\subsection{Mamografia}

A mamografia é um exame para a detecção precoce do câncer de mama. O exame de mamografia é uma forma particular de radiografia que examina tecidos com contrastes relativamente baixo, fibroso e glandular, materiais com densidades aproximadas, como tumores e tecido da mama normal ou microcalcificação (da ordem de até $0,1 \mathrm{~mm}$ em diâmetro). Para isso é necessário se ter uma boa resolução espacial e contraste. Para se ter uma imagem com altíssimo contraste a voltagem deve variar de 25 a $40 K V_{p}$ (energias mais baixas) para se conseguir 
distinguir os tecidos de gordura e músculo. Para altas energias, o coeficiente de atenuação de massa da gordura, região de interesse na detecção de tumores, teria uma baixa atenuação da energia, e conseqüentemente a resolução da imagem seria prejudicada (SOUZA, 2005).

Este exame é destinado a registrar imagens da mama, a fim de diagnosticar a presença ou ausência de estruturas que possam indicar doenças como o câncer em estágio inicial. Em virtude de ainda ser um método caro em nosso país, os especialistas recomendam a realização da mamografia nos casos de exame clínico suspeito e em mulheres com situação de alto risco, com idade igual ou maior que 40 anos, mesmo que não apresentem alterações no exame clínico (exame de toque) (INCA, 2002). A mamografia, é realizada em aparelho de raios X apropriado, chamado de mamógrafo (veja a Figura 2.3).

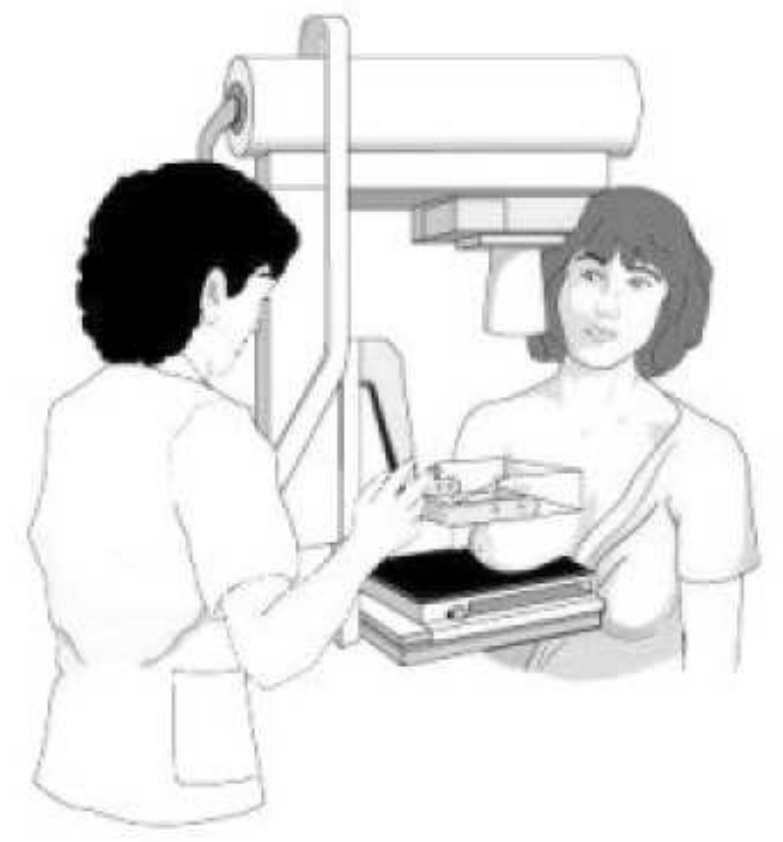

Figura 2.3: Ilustração do aparelho de raios-x.

Ilustração de um aparelho de raios-X especial para a realização da mamografia.

(Fonte: Disponível em http://www.isu.edu/ departments/anthro/

hhp/nosearch/images/hhp-mamografia. Acessado em 16/03/2004.)

Durante a aquisição da imagem, a mama sofre uma compressão no mamógrafo 
(vide ilustração na Figura 2.3) e são feitas duas incidências na mama da esquerda e na mama da direta: crânio-caudal (CC) e médio-lateral oblíqua (MLO), ilustradas na Figura 2.4. A incidência MLO é mais precisa pelo fato de mostrar uma quantidade maior do tecido mamário. Por outro lado, a incidência CC serve como um complemento da incidência MLO.

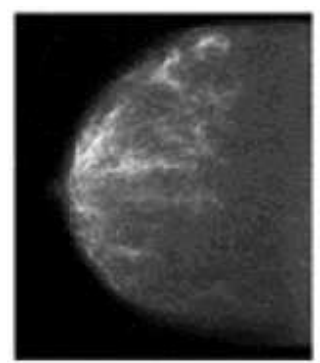

$\mathrm{CC}$

(Crânio Caudal lado direito)

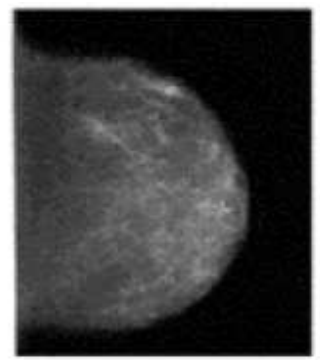

$\mathrm{CC}$

(Crânio Caudal lado esquerdo)

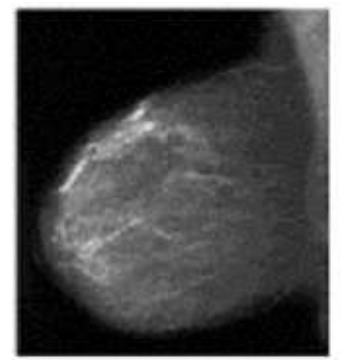

MLO

(Médio Lateral

Oblíqua lado direito)

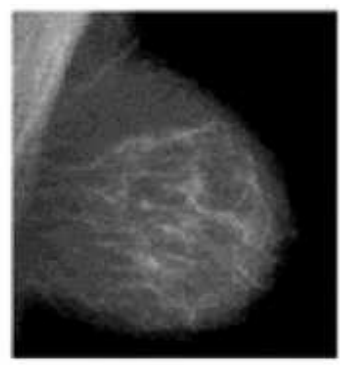

MLO

(Médio Lateral Oblíqua

lado esquerdo)

Figura 2.4: Exemplos de aquisições de imagens feitas em um exame de raios-x. Ilustrações das duas incidências necessárias no exame de mamografia. É preciso fazer as mesmas incidências na mama do lado esquerdo e do lado direito. Fonte: Disponível em http://www.miraluma.com/hcp/presentations/ob/. Acessado em 22/05/2004.

A capacidade de perceber detalhes na imagem da mamografia é considerada alta, mesmo que estudos evidenciam perdas nos detalhes de $10 \%$ a $15 \%$ dos casos de câncer com tumor detectável ao exame clínico (INCA, 2002). Essa capacidade está diretamente relacionada à idade da mulher. Em mulheres jovens, a densidade do tecido mamário é alta, o que implica na diminuição da capacidade de percepção.

O reconhecimento de estruturas que possam indicar a presença de câncer se dá através da constatação de uma diferença de contraste entre os diversos tecidos envolvidos. Geralmente, as lesões como microcalcificações e nódulos aparecem em tonalidades mais claras na imagem obtida após a revelação do filme mamográfico.

O diagnóstico de carcinomas $^{1}$ não palpáveis é possível através de uma mi-

\footnotetext{
${ }^{1}$ Carcinomas são os tipos mais comuns de câncer. Eles se originam de células que revestem
} 
nuciosa mamografia, capaz de verificar detalhes que evitem o diagnóstico falsopositivo $^{2}$, que acarreta em um aumento dos números desnecessários de biópsias e os falso-negativos ${ }^{3}$, que podem levar a um retardo na biópsia.

As causas mais importantes de mamogramas falso-negativos e falso-positivos são:

- tecido mamário denso (insuficiência de gordura para separar a anormalidade do parênquima ${ }^{4}$ mamário circunvizinho);

- fatores técnicos (necessidade de equipamentos especializados e radiologistas qualificados em perceber sinais sutis no exame) e

- erro de interpretação: radiologistas bem treinados para distinguir com precisão, algumas características que parecem pertencer a um nódulo benigno, mas que é maligno e nódulo que é maligno, mas que aparenta ser benigno.

Para contribuir na diminuição dos erros, sistemas computadorizados estão sendo desenvolvidos para auxiliar os radiologistas na identificação e no diagnóstico do câncer de mama. Esses sistemas também são conhecidos como CAD (Diagnóstico Auxiliado por Computador. Computer Aided Diagnosis), assunto detalhado na próxima seção.

as superfícies do corpo, incluindo a pele e uma série de revestimentos internos. Entre esses estão os da boca, garganta, brônquios, o esôfago (o tubo para engolir), estômago, intestino, bexiga, útero e ovários e os revestimentos dos dutos mamários, próstata e pâncreas (NACAPAN, 2004).

${ }^{2}$ falso-positivo: quando o paciente não tem câncer, mas o resultado do exame diz que a pessoa tem a doença. Mais detalhes sobre este conceito no Capítulo 5.

${ }^{3}$ falso-negativo: quando o paciente tem câncer e o resultado do exame diz que a pessoa não tem a doença. Mais detalhes sobre este conceito no Capítulo 5.

${ }^{4}$ Parênquima: Tecido de preenchimento (tecido fundamental) constituído por células vivas, geralmente com formato poliédrico, apresentando parede primária ou paredes primária e secundária (KRAUS; PISANESCHI, 2004). 


\subsection{Diagnóstico Auxiliado por Computador ou CAD}

Com o intuito de minimizar os erros de disgnósticos têm sido desenvolvidos sistemas que utilizam técnicas computacionais, comumente chamados de CAD (Diagnóstico Auxiliado por Computador em inglês, Computer Aided Diagnosis).

Estes sistemas são desenvolvidos para auxiliar os radiologistas na avaliação e no diagnóstico dos exames de mamografia e procuram reduzir os números desnecessários de biópsia, considerando que de $20 \%$ a $30 \%$ dos casos enviados à biópsia são comprovadamente malignos (HERMANN et al., 1987; HALL et al., 1988; JACOBSON; EDEIKEN, 1990; ARAUJO, 2000).

O CAD é desenvolvido conjugando duas ferramentas complementares: técnicas de processamento de imagens e técnicas de inteligência computacional. As técnicas de processamento de imagens são empregadas para detectar as marcações dos nódulos não palpáveis previamente identificadas pelo radiologista e extrair destas marcações determinadas características quantitativas ("medidas"). Algumas tentativas de identificação e extração automática de nódulos não palpáveis na mama em imagens de mamografia foram tentadas por Sahiner et al. (SAHINER et al., 1998a, 1998b), mas os resultados obtidos com técnicas totalmente automáticas são inferiores quando comparadas com as técnicas que utilizam a experiência do radiologista.

As técnicas de inteligência computacional são aplicadas para classificar as características extraídas dos nódulos através das técnicas de processamento de imagens, como benignas ou malignas. As Redes Neurais Artificiais (RNA) são um exemplo de técnica de inteligência computacional que vem sendo utilizada para a classificação dos vetores de características extraídos das imagens de mamografias (YU; GUAN, 2000; HALKIOTIS; MANTAS; BOTSIS, 2002; ANDRE; RANGAYYAN, 2003; SILVA; DEL-MORAL-HERNANDEZ; RANGAYYAN, 2004, 2005). 
O procedimento do sistema CAD, neste contexto de trabalho é realizado a partir das seguintes etapas:

1. O radiologista faz um rastreamento no exame de mamografia e ao identificar uma lesão (neste trabalho estamos considerando apenas os nódulos não palpáveis) ele faz uma marcação manual deste nódulo e a região que contém a marcação, denominada de região suspeita (ROI), é extraída.

2. A partir da ROI digitalizada são aplicadas as técnicas de processamento de imagens para extrair algumas características do nódulo capazes de caracterizar o nódulo benigno e o nódulo maligno.

3. Estas características extraídas são apresentadas à rede neural artificial (previamente treinada), que classifica o nódulo como benigno ou maligno.

O procedimento descrito anteriormente, está ilustrado na Figura 2.5.

O objetivo deste trabalho foi utilizar uma proposta de classificação utilizando um classificador de redes neurais artificiais para melhorar os resultados de classificação de um sistema CAD. Assim, a contribuição deste trabalho está na etapa de classificação como indicado na Figura 2.5 pela região destacada (linha pontilhada). As características extraídas das ROIs utilizadas neste trabalho para a classificação foram fornecidas pelo grupo de pesquisas e colaboradores do Professor Rangaraj Mandaraj Rangayyan do Departamento de Engenharia Elétrica da University of Calgary, Calgary, Alberta, Canadá.

Nos próximos capítulos são apresentadas as características extraídas utilizando as técnicas de processamento de imagens e em seguida será explicado detalhadamente o classificador Máquina de Comitê. 


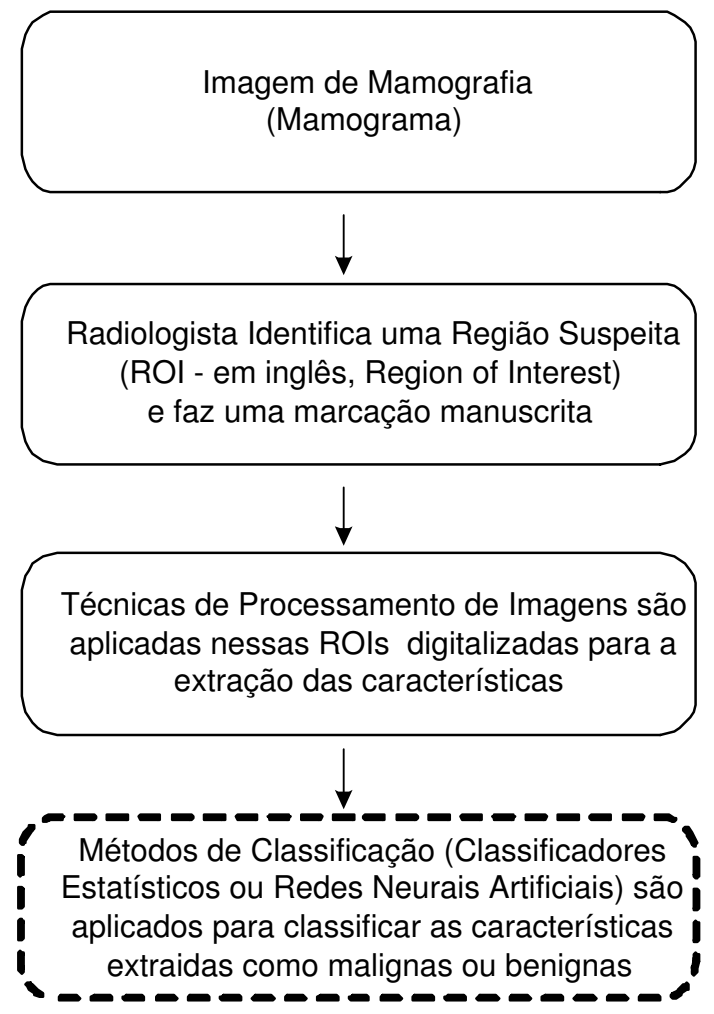

Figura 2.5: Diagrama esquemático do sistema CAD.

Ilustração de um diagrama de blocos do procedimento de um sistema CAD. O bloco destacado por pontilhados, ilustra em qual etapa do sistema CAD o projeto é aplicado. Este projeto, vem recebendo colaborações do grupo de pesquisas da University of Calgary que desenvolveram e aplicaram as técnicas de processamento de imagens para a extração das características dos nódulos não palpáveis suspeitos de câncer (bloco anterior ao destacado). 


\section{Extração das Características}

\subsection{Base de Imagens Usadas para o Trabalho}

Neste trabalho, foi usado um conjunto de 57 regiões com nódulos suspeitos (ROIs) de mamogramas digitalizados com uma resolução de $50 \mu \mathrm{m}$ com 12 bits por pixel. Das 57 ROIs, 37 foram identificadas como benigna (Figura 3.1) e 20 como maligna (Figura 3.2), após o exame de biópsia. Os mamogramas foram selecionados do Programa Alberta para a deteç̧ão precoce do câncer de mama (ALBERTACANCER-BOARD, 2001; ALTO; RANGAYYAN; DESAUTELS, 2005).

\subsection{Procedimento Clínico de um Radiologista}

O procedimento clínico de um radiologista na análise de um mamograma é realizado através do rastreamento na imagem de mamografia (mamograma) em busca de algum indicador de doença. Algumas anormalidades são facilmente perceptíveis, entre outras, destacamos:

- assimetria entre as mamas;

- distorção no tecido da mama;

- aumento na densidade do tecido da mama e

- presença significativa de lesões como nódulos e calcificações. 

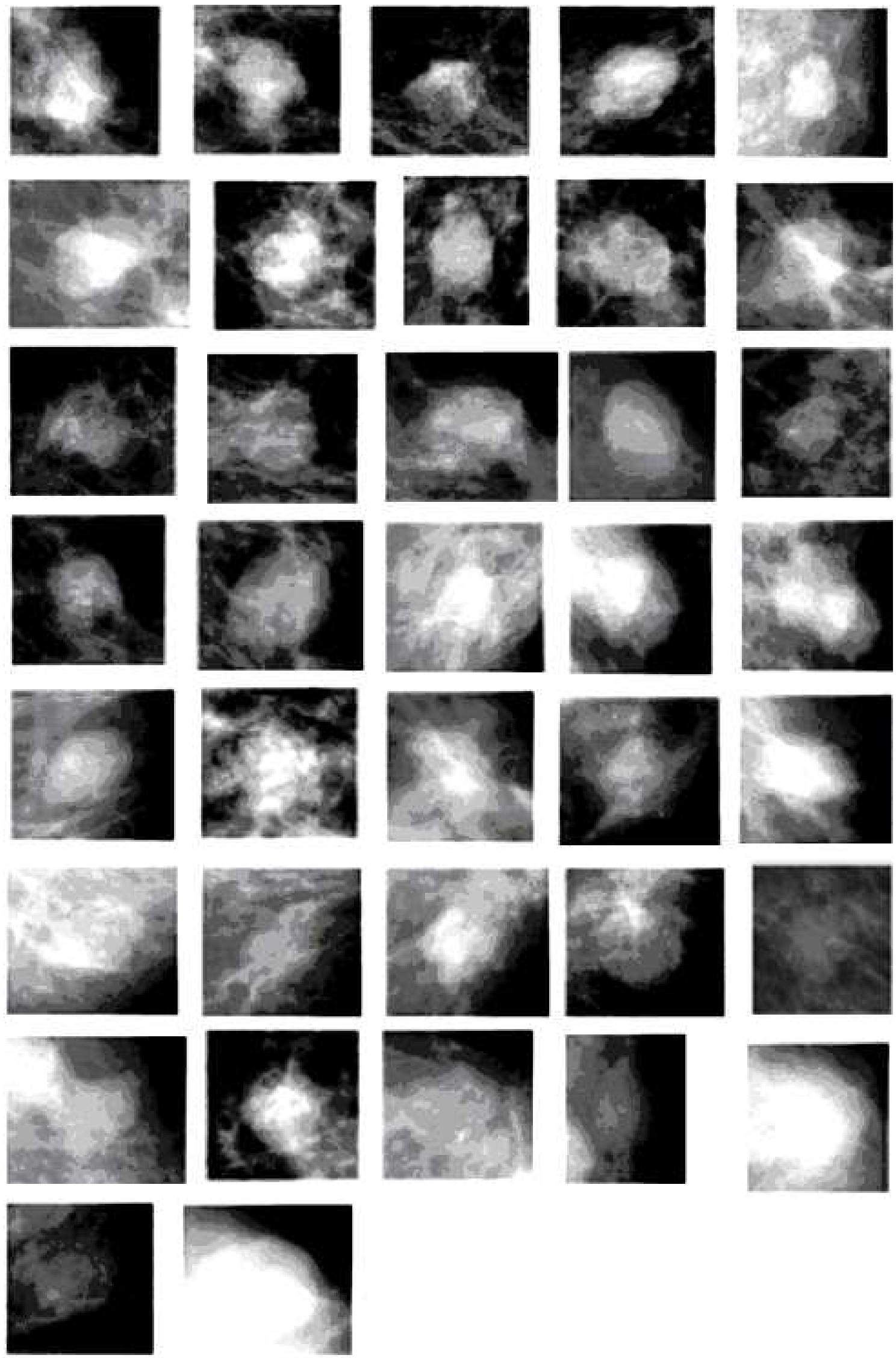

Figura 3.1: Ilustração das 37 ROIs benignas.

(Fonte (ALTO; RANGAYYAN; DESAUTELS, 2005)) 

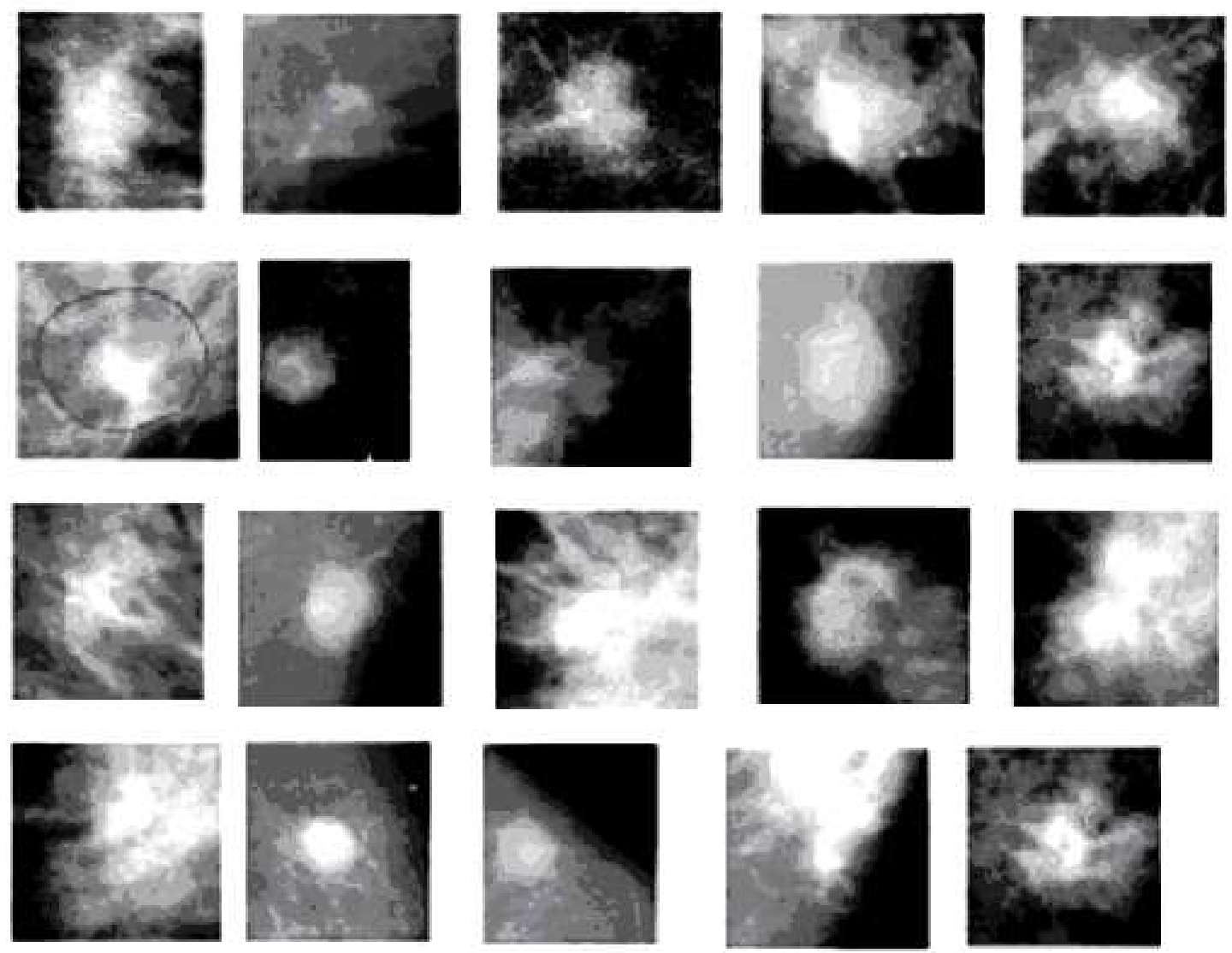

Figura 3.2: Ilustração das 20 ROIs malignas. (Fonte (ALTO; RANGAYYAN; DESAUTELS, 2005)) 
Essas anormalidades foram inicialmente apresentadas por Claridge e Richter (1994).

Para este trabalho, foi investigada a possibilidade de um nódulo não palpável ser benigno ou maligno através de atributos (características quantitativas) de nódulos como forma, textura e nitidez da borda. Para facilitar a computação das características, um radiologista experiente em mamografia fez a marcação manuscrita em cada borda do nódulo (ALTO; RANGAYYAN; DESAUTELS, 2005).

Em caso de indicadores malignos, observa-se que a forma do nódulo é mais irregular do que em casos benignos. A maioria dos nódulos benignos possui o contorno bem circunscrito, compacto e aproximadamente elíptico (Figura 3.3).

Por outro lado, os nódulos malignos geralmente apresentam bordas borradas, sua aparência é irregular e são cercados por espículos (em inglês, spiculations) radiantes e lineares (forma de estrela), conforme exemplo da Figura 3.4 (CLARIDGE; RICHTER, 1994; RANGAYYAN; MUDIGONDA; DESAUTELS, 2000; RANGAYYAN et al., 1997).

Porém, alguns nódulos benignos podem ter bordas espiculadas ou bordas borradas (Figura 3.5) e alguns nódulos malignos podem ter forma arredondada e bem definida (Figura 3.6) (CLARIDGE; RICHTER, 1994; RANGAYYAN; MUDIGONDA; DESAUTELS, 2000; RANGAYYAN et al., 1997).

Com base nas informações descritas acima, diversos autores vêm pesquisando técnicas de processamento de imagens para a extração das características de nódulos benignos e malignos para uma correta classificação (FERRARI et al., 2001; SAHINER et al., 2001; SHEN et al., 1994; SANTOS, 2002; RANGAYYAN; MUDIGONDA; DESAUTELS, 2000; RANGAYYAN et al., 1997; MUDIGONDA; RANGAYYAN; DESAUTELS, 2000; SAHINER et al., 1998a). 


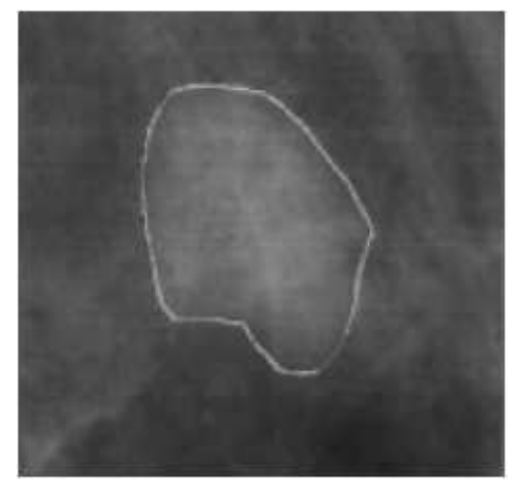

Figura 3.3: Nódulo benigno com contorno circunscrito. Ilustração de um nódulo benigno com contorno circunscrito. (Fonte: (RANGAYYAN et al., 1997) pertencente à base de dados MIAS (mdlb 010rm)).

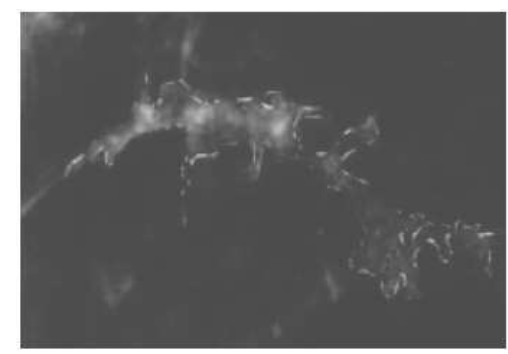

Figura 3.4: Nódulo maligno com contorno espiculado.

Ilustração de um nódulo maligno com contorno espiculado. (Fonte: (RANGAYYAN et al., 1997) pertencente à base de dados de Calgary (S-404-94-4)).

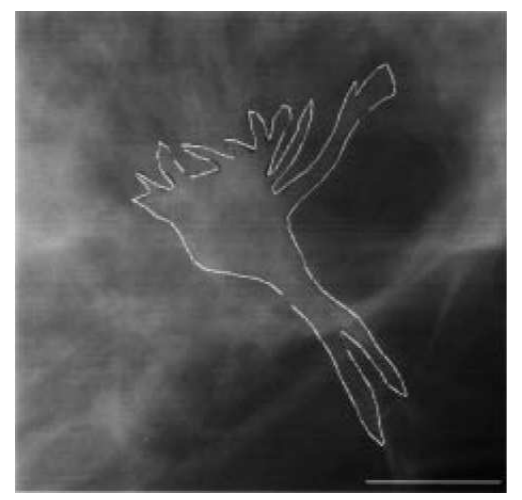

Figura 3.5: Nódulo benigno com contorno espiculado.

Ilustração de um nódulo benigno com contorno espiculado. (Fonte: (RANGAYYAN et al., 1997) pertencente à base de dados MIAS (mdlb 193II)). 


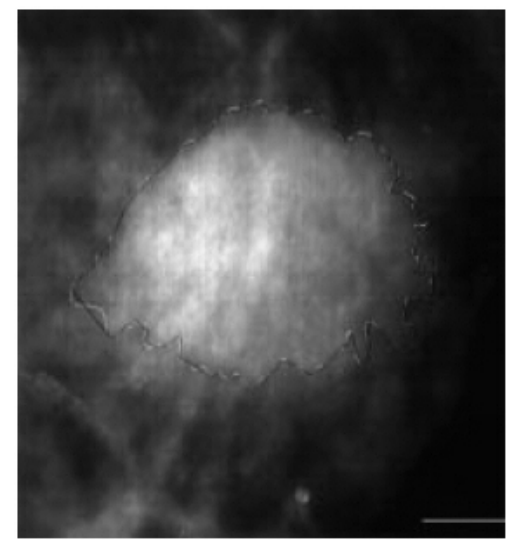

Figura 3.6: Nódulo maligno com contorno circunscrito.

Ilustração de um nódulo maligno com contorno circunscrito. (Fonte: (RANGAYYAN et al., 1997) pertencente à base de dados Calgary (fh161878)).

Para este trabalho são utilizadas as características pesquisadas por Rangayyan et al (RANGAYYAN; MUDIGONDA; DESAUTELS, 2000; RANGAYYAN et al., 1997), que são as características de forma, textura e nitidez da borda de cada nódulo e que serão descritas a seguir.

\subsection{Características de Forma da Borda do Nódulo}

As características de forma extraídas da borda do nódulo de cada ROI são denominadas conforme (RANGAYYAN; MUDIGONDA; DESAUTELS, 2000). Essas características são denominadas como: compacidade (ou compactness, em inglês) $(C)$, concavidade fracionária (ou fractional concavity, em inglês) $\left(F_{c c}\right)$ e grau de espicularidade (ou spiculation index, em inglês) (SI) (RANGAYYAN; MUDIGONDA; DESAUTELS, 2000). Estas características permitem mensurar a complexidade da forma do nódulo.

A característica $C$ é uma medida da complexidade do contorno do nódulo que indica 0 para um círculo e caso a borda se torne mais irregular este valor é aumentado até um valor máximo 1 (RANGAYYAN; MUDIGONDA; DESAUTELS, 2000). A expressão para o cálculo de $C$ é mostrada a seguir: 


$$
C=1-\frac{4 \pi a}{p^{2}}
$$

Onde $a$ é a área e $p$ o perímetro do contorno.

A característica $F_{c c}$ mede a relação entre o comprimento cumulativo da concavidade do contorno e o comprimento total do contorno. Assim, para nódulos benignos onde geralmente o contorno é arredondado ou oval, o valor apresentado é baixo (RANGAYYAN; MUDIGONDA; DESAUTELS, 2000); por outro lado, para os nódulos malignos com o contorno elíptico ou lobulado deve-se esperar por diversas partes côncavas significativas.

A estimação de $F_{c c}$ deve ser realizada a partir da segmentação do contorno do nódulo em duas partes separadas côncavo e convexo por pontos de inflexão no contorno do nódulo (RANGAYYAN; MUDIGONDA; DESAUTELS, 2000). As partes côncavas e convexas do contorno de um nódulo macrolobulado benigno são mostrados na Figura 3.7.

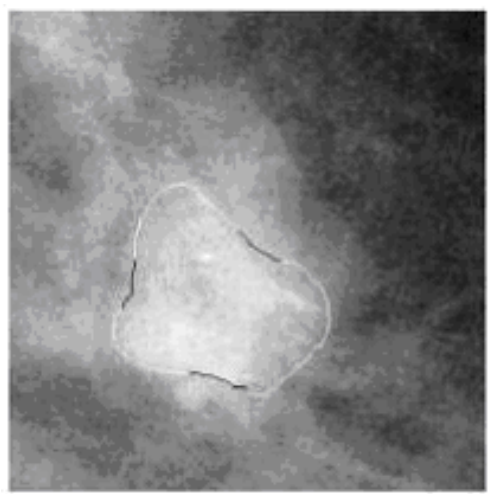

Figura 3.7: Nódulo demonstrando a parte côncava e convexa do contorno. Ilustração de uma ROI com um contorno de nódulo demonstrando a parte côncava em preto e em branco a parte convexa. (Fonte: (ALTO; RANGAYYAN; DESAUTELS, 2005)).

A característica SI é o cálculo do grau de espicularidade do contorno e utiliza um método proposto por Rangayyan et al (RANGAYYAN; MUDIGONDA; DESAUTELS, 2000), o qual se baseia em um modelo poligonal de um dado contorno 
e uma combinação de comprimento do segmento, larguras de base e ângulos de possíveis espículos. Carcinomas invasivos, devido a sua natureza de se infiltrar no tecido da mama, formam um contorno com limites bem definidos distorções em forma de estrelas em seu contorno características que resultam em altos valores de $S I$.

Estas características foram incluídas em nossos experimentos, pela efetividade na discriminação de nódulos como descrito por Rangayyan (RANGAYYAN; MUDIGONDA; DESAUTELS, 2000). Quando usadas por classificadores de Redes Neurais Artificiais, estas características têm se mostrado bastante eficientes na classificação de nódulos benignos e malignos (ANDRE; RANGAYYAN, 2003; SILVA; DEL-MORAL-HERNANDEZ; RANGAYYAN, 2004, 2005; ALTO; RANGAYYAN; DESAUTELS, 2005).

Estas características $\left[C, F_{c c}, S I\right]$ são chamadas nos próximos capítulos de características de forma .

\subsection{Características de Textura}

Em exames de mamografia pode ser verificado uma variedade de texturas que representam parênquima, gordura, tecido normal, tecido anormal e nódulos. Pesquisadores que têm aplicado as características de textura para a classificação de nódulos de mama têm indicado que a medida de homogeneidade deve ser usada para decidir entre um nódulo benigno e maligno (PETROSIAN et al., 1994; CHAN et al., 1995; BAEG; KEHTARNAVAZ, 2000; MAVROFORAKIS et al., 2002). Muitos pesquisadores têm aplicado varias combinações das características de textura propostas por Haralick (HARALICK; SHANMUGAM; DINSTEIN, 1973) para imagens de mamografia com o objetivo de classificá-las de acordo com a microestrutura interna da mama (MUDIGONDA; RANGAYYAN; DESAUTELS, 2000; MAVROFORA- 
KIS et al., 2002; PETROSIAN et al., 1994; SAHINER et al., 1998a, 1998b; CHAN et al., 1995).

A formação de microcalcificações no tecido da mama causa mudanças na textura e com isso começam a desenvolver espículos que podem ser observados com a formação de linhas pontudas como agulha fina e radiadas na margem do nódulo. Dessa forma, tem sido feito esforços na quantificação do conteúdo da textura e das margens do nódulo (MUDIGONDA; RANGAYYAN; DESAUTELS, 2000; CHAN et al., 1995).

Assim, utilizamos nos nossos estudos um conjunto de características composto por medidas de textura. Catorze características de textura foram calculadas de acordo com as definições de Haralick (HARALICK; SHANMUGAM; DINSTEIN, 1973), a saber:

- Variância $\left(f_{1}\right)$ : mensura a variação da tonalidade do fundo da ROI.

- Correlação $\left(f_{2}\right)$ : medida que indica uma estrutura envolvida na textura da ROI ou um fundo suave.

- Contraste $\left(f_{3}\right)$ : texturas com baixo contraste geralmente têm valores menores quando comparadas com as texturas de alto contraste porém, artefatos e texturas rugosas causam um alto valor desta medida.

- Entropia $\left(f_{4}\right)$ : medida da desorganização entre os pixels do nódulo do ROI.

- Soma da Entropia $\left(f_{5}\right)$ : medida da soma da quantidade de desorganização entre os pixels do fundo da ROI.

- Diferença da Entropia $\left(f_{6}\right)$ : medida da diferença da quantidade de desorganização entre os pixels de um fundo (semelhante a Soma da Entropia). 
- Momento da Diferença Inversa $\left(f_{7}\right)$ : cálculo da média das tonalidades dos pixels do fundo da ROI.

- Média da Soma $\left(f_{8}\right)$ : cálculo da média das tonalidades dos pixels vizinhos (pares) do fundo da ROI.

- Variância da Soma $\left(f_{9}\right)$ : mede a variação dos tons do fundo da ROI

- Média da Diferença ou Coeficiente de Máxima Correlação $\left(f_{10}\right)$ : é um indicador da não homogeneidade da distribuição dos níveis de cinza da ROI.

- Variância da Diferença $\left(f_{11}\right)$ : medida similar a Variância da Soma, mas com a média centrada em zero.

- Energia ou Segundo Momento Angular $\left(f_{12}\right)$ : medida que indica a uniformidade ou suavidade da textura. Texturas homogêneas apresentam um alto valor de energia comparada com as texturas não homogêneas, pois as texturas suaves possuem densidades mais concentradas que as texturas rugosas. Texturas rugosas têm densidades com alto espalhamento ou variância.

- MIC1 $\left(f_{13}\right)$ : medida da correlação com base no cálculo da entropia dos elementos independentes e pares de elementos da ROI.

- MIC2 $\left(f_{14}\right)$ : cálculo da média da correlação com base na similaridade entre a entropia dos elementos independentes da imagem e pares de elementos da ROI.

As 14 características de textura de Haralick apresentadas anteriormente foram calculas usando os pixels de uma faixa do contorno do nódulo. Mudigonda et. al. (MUDIGONDA; RANGAYYAN; DESAUTELS, 2000) mostraram que as características da textura calculadas usando uma faixa do contorno (faixa ao redor do contorno do nódulo) pode melhorar a discriminação entre nódulos benignos e malignos, 
quando comparadas com as características de texturas calculadas usando toda a região do nódulo. A diferença entre uma região do nódulo e uma faixa está ilustrada na Figura 3.7 e Figura 3.8 respectivamente.

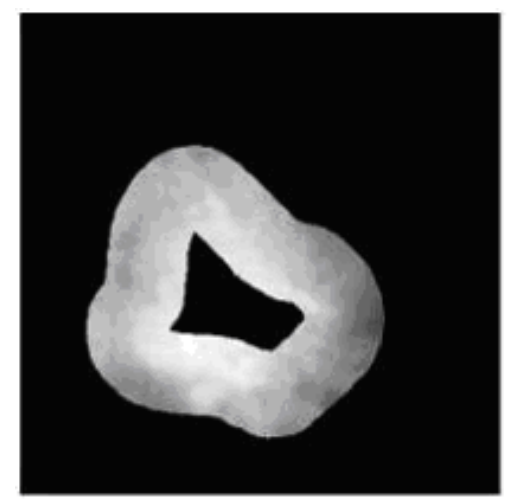

Figura 3.8: Faixa de pixels do contorno do nódulo.

Faixa de pixels utilizada para o cálculo das características de textura. Esta seleção foi obtida aplicando duas técnicas de morfologia matemática, dilatação e erosão, no contorno da Figura 3.10b. (Fonte: (ALTO; RANGAYYAN; DESAUTELS, 2005)).

Com o objetivo de extrair a faixa marcada como nódulo, o seu contorno é erodido para dentro e dilatado para fora do contorno. A região entre o contorno erodido e dilatado é usada no desenvolvimento da matriz de níveis de cinza que é necessária para calcular as características de textura. As características de textura foram calculadas usando imagens com uma resolução de $200 \mu \mathrm{m}$ suavizadas por Gaussianas. Nas próximas seções, o conjunto total de 14 características de textura será chamado de características de textura.

\subsection{Características de Nitidez da Borda do Nó- dulo}

O terceiro conjunto de características usado neste trabalho é o das características de nitidez da borda do nódulo. Estas características são extraídas das regiões em torno da borda do nódulo (RANGAYYAN et al., 1997; MUDIGONDA; RANGAYYAN; DESAUTELS, 2000). As características são: descontinuidade (ou Acutance, em 
inglês) $(A)$, contraste (ou contrast em inglês) (contraste) e coeficiente de variação (ou coefficient of variation, em inglês) $(C V)$.

O cálculo da característica $A$, como descrito em Rangayyan et. al. (RANGAYYAN et al., 1997) é uma medida de suavidade ou mudança na densidade ao longo do contorno do nódulo (veja Figura 3.9).

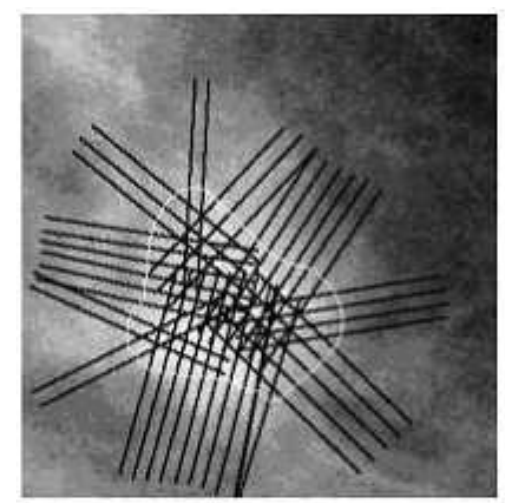

Figura 3.9: Linhas perpendiculares traçadas em torno do contorno do nódulo. Ilustração de linhas perpendiculares a cada décimo de ponto (pixel) do contorno. Usado para o cálculo da nitidez da borda. (Fonte: (ALTO; RANGAYYAN; DESAUTELS, 2005)).

Para o cálculo de $A$, uma linha de pixels é definida na direção perpendicular de cada pixel do contorno (veja a Figura 3.9). Uma distância de 80 pixels ou 4 $m m$ dentro e fora do contorno do nódulo. No caso de um espículo ou concavidade limitada, o máximo de pixel possível é usado tal que, a linha dos pixels ao longo da perpendicular do contorno não cruze o contorno mais de uma vez. A média das diferenças entre os pixels eqüidistantes no interior e a parte externa ao contorno do nódulo ao longo da perpendicular de cada pixel da borda é calculada $(C V)$. O cálculo do contraste ao longo da perpendicular do contorno também é efetuado (MUDIGONDA; RANGAYYAN; DESAUTELS, 2000).

Os nódulos benignos tendem a demonstrar a margem mais definida e conseqüentemente resultam em uma grande desigualdade nos valores dos pixels entre a parte interna e externa à ROI do nódulo enquanto que, os nódulos malignos 
tendem a ser mais difusos ou ter margens mal definidas o que resulta em menor diferença entre os valores dos pixels. As margens de nódulos parcialmente escuros ou contorno mal definidas devem resultar em baixos valores de $A$. O valor de $A$ esperado poderia ser alto se um nódulo é na maior parte redondo, claramente visível e mais denso que o a região ao redor do tecido da mama.

Um nódulo muito espiculado, como o exemplo da Figura 3.10d, geralmente terá sua margem fracamente definida e conseqüentemente a diferença entre os valores dos pixels em torno do contorno é pequena; isto resulta em valor baixo de $A$

O nódulo na Figura 3.10a tem uma margem parcialmente obscura, mas é possível perceber as mudanças na densidade em torno do contorno do nódulo; o mesmo acontece nos nódulos da Figura 3.10b e 3.10c. A Figura 3.10d tem um nódulo altamente espiculado além deste ser parcialmente obscuro, o resultado é um valor muito baixo de $A$.

Esse conjunto de características $[C V, A$, contraste $]$ será chamado nos próximos capítulos de características de nitidez da borda. 

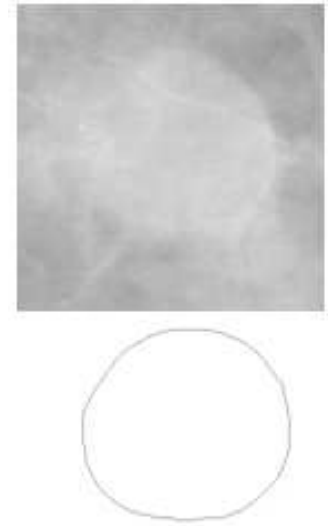

(a) b1451c95
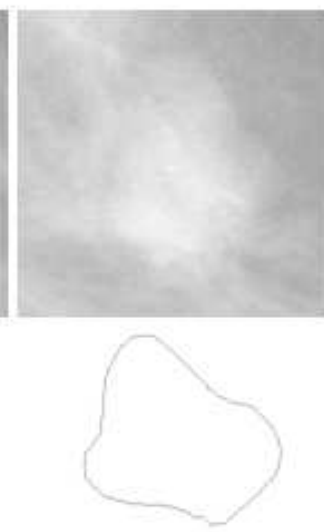

(b) b164ro94
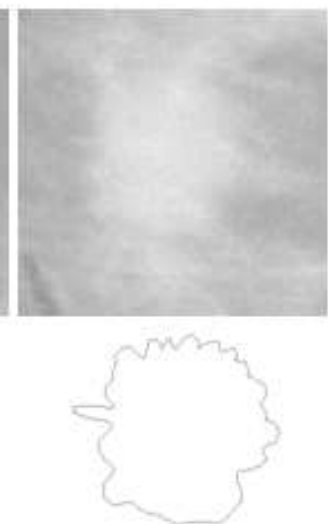

(c) $\operatorname{m} 51 \mathrm{rc} 97$
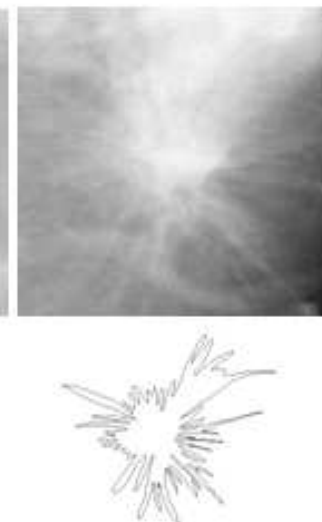

(d) $\mathrm{m} 551097$

Figura 3.10: Ilustração de deferentes contornos do nódulo.

(a) Nódulo benigno circunscrito; (b) Nódulo benigno microlobulado; (c) Tumor maligno espiculado; (d) Tumor maligno espiculado. Os nódulos e seus contornos são de tamanhos diferentes, mas nesta ilustração eles foram escalados para terem o mesmo tamanho. A primeira letra do identificador do caso indica um diagnóstico maligno com "m" e um diagnóstico benigno com "b" baseado na biópsia. As letras após os números do identificador representam l: esquerda (de left), $\mathrm{r}$ : direito (de right); c: de vista crânio-caudal, o: de vista médio lateral oblíquo. Os últimos dois dígitos representam o ano da aquisição do mamograma. (Fonte: (ALTO; RANGAYYAN; DESAUTELS, 2005)). 


\section{Classificador Utilizando uma Arquitetura de Rede Neural Artificial do tipo Máquina de Comitê}

Neste Capítulo, será discorrido sobre o classificador neural do tipo Máquina de Comitê, assim como, as categorias encontradas da Máquina de Comitê e os detalhes de implementação da categoria utilizada. Porém, antes de iniciar as explicações citadas anteriormente, serão apresentados a seguir um breve histórico, conceitos básicos e exemplos de aplicações das redes neurais artificiais.

\subsection{Breve Histórico sobre as Redes Neurais Arti- ficiais}

As pesquisas sobre redes neurais artificiais tiveram início em 1943 com Warrem McCulloch e Walter Pitts. A estrutura proposta abstraía a complexidade da atividade neural em sistemas neurais reais e estabeleceu a base da neurocomputação, concebendo procedimentos matemáticos análogos ao funcionamento dos neurônios biológicos (KOVACS, 1996). A contribuição desta pesquisa foi puramente conceitual e tomada como base para a maioria dos modelos conexionistas desenvolvidos posteriormente.

Em 1949 Donald Hebb publica The Organization of Behavior e dá um passo 
muito importante na história das redes neurais. Ele propôs um modelo onde se assumiu que a aprendizagem do conhecimento representado em uma rede neural seja alcançada pelo fortalecimento das conexões entre os neurônios adjacentes, sempre que estes estiverem excitados.

Em 1958, Frank Rosenblatt criou o perceptron, um modelo cognitivo que consistia de unidades sensoriais conectadas a uma única camada de neurônios de McCulloch e Pitts, capaz de aprender tudo o que pudesse representar. Rosenblatt demonstrou que, se acrescidas sinapses ajustáveis às redes neurais de McCulloch e Pitts, estas poderiam ser treinadas para classificar padrões de classes linearmente separáveis.

Com base no modelo de McCulloch e Pitts, no início da década de 60 Widrow e Hoff publicaram um artigo especificando o neurônio artificial, denominado adaline. A contribuição deste trabalho está associada à regra de aprendizagem proposta, a regra Delta.

Mas, em 1969 Minsky e Papert na publicação Perceptrons, expuseram as limitações do modelo de Rosenblatt, provando que tais redes não são capazes de resolver uma ampla classe de problemas devido às restrições de representação. Nesta época, pensava-se que para reproduzir o comportamento do cérebro humano, bastaria construir uma rede neural suficientemente grande. Uma rigorosa análise matemática, no entanto, comprovou o pouco poder computacional dos modelos de redes neurais utilizados na época, levando as pesquisas neste campo a ficarem esquecidas em meados dos anos 60 até o início da década de 80 .

Nos anos 80, o interesse pela área retornou devido, em grande parte, ao surgimento de novos modelos neurais como o proposto por Hopfield e Kohonen em 1982 e de algoritmos de aprendizado mais poderosos. Além disso, nesta mesma época, ocorreu o surgimento de computadores mais rápidos e poderosos, facilitando a 
implementação das redes neurais.

O modelo conexionista proposto por John Hopfield em 1982 permitiu esclarecer pelas suas características computacionais e estabilidade boa parte das dúvidas até então existentes em relação ao processo dinâmico executado por certas redes neurais. No mesmo ano, Kohonen publica um artigo descrevendo a rede neural artificial baseada em auto-organização e nas características de aprendizado adaptativo do cérebro humano.

Com a incorporação da dinâmica estocástica, em 1983, Hinton e Seynowsky estenderam o modelo de Hopfield. Este modelo de rede neural passou a ser conhecido como Máquina de Boltzmann.

Cerca de dois anos mais tarde, Rumelhart, Hinton e Williams aperfeiçoaram a idéia de perceptron, criando o algoritmo retropropagação do erro (em inglês, error backpropagation) (HAYKIN, 1999), levando a uma explosão de interesse em redes neurais. O sucesso deste algoritmo estimulou o desenvolvimento de muitas pesquisas em redes neurais artificiais e de uma variedade de modelos cognitivos.

\subsection{Conceitos Básicos sobre as Redes Neurais Ar- tificiais}

$\mathrm{Na}$ tentativa de se criar um modelo computacional capaz de simular a estrutura e o funcionamento do cérebro humano, se deu origem as redes neurais artificiais.

A Figura 4.1a ilustra uma representação do neurônio biológico e a Figura 4.1b ilustra uma representação do neurônio artificial. De acordo com estas ilustrações, pode-se perceber a semelhança entre as duas estruturas. Analogamente, as entradas de um neurônio artificial representam os dendritos do neurônio biológico, a junção aditiva no neurônio artificial representa o corpo celular no neurônio biológico e a saída do neurônio artificial representa o axônio. 


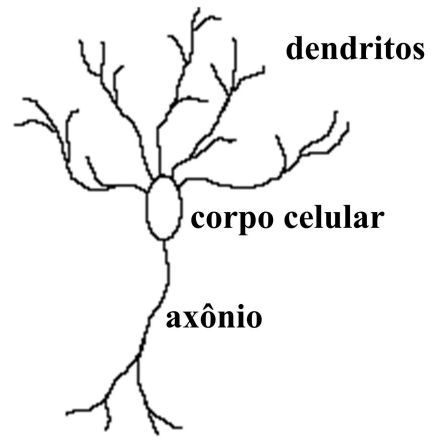

(a)

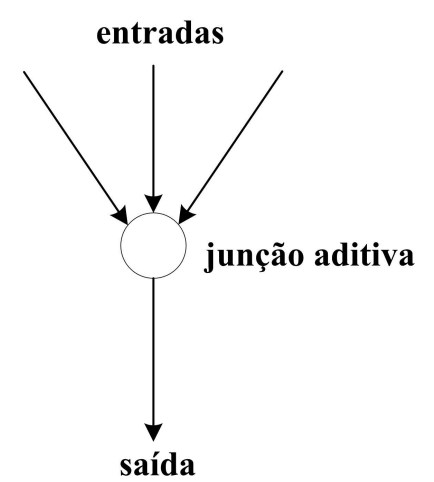

(b)

Figura 4.1: Ilustração de neurônio biológico e neurônio artificial.

(a) representação de um neurônio biológico; (b) ilustração de um neurônio artificial.

Uma rede neural artificial ou RNA, como será chamada no decorrer do texto, é uma tradução grosseira do funcionamento do cérebro humano, a partir de algoritmos. As RNAs caracterizam-se por possuírem:

- Elevado número de elementos de processamento simples, inspirados no funcionamento do neurônio biológico;

- Conexão entre os elementos de processamento;

- Cada conexão tem um peso associado que representa o quanto forte é a interação ou acoplamento entre os elementos de processamento e se a sua natureza é excitatória ou inibitória.

As redes neurais artificiais possuem várias características vantajosas que estimulam as pesquisas na área, entre outras destacamos (HAYKIN, 1999):

- Controle paralelo e distribuído;

- Capacidade de aprendizado através de um conjunto de exemplos sendo estes com ou sem informação de respostas desejadas; 
- Capacidade de adaptar a modificações operativas do ambiente (retreinamento);

- e outras como robustez, implementação em VLSI e tolerância a falhas.

Por outro lado, ainda não foi explicado conceitualmente como a rede neural aprende o conhecimento. Esta falta de embasamento teórico das redes neurais ainda é uma séria desvantagem, pois gera desconfiança na sua aplicação. Outra desvantagem das redes neurais é o tempo requerido na fase de aprendizado da rede. Em algumas aplicações a fase de aprendizado pode durar horas e até dias para ser realizada. Com as crescentes pesquisas em processamento paralelo, em breve, o tempo de aprendizado não será mais problema. O outro problema, a desconfiança das RNA, está sendo resolvido com as publicações sobre aplicações das RNA nas mais diferentes áreas (engenharia, medicina, mercado de risco, agricultura, etc.)

\subsection{Aplicações das Redes Neurais}

As Redes Neurais Artificiais (RNA) são um exemplo de técnica de inteligência computacional que vem sendo utilizada em diversas aplicações como (DUDA; HART; STORK, 2000):

- reconhecimento de voz,

- reconhecimento de face e classificação,

- reconhecimento de padrões,

- reconhecimento e classificação de imagens para reconhecer: textos, assinaturas, impressões digitais, objetos e outros. 
Além destas e outras utilizações a RNA também vem sendo utilizada em sistemas de auxílio ao diagnóstico (CAD) para classificar regiões de mamogramas suspeitas de câncer (ROIs) em nódulos benignos ou malignos (HALKIOTIS; MANTAS; BOTSIS, 2002; YU; GUAN, 2000; ANDRE; RANGAYYAN, 2003; SILVA; DELMORAL-HERNANDEZ; RANGAYYAN, 2004, 2005).

Para a classificação das características do nódulo da região de interesse (ROI), diferentes arquiteturas de RNA vêm sendo empregadas, como o Perceptron de Múltiplas Camadas (em inglês, Multi-Layer Perceptrons) (MLPs) (HALKIOTIS; MANTAS; BOTSIS, 2002; YU; GUAN, 2000; ANDRE; RANGAYYAN, 2003), e Perceptron de Única Camada (em inglês, Single-Layer Perceptrons) (SLPs) (ANDRE; RANGAYYAN, 2003) que são aplicadas na tentativa de uma melhor classificação entre nódulos benignos e malignos.

Com a procura de melhorar os resultados dos classificadores utilizando as RNA obtidos com as arquiteturas MLP e SLP neste trabalho é apresentada uma nova proposta para a classificação, também utilizando as redes neurais artificiais baseadas no principio de dividir e conquistar conhecida como Máquinas de Comitê (HAYKIN, 1999; SCHAPIRE, 1999; DUDA; HART; STORK, 2000; SCHAPIRE, 2002). Os resultados iniciais desta tentativa estão apresentados no trabalho de Silva et al. (SILVA; DEL-MORAL-HERNANDEZ; RANGAYYAN, 2004, 2005).

\subsection{Máquinas de Comitê}

A idéia básica, é treinar um comitê de RNAs (Redes Neurais Artificiais) para resolver uma tarefa computacionalmente complexa. Em uma Máquina de Comitê, os resultados individuais de cada RNA, também chamada de especialista são combinados para se conseguir um melhor desempenho de generalização. Este processo é conhecido também como princípio de "dividir e conquistar" (HAYKIN, 
1999; SCHAPIRE, 1999; DUDA; HART; STORK, 2000; HU; HWANG, 2001).

As Máquinas de Comitê são divididas em duas grandes categorias que são as estruturas estáticas e as estruturas dinâmicas (HAYKIN, 1999).

As estruturas estáticas são assim consideradas pelo fato das saídas dos especialistas serem combinadas sem envolver o sinal de entrada (padrões de entrada envolvidos no treinamento). Esta categoria possui dois métodos de aplicar o sinal de entrada, que são a média de ensemble e o reforço.

No método média de ensemble, o sinal de entrada é o mesmo para todos os especialistas e a saída global é dada pela combinação linear das saídas dos especialistas individuais. O método de reforço caracteriza-se pela diferente distribuição do sinal de entrada dos especialistas. O reforço pode ser implementado de três modos, a saber: reforço por filtragem, reforço por sub-amostragem e reforço por ponderação. Estes três métodos são detalhados em (HAYKIN, 1999).

Por outro lado, as Máquinas de Comitê de estruturas dinâmicas diferem das estruturas estáticas pelo fato do sinal de entrada estar aplicado não apenas às entradas dos especialistas, mas também sobre o combinador das saídas dos especialistas. Desse modo, a saída do comitê depende do sinal de entrada e da saída dos especialistas.

A principal técnica de estrutura dinâmica é a mistura de especialistas, que apresenta como característica uma unidade denominada de rede de passagem, responsável por fazer a combinação não linear das saídas dos especialistas (HAYKIN, 1999).

Em resumo, uma Máquina de Comitê pode ser interpretada como um grupo de RNAs combinadas para realizar uma classificação. Neste trabalho, será utilizado o método de reforço implementado por filtragem da categoria de estrutura estática da Máquina de Comitê. Como especialista do comitê, será utilizada a 
arquitetura de RNA, Perceptrons de Múltiplas Camadas (ou MLP, em inglês, Multi-Layer Perceptrons), com o algoritmo de aprendizado de retropropagação do erro (HAYKIN, 1999; DUDA; HART; STORK, 2000).

A seguir, será descrito em detalhes o método de reforço por filtragem.

\subsubsection{Reforço por Filtragem}

Reforço (ou boosting) é um método de estrutura estática da Máquina de Comitê, cujo objetivo é construir um modelo de aprendizado que seja independente da distribuição do conjunto de padrões de treinamento. O problema neste método, é a necessidade de um elevado repertório de amostras (padrões) no conjunto de treinamento (HAYKIN, 1999; DUDA; HART; STORK, 2000).

Esse problema pode ser superado usando-se o algoritmo chamado AdaBoost (reforço adaptativo em inglês, adaptive boosting) (HAYKIN, 1999; DUDA; HART; STORK, 2000; FREUND; SCHAPIRE, 1996, 1997; SCHAPIRE, 1999, 2002); este método de reforço por filtragem tem a capacidade de operar com uma quantidade de padrões do conjunto de treinamento reduzido, pois permite a sua reutilização. O algoritmo AdaBoost será aplicado na classificação de nódulos mamográficos (veja também em (SILVA; DEL-MORAL-HERNANDEZ; RANGAYYAN, 2004, 2005)). O método de aprendizado e operação desse algoritmo de reforço alternativo será descrito a seguir.

\subsubsection{AdaBoost}

O AdaBoost (reforço adaptativo em inglês, adaptive boosting) constrói uma composição de especialistas, neste trabalho utilizada a arquitetura neural MLP, com um comitê de treinamento seqüencial.

O princípio da teoria do AdaBoost consiste em um sistema que pode se ajus- 
tar adaptativamente aos erros das hipóteses de classificação retornadas por um conjunto de especialistas. A hipótese final será dada combinando a hipótese de cada especialista.

O AdaBoost é inspirado no modelo PAC (Provavelmente Aproximadamente Correto, em inglês, Probably Approximately Correct) (RAO; OBLOW, 1994; HOLDEN; RAYNER, 1995; BERGADANO; CUTELLO, 1995; HERNANDEZ-AGUIRRE, 2000), e sua proposta é melhorar o desempenho de qualquer algoritmo de aprendizado através de um processo iterativo. Em cada iteração deste processo, um novo especialista (RNA) é adicionado ao comitê. O índice de iteração é nomeado como "ne", onde ne representa o número de especialistas incorporados ao comitê e o índice de iteração máximo, foi nomeado como "NTE", onde NTE representa o número total de especialistas incorporado ao comitê.

A partir de uma arquitetura de rede neural usada para implementar os especialistas do comitê, nomeados $R N_{1}, R N_{2}, \ldots, R N_{n e}, \ldots, R N_{N T E}$, e a partir de um dado conjunto de padrões de treinamento $\operatorname{Tr}=\left\{\left(x_{1}, y_{1}\right),\left(x_{2}, y_{2}\right), \ldots,\left(x_{i}, y_{i}\right)\right.$, $\left.\ldots,\left(x_{N}, y_{N}\right)\right\}$ onde, $x_{i}$ pertence ao mesmo domínio ou espaço instanciado pelo conjunto de padrões de treinamento $X, y_{i}$ pertence ao conjunto de classes de saída $Y$ e $N$ é o número de padrões do conjunto de treinamento, o algoritmo AdaBoost apresenta uma hipótese final com base na combinação da hipótese de cada especialista.

O algoritmo é baseado na definição de um conjunto adaptativo de pesos probabilísticos associados com os elementos do conjunto de padrões de treinamento. O particular peso probabilístico distribuído sobre o conjunto de padrões de treinamento em cada iteração ne é chamado $D_{n e}(i), i=1,2, \ldots, N$.

Inicialmente, para ne $=1$, todos os pesos probabilísticos são iguais de mesmos valores. Os pesos são atualizados em cada iteração ne com base no sucesso ou 
falha da hipótese $h_{n e-1}$ determinada pelo especialista $R N_{n e-1}$.

Quando o especialista $R N_{n e}$ recebe um conjunto de padrões de treinamento $\left(\operatorname{Tr}_{n e \sim D_{n e}}\right)$ com os pesos probabilísticos $D_{n e}$, este produz uma hipótese $h_{n e}$. A amostra do conjunto de padrões de treinamento classificada erroneamente por $h_{n e}$ terá o seu peso probabilístico aumentado enquanto que a amostra classificada corretamente terá o seu peso probabilístico diminuído quando considerado durante o treinamento do novo especialista. Na próxima iteração, o especialista $R N_{n e+1}$ é forçado a focar nas amostras mais "difíceis" (classificações incorretas) do conjunto de padrões de treinamento. Este comportamento adaptativo pode ser observado na Figura 4.2.

ILUSTRAÇÄO DA ATUALIZAÇÄO DOS PESOS PROBABILÍSTICOS

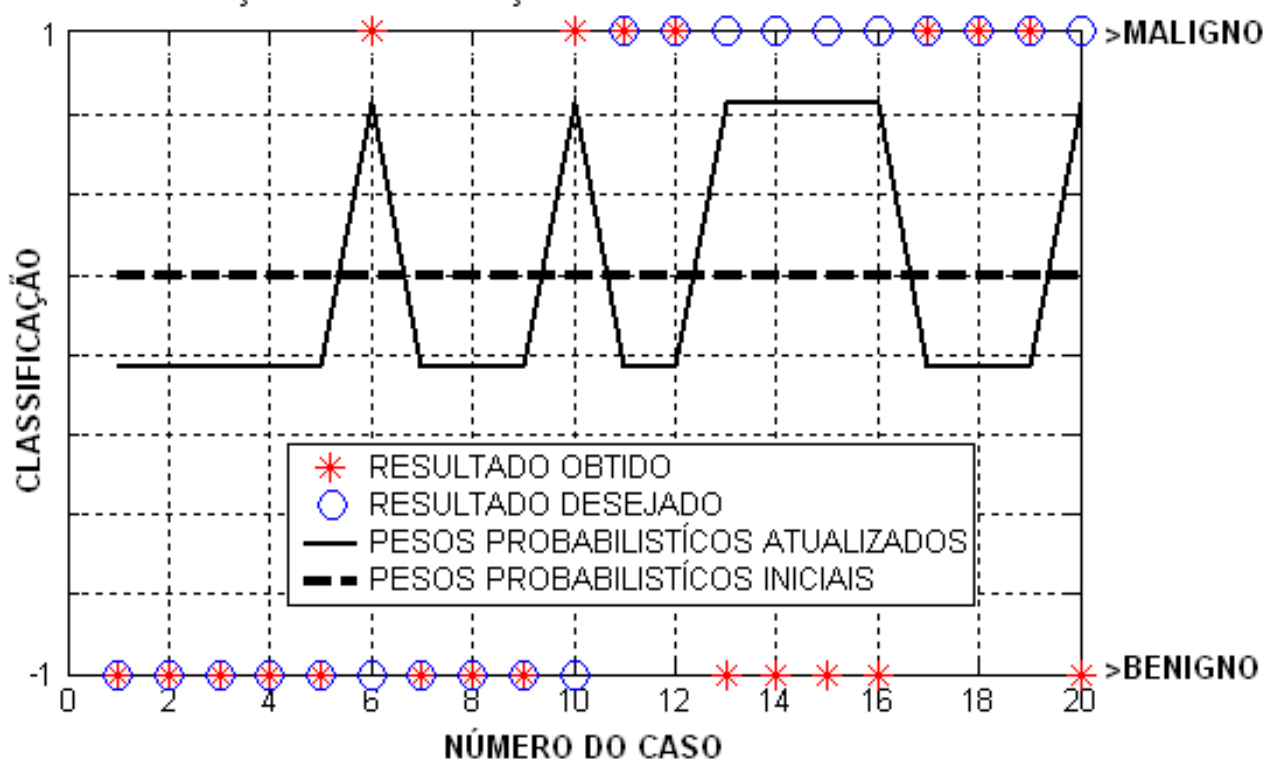

Figura 4.2: Ilustração dos pesos probabilísticos.

Atualização do peso probabilístico do conjunto de padrões de treinamento. Perceba que o peso probabilístico das amostras classificadas incorretamente é aumentado, enquanto que o peso probabilístico das amostras classificadas corretamente é diminuído. Neste exemplo foram usados 20 casos (amostras) (1 a 10 benigno e 11 a 20 maligno). A saída desejada é -1 para caso benigno e 1 para caso maligno. Os valores dos pesos probabilísticos, não pertencem à escala vertical do gráfico, eles foram assim colocados para facilitar a ilustração da explicação do conceito, pois os valores reais dos pesos probabilísticos são distribuídos de forma que a soma de todos os pesos probabilísticos resulta no valor 1 assim, se colocados na escala vertical do gráfico (-1 a 1) a visualização da atualização dos pesos probabilísticos seria prejudicada. 
A qualidade do resultado da hipótese $\left(h_{n e}\right)$ é calculada pelo seu erro:

$$
\epsilon_{n e}=\sum_{i=1}^{N} D_{n e}(i)\left|h_{n e}(x(i))-y(i)\right|
$$

Onde $N$ é a cardinalidade do conjunto de treinamento.

Uma vez recebida a hipótese $h_{n e}$ do especialista é necessário calcular um parâmetro $\alpha_{n e}$ para mensurar a importância com que $h_{n e}$ foi determinada.

No resumo do algoritmo AdaBoost (Figura ??) pode ser verificado que $\alpha_{n e} \geq 0$ se $\epsilon_{n e} \leq 0,5$ (onde é assumido que não existe nenhuma perda de generalização) e que $\alpha_{n e}$ será maior conforme $\epsilon_{n e}$ diminui) (SCHAPIRE, 1999).

A próxima distribuição $D_{n e}$ é atualizada conforme mostrado na Figura ??. Dessa maneira, o algoritmo AdaBoost aumenta o peso do padrão de treinamento classificado incorretamente por $h_{n e}$ e diminui o peso do padrão de treinamento classificado corretamente (veja a Figura 4.2). Assim, os pesos tendem a se concentrar nos padrões do conjunto de treinamento mais difíceis.

Esse processo é repetido até que o $\epsilon_{n e} \leq$ erro $_{\max }$ ou enquanto ne $\leq N T E$, no final desta iteração, temos um comitê de redes neurais $R N_{1}, R N_{2}, \ldots, R N_{n e}$, $\ldots, R N_{N T E}$, (veja a Figura 4.3). A hipótese final $H(x)$ será dada por:

$$
H(x)=\operatorname{sign}\left[\left(\sum_{n e=1}^{N T E} \alpha_{n e} h_{n e}(x)\right)\right]
$$

Dessa forma, o Adaboost vem sendo aplicado em diversos problemas como reconhecimento de voz continuado (on-line) (SCHWENK, 1999), detecção de face (VIOLA; JONES, 2001), solução de problemas de diagnóstico de falha em aparelhos (MURPHEY; CHEN; FELDKAMP, 2001, 2002), tratamento de resultados na detecção de padrões e classificação em um ambiente real e complexo (detecção de faces em um ambiente de aeroporto) (JIANG; LOE, 2003), predição das características que 


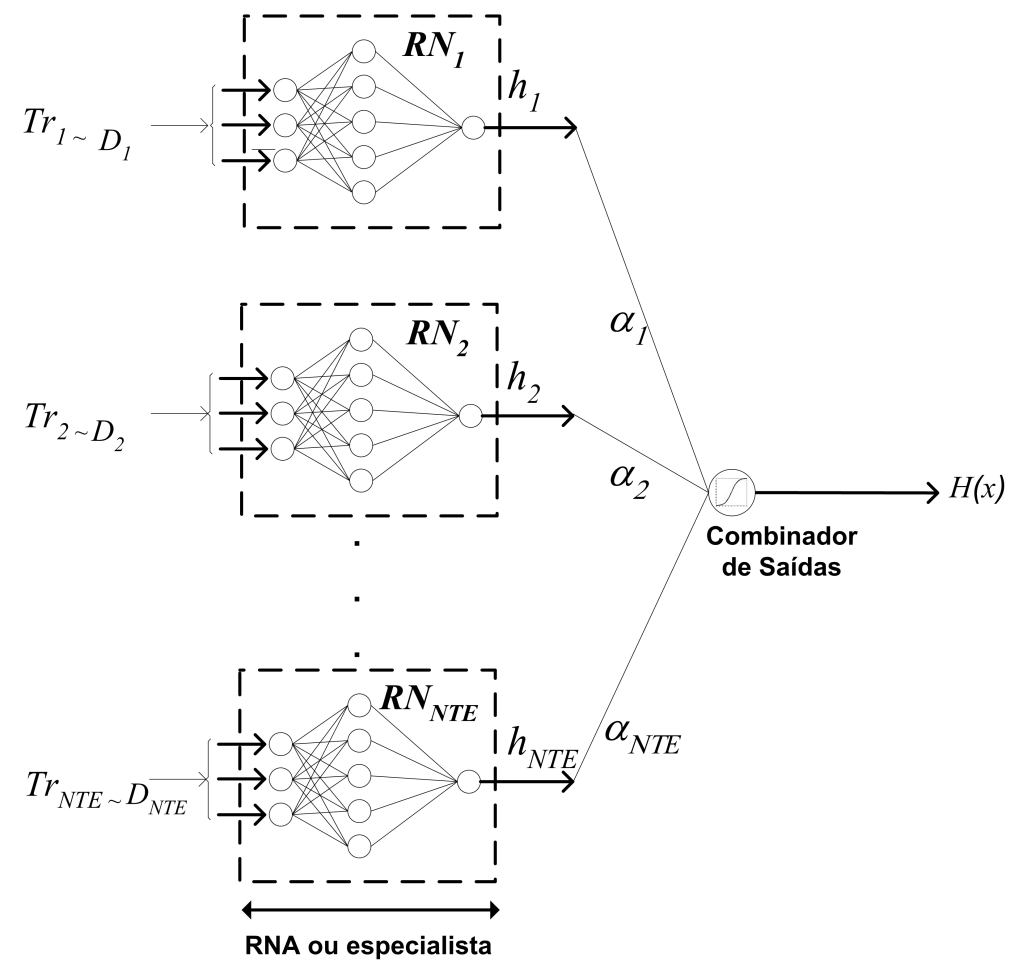

Figura 4.3: Ilustração da arquitetura Máquina de Comitê.

podem separar drogas de produtos farmacêuticos (GOH; LIM; PEH, 2003).

Neste trabalho foi utilizado o algoritmo AdaBoost para melhorar o aprendizado da arquitetura Perceptron de Múltiplas Camadas treinada com o algoritmo de aprendizado conhecido como retropropagação do erro. Essa tentativa já foi realizada por (ROMERO; ALQUEZAR, 2002) em um modelo para ajuste dos pesos para o critério da soma do erro quadrático, para que a arquitetura neural Perceptron de Múltiplas Camadas, apresente o mesmo resultado de classificação, para classes linearmente separáveis em comparação com os resultados do classificador SVM (Support Vector Machine). Uma outra tentativa de melhorar o aprendizado de retropropagação foi realizada em dois trabalhos de Silva et. al. (SILVA; DELMORAL-HERNANDEZ; RANGAYYAN, 2004, 2005) para a classificação de nódulos mamográficos em benigno ou maligno a partir da região de interesse identificadas no exame de mamografia pelo radiologista. 


\section{Resumo Algoritmo do AdaBoost}

$\begin{array}{ll}\text { Entrada: } & \text { Amostras do conjunto de treinamento } \\ & \operatorname{Tr}=\left\{\left(x_{1}, y_{1}\right), \ldots,\left(x_{i}, y_{i}\right), \ldots,\left(x_{N}, y_{N}\right)\right\} \\ & \text { onde, } x_{i} \in X, y_{i} \in Y=\{-1,1\} \\ & \text { Algoritmo aprendizado (fraco) retroprop } \\ & \text { Inteiro NTE especificando o número m } \\ & \text { ações do algoritmo } \\ & \\ \text { Inicialização: } & \text { ne }=1, D_{n e}(i)=1 / N, \text { para } i=1, \ldots, N \\ \text { Computação: } & \text { Faça enquanto ne } \leq \text { NTE e } \epsilon>\text { erro }_{\max }\end{array}$

1. Normalize $D$, de modo que $\sum_{i=1}^{N} D_{n e}(i)=1$

2. Chame o modelo de aprendizagem fraca retropropagação, usando a distribuição $D_{n e}(i)$ que retornará uma hipótese

$$
h_{n e}: \mathrm{X} \rightarrow\{-1,1\}
$$

3. Calcule o erro da hipótese

$$
h_{n e}: \epsilon_{n e}=\sum_{i=1}^{N} D_{n e}(i)\left|h_{n e}(x(i))-y(i)\right|
$$

4. Faça $\alpha_{n e}=\frac{1}{2} \cdot \ln \cdot\left[\frac{1-\epsilon_{n e}}{\epsilon_{n e}}\right]$

5. Atualize os pesos

$$
D_{n e+1}(i)=\frac{D_{n e}(i)}{Z_{n e}} \times \begin{cases}e^{-\alpha_{n e}} & \text { se } h_{x}(i)=y_{i} \text { (classificação correta) } \\ e^{\alpha_{n e}} & \text { se } h_{x}(i)=y_{i} \text { (classificação incorreta) }\end{cases}
$$

onde $Z_{n e}$ é um fator de normalização (escolhido de modo que $D_{n e+1}$ seja normalizado )

6. ne $=$ ne +1

Saída: $\quad$ A hipótese $H(x)=\operatorname{sign}\left[\sum_{j=1}^{N T E} \alpha_{j} h_{j}(x)\right]$

Figura 4.4: Resumo do Algoritmo AdaBoost 
O aprendizado de retropropagação é um dos métodos mais simples e mais populares para o treinamento de redes neurais e utilizado em diversas aplicações, mas ainda existem problemas como por exemplo, o da generalização (HAYKIN, 1999; MURPHEY; CHEN; FELDKAMP, 2001). Uma tentativa para solucionar esse problema é aplicar o algoritmo AdaBoost.

Em (HAYKIN, 1999) são apresentados dois gráficos, ilustrados na Figura 4.5 e 4.6, de experimentos de desempenho de erro realizados com o AdaBoost e com o Perceptron de Múltiplas Camadas treinado com algoritmo de retropropagação.

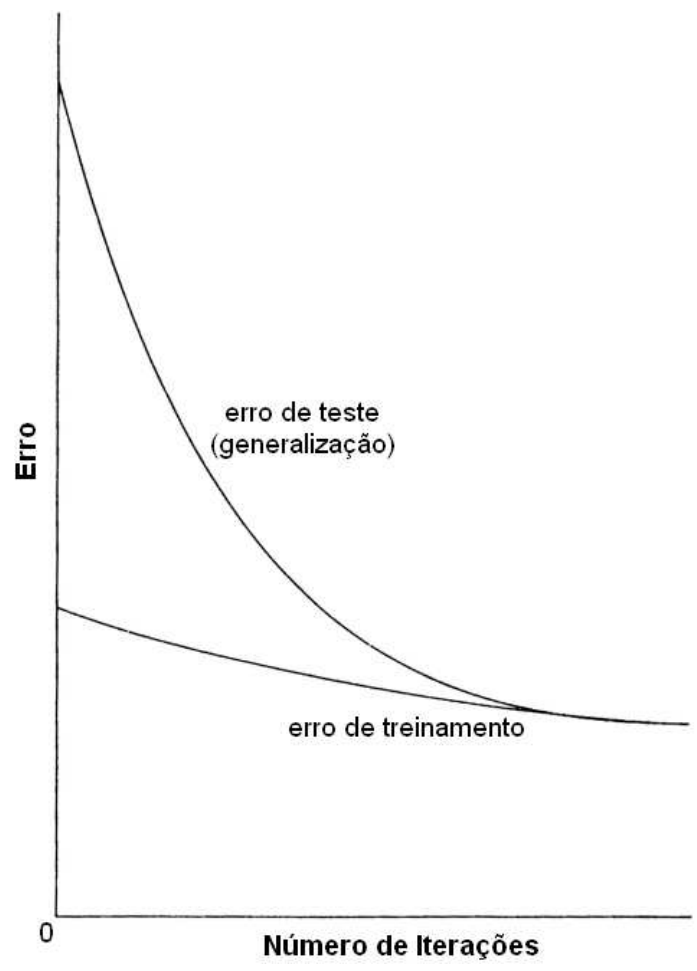

Figura 4.5: Desempenho do erro de generalização do AdaBoost.

Figura que ilustra o desempenho do erro de generalização do algoritmo AdaBoost. Figura retirada do livro (HAYKIN, 1999) página 398.

O resultado apresentado pelo AdaBoost (Figura 4.5) mostra que o erro de teste diminui de acordo com o erro de treinamento, enquanto que nos experimentos com o Perceptron de Múltiplas Camadas treinado com o algoritmo da retropropagação, o gráfico apresenta um comportamento diferente ao apresentado pelo AdaBoost, o erro de teste (validação) decresce até um mínimo e depois 


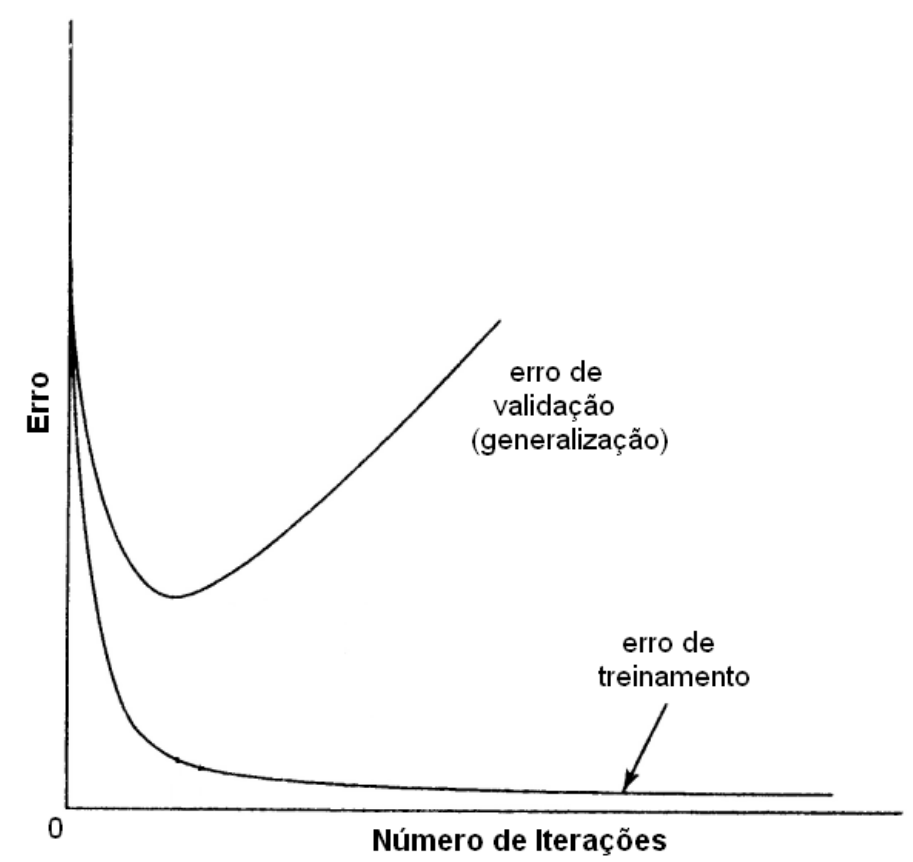

Figura 4.6: Desempenho do erro de generalização do aprendizado de retropropagação do erro.

Figura que ilustra o desempenho do erro de generalização do aprendizado de retropropagação dos Perceptrons de Múltiplas Camadas. Figura adaptada do livro (HAYKIN, 1999) página 243.

aumenta devido ao treinamento excessivo (veja a Figura 4.6). De acordo com estas duas figuras (Figura 4.5 e Figura 4.6), fica evidente que o algoritmo do AdaBoost melhora a capacidade de generalização do aprendizado de retropropagação do erro.

Para completar a explicação do classificador máquina de comitê, descreve-se a seguir a arquitetura neural do especialista $\left(R N_{N T E}\right)$ citada anteriormente na explicação do AdaBoost, a arquitetural neural Perceptron de Múltiplas Camadas.

\subsubsection{Arquitetura Neural $R N_{N T E}$ - Perceptrons de Múlti- plas Camadas}

A $R N_{N T E}$ (ou especialista) usada na Máquina de Comitê é a conhecida como arquitetura MLP (Perceptrons de Múltiplas Camadas). As redes neurais de arquitetura MLP tipicamente consistem de uma especificação do número de camadas, 
tipo de função de ativação de cada unidade e pesos de conexões entre as diferentes unidades que devem ser definidas para a construção desta arquitetura neural.

A Figura 4.7 ilustra uma arquitetura do tipo MLP com $N_{e_{m}}$ neurônios na camada de entrada (neurônios sensores), $N_{o_{n}}$ neurônios na camada escondida e com um único neurônio de saída $\left(N_{s_{1}}\right)$.

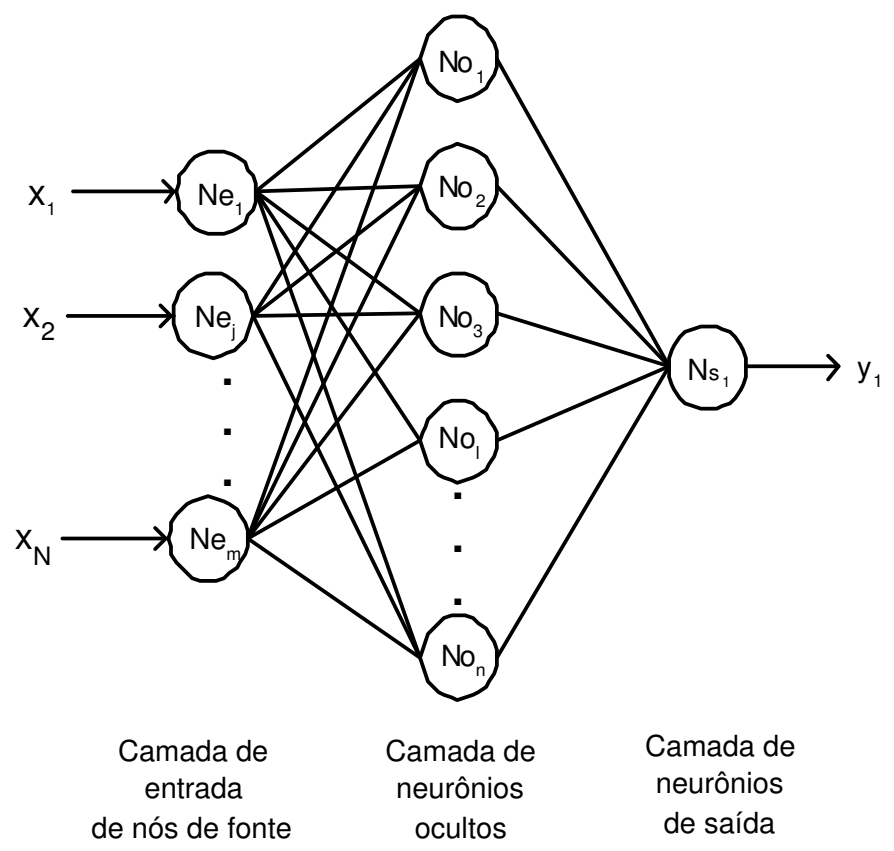

Figura 4.7: Ilustração do MLP.

Ilustração de uma arquitetura de Perceptrons de Múltiplas Camadas (MLP em inglês, Multi-Layer Perceptrons). Nessa ilustração, a topologia do MLP é a seguinte: $N_{e_{m}}$ neurônios na camada de entrada (neurônios sensores), $N_{o_{n}}$ neurônios na camada escondida e um único neurônio de saída $\left(N_{s_{1}}\right)$.

O funcionamento da arquitetura MLP é iniciado quando aplicado um dado padrão de entrada do conjunto de treinamento nos neurônios da camada de entrada que se propaga para frente, de camada em camada, até atingir os neurônios da camada de saída. A resposta de saída $f_{M L P}$ é calculada como mostrado a seguir:

$$
f_{M L P}(\mathbf{x})=\varphi\left(\sum_{l=1}^{N_{o_{n}}} v_{l} \cdot \varphi\left(\sum_{j=1}^{N_{e_{m}}} w_{l j} x_{l}+b_{l 0}\right)+b_{0}\right)
$$


onde $N_{O_{n}}$ é o número de neurônios na camada oculta (ou escondida) e $N_{e_{m}}$ é o número de neurônios na camada de entrada. Os pesos sinápticos são representados por $v_{l}$ e $w_{l j} ; b_{l 0}$ e $b_{0}$ são os biases; e a função $\varphi(\cdot)$ é a função de ativação, comumente especificada como sendo a função sigmoidal (Figura 4.8).

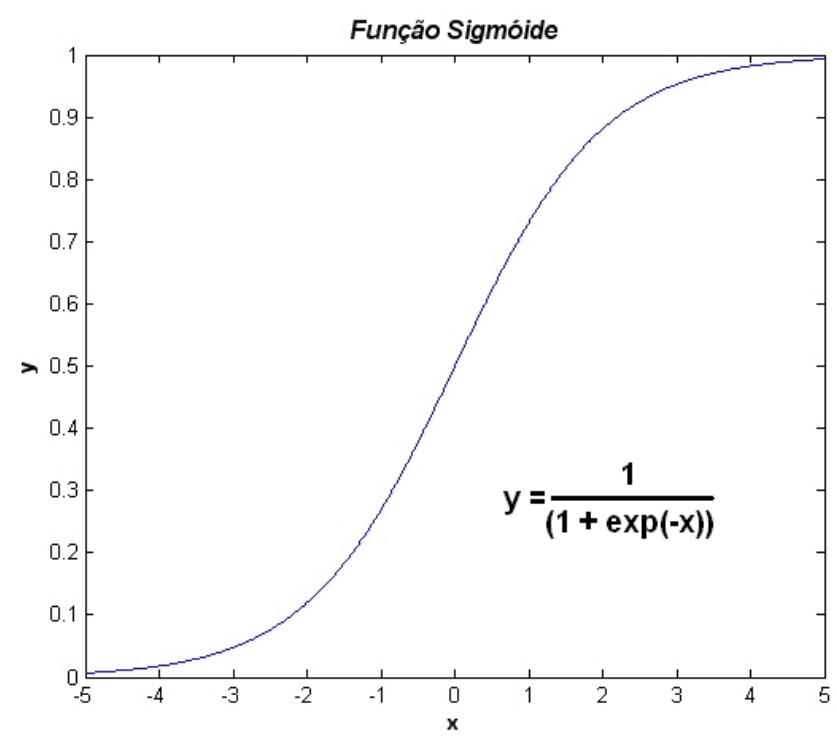

Figura 4.8: Exemplo da função sigmóide.

Função sigmóide, usualmente utilizada como função de transferência dos neurônios da camada escondida e dos neurônios da camada de saída.

O objetivo do processo de treinamento é escolher parâmetros adequados para minimizar uma função de custo pré-determinada. A função da soma do erro quadrático é a mais usual:

$$
E(X)=\sum_{i=1}^{N} \frac{1}{2}\left[f_{M L P}\left(x_{i}\right)-y_{i}\right]^{2} .
$$

Onde $N$ é o número de padrões do conjunto de treinamento.

A função soma do erro quadrático $E(X)$ é uma aproximação para a norma quadrática da função de erro $\left(f_{M L P}(\mathbf{x})-y\right)$ (HAYKIN, 1999).

A arquitetura (conexões, número de neurônios na camada escondida e função de ativação) é usualmente fixada como um conhecimento a priori; por outro lado, os pesos são ajustados durante o processo de treinamento pela retropropagação 
do erro.

Pesquisas têm mostrado que a rede neural de múltiplas camadas (MLP) são capazes de aprender qualquer tipo de função (KOVACS, 1996; HAYKIN, 1999). Porém, quando a MLP é treinada com o algoritmo de retropropagação do erro, a aproximação se torna uma tarefa difícil, devido ao problema do mínimo local. Assim, para a arquitetura MLP não existe um procedimento a ser aplicado no algoritmo de retropropagação do erro que possa garantir uma solução ótima, o mínimo local é sempre uma possibilidade. Apesar disso, o algoritmo de retropropagação, usado no treinamento das redes neurais MLP, têm mostrado eficientes resultados sobre uma grande faixa de problemas de aplicação. Quanto a topologia da arquitetura, ou seja, quantas camadas escondidas e quantas unidades de neurônios na camada escondida, ainda não existe um consenso e vêm sendo bastante pesquisadas.

Experimentos com a arquitetura MLP foram realizados para efeito comparativo com o classificador Máquina de Comitê assim como, outros resultados apresentados pelos classificadores MLP e SLP foram comparados. As comparações são feitas a partir do resultado de $A_{z}$ de cada classificador. O $A_{z}$, que é o cálculo da área sob a curva ROC, é um método utilizado para medir a capacidade de discriminação. Os detalhes deste método são descritos no próximo capítulo. 


\section{5 Área Sob a Curva ROC $-\boldsymbol{A}_{\boldsymbol{z}}$}

\subsection{Métrica de Análise de Desempenho na Medi- cina}

Na medicina, há a necessidade de estabelecer critérios para determinar se o resultado de um exame é normal ou anormal. A partir de testes, exames (laboratoriais, raios-x e etc) e também das técnicas de inteligência computacional é possível melhorar a estimativa da probabilidade de que um paciente tenha uma dada doença ou não.

As medidas (testes) feitas em uma população de pessoas doentes e não doentes, na maioria dos exames, geram variáveis contínuas, que estão distribuídas estatisticamente de alguma maneira específica. O modelo de distribuição estatística mais comumente usado para aproximar as distribuições obtidas experimentalmente em exames tradicionais na medicina é o da distribuição normal (ou gaussiana) (SILVA-FILHO, 2004).

No caso da utilização de técnicas de inteligência computacional, em especial as redes neurais artificiais (RNA), também existem variáveis continuas. As variáveis continuas são oferecidas pela escolha adequada da função de ativação da rede neural artificial.

Para facilitar o entendimento de um teste para indivíduos sadios e doentes, assumimos que os valores do teste se distribuem de maneira normal, tanto 
para uma população como para a outra, com médias e desvios-padrão diferentes, mas em geral existe uma sobreposição entre as duas curvas. Na Figura 5.1 é ilustrado um exemplo de resultado para um certo número de pacientes diagnosticados como doentes (nódulo maligno, por exemplo) e sem doença (nódulo benigno, por exemplo), onde se mostra que erros no diagnóstico, com base unicamente em um determinado exame, são inevitáveis.

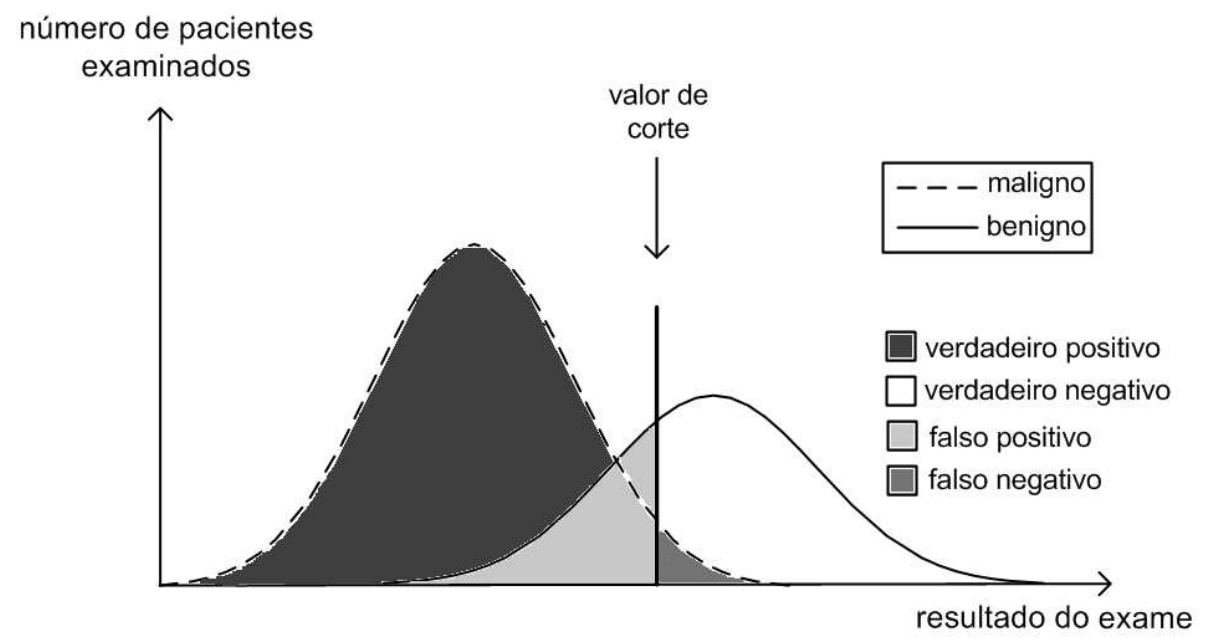

Figura 5.1: Exemplo de resultados de um diagnóstico.

Esta figura ilustra um exemplo de resultado do exame para um certo número de pacientes diagnosticados como doentes (maligno) e não doentes (benigno). É possível notar que erros são inevitáveis, e que para cada valor de corte escolhido temos os 4 possíveis casos de classificação (VP, VN, FP e FN).

Em geral, o valor de um teste é classificado como benigno quando está acima de um valor de corte definido. Quando está abaixo desse valor de corte ele é considerado como maligno.

Um teste ideal é aquele em que não há sobreposição entre as distribuições de valores para as populações de indivíduos saudáveis e doentes. Quase nenhum teste satisfaz este critério.

Em testes reais existe sempre uma sobreposição entre as duas populações (maligno e benigno) e qualquer que seja o valor de corte definido haverá sempre erros. Os dois tipos de erros são: classificar um indivíduo que não tem a doença 
como doente (quando o teste dá positivo, mas tal resultado é falso, portanto falsopositivo) e classificar um indivíduo doente como sem doença (quando o teste dá negativo, mas o resultado é positivo, portanto falso-negativo).

Os termos usados para denotar os casos possíveis são:

- Verdadeiro positivo (VP): o nódulo é classificado como sendo câncer (maligno) e comprova ser câncer;

- Verdadeiro negativo (VN): o nódulo é classificado como não sendo câncer (benigno) e comprova não ser câncer;

- Falso negativo (FN): o nódulo é classificado como não sendo câncer (benigno) mas comprova ser câncer (maligno).

- Falso positivo (FP): o nódulo é classificado como sendo câncer (maligno) mas comprova não ser câncer (benigno).

Esses resultados de classificação, podem ser expressos em uma tabela que resume todos os casos possíveis (Tabela 5.1).

\begin{tabular}{|l|c|c|c|}
\hline Resultado do Teste & Com Doença & Sem Doença & Total \\
\hline Positivo & $\mathrm{VP}$ & $\mathrm{FP}$ & $\mathrm{VP}+\mathrm{FP}$ \\
\hline Negativo & $\mathrm{FN}$ & $\mathrm{VN}$ & $\mathrm{FN}+\mathrm{VN}$ \\
\hline Total & $\mathrm{VP}+\mathrm{FN}$ & $\mathrm{FP}+\mathrm{VN}$ & $\mathrm{N}$ \\
\hline
\end{tabular}

Tabela 5.1: Tabela de Contingência.

Tabela que expressa o resultado de classificação em VP, VN, FP e FN, para um dado valor de corte escolhido.

\subsection{Métrica de Desempenho para Classificador Au- tomático Aplicado na Medicina}

A primeira métrica de desempenho proposta para analisar os resultados de classificadores automáticos sobre duas classes (com doença ou sem doença), é a conhe- 
cida como área sob a curva ROC (do inglês Receiver Operating Characteristic) designada por $\left(A_{z}\right)$ (WOODS; BOWYER, 1997; DELEO; CAMPBELL, 1995; DELEO, 2002). Esta técnica é derivada da metodologia ROC que teve a sua origem na teoria de deteç̧ão de sinal desenvolvida durante a $2^{\text {a }}$.Guerra Mundial para a detecção de imagens de radar (TAPE, 2004).

A metodologia ROC, é a discretização dos valores contínuos, resultantes de uma classificação, em um valor bipolar $[-1,1]$. A discretização é feita a partir das diferentes escolhas dos valores de corte (threshold) (veja exemplo na Figura 5.1). Para o diagnóstico médico, a variação do valor de corte implicará no compromisso de classificar melhor um paciente que tenha realmente câncer ou então classificar melhor um paciente que não tem câncer. Para um melhor entendimento desse conceito, está ilustrado na Figura 5.1 um exemplo de resultado do diagnóstico para diversos pacientes em duas classes, benigno ou maligno. Neste exemplo fica fácil perceber as conseqüências da variação do valor de corte em uma classificação.

Assim, para um resultado de classificação, a cada valor de corte escolhido calcula-se os valores de VP, VN, FP e FN. Esses resultados podem ser expressos em uma tabela de contingência (Tabela 5.1) e que indicara todos os resultados possíveis da classificação.

Após a construção dessa tabela são calculadas duas variáveis que caracterizam o desempenho do classificador como indicador da presença de uma anormalidade, que é a sensibilidade e a especificidade.

A sensibilidade de um teste é a probabilidade de que ele classifique corretamente um paciente doente, ou seja, é a probabilidade de que ele dê positivo para um paciente que tenha a doença. Uma maneira de estimar a sensibilidade de um teste é pela sua taxa verdadeiro-positivo (TVP), que é a fração do número total de pacientes doentes para a qual o teste dá positivo: 


$$
T V P=\frac{\text { nódulos malignos classificados como malignos }}{\text { número total de nódulos malignos }}=\frac{V P}{V P+F N}
$$

A especificidade de um teste é a probabilidade de que ele classifique corretamente um paciente sem a doença, ou seja, é a probabilidade de que o teste dê negativo para um paciente que não está com a doença. Uma maneira de calcular a especificidade de um teste é pela sua taxa verdadeiro-negativo (TVN), que é a fração do número total de pacientes sem a doença para a qual o teste dá negativo:

$$
T V N=\frac{\text { nódulos benignos classificadas como benignos }}{\text { número total de nódulos benignos }}=\frac{V N}{V N+F P}
$$

Dessa maneira, ao se variar os valores de corte está sendo realizada uma verificação onde a especificidade e a sensibilidade são maiores. Assim, depois de feita esta investigação da variação do valor de corte, um conjunto de pares de pontos de qualidade de classificação é obtido (TVP e TVN). A partir dos pares de pontos de operação é construída a curva ROC, que mostra a taxa de verdadeiro positivo (sensibilidade) pela taxa de falso positivo (1-especificidade).

A curva ROC é um gráfico de pontos de operação, que mostra a relação entre TVP (sensibilidade) versus TFP (1-especificidade). A curva ROC pode ser usada para contrastar resultados obtidos por diferentes classificadores. Um exemplo de curva ROC é mostrado na Figura 5.2. Nesse exemplo, é ilustrado o resultado do classificador Máquina de Comitê comparado com o resultado obtido por outros dois classificadores, o Perceptron de Múltiplas Camadas (MLP) e o Perceptron de Única Camada (SLP) e ambos são testados com as características extraídas da nitidez da borda $([C V, A$, contraste $])$.

Para medir a capacidade do classificador em discriminar um nódulo benigno 


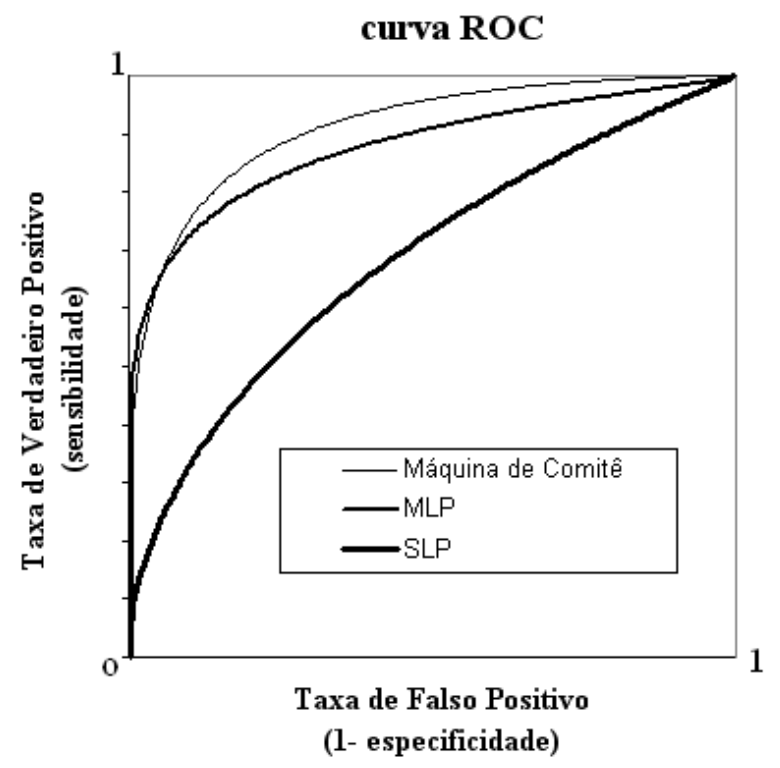

Figura 5.2: Exemplo da curva ROC.

Curva ROC para três resultados de classificação apresentados pelas Máquinas de Comitê $(A z=0,88), \operatorname{MLP}(A z=0,84)$ e $\operatorname{SLP}(A z=0,61)$ e testados neste trabalho com as características de nitidez da borda $[C V, A$, contraste $]$. Este gráfico foi construído utilizando o pacote ROCKIT (ROCKIT, 2004).

de um nódulo maligno é realizado o cálculo da área sob a curva ROC, geralmente chamado de $A_{z}$ (WOODS; BOWYER, 1997; DELEO; CAMPBELL, 1995; DELEO, 2002).

No caso de se aplicar um classificador automático no auxílio ao diagnóstico de pacientes doentes ou não doentes, pode-se usar a metodologia de construção da curva ROC para decidir em qual valor de corte o número de acertos do classificador para determinado caso (doente ou não doente) é maior. Porém, a decisão deve ser ponderada sobre o seguinte problema de custo-benefício: que tipo de erro é mais tolerável para o caso em questão: falso-negativos (casos de câncer nãodetectados) ou falso-positivos (pacientes sem a doença, erroneamente classificados como doentes). Essa escolha cabe ao médico decidir para que tipo de caso ele pretende maximizar os acertos.

Para a decidir em qual caso é mais importante maximizar os acertos, o médico 
analisa o tipo de doença para o qual o teste esta sendo aplicado. Se a doença é séria, mas existe terapia disponível capaz de salvar o paciente, então é melhor tentar minimizar o número de resultados falso-negativos (aumentar a sensibilidade). Se a doença não é grave e a terapia disponível é dolorosa para o paciente ou custosa, então é melhor tentar minimizar o número de falso-positivos (aumentar a especificidade).

Os experimentos e as análises realizadas são apresentadas no capítulo seguinte assim como, a descrição sobre as características utilizadas nos experimentos e seus agrupamentos para os testes; será descrito também como o auxílio de um experimento, a construção da curva ROC e o cálculo sob a sua área, $A_{z}$. Os resultados obtidos são apresentados no capítulo seguinte. 


\section{Experimentos Realizados e Análise}

\subsection{Base de Dados Utilizada nos Experimentos}

Para a realização dos experimentos de classificação são utilizados os seguintes conjuntos de características, discutidas no Capítulo 3: forma da borda $\left[F_{c c}, S I, C\right]$, características de textura (14 medidas) e nitidez da borda $[C V, A$, contraste $]$ extraídos das 57 ROIs, sendo 37 ROIs classificadas como benignas e 20 como malignas.

Para garantir que as características extraídas de cada ROI sejam realmente pertencentes a nódulos benignos e malignos, os nódulos referentes às ROIs analisadas foram submetidos ao exame de biópsia. Esta é a principal razão de não encontrar disponível base de dados com maiores números de casos, que seriam úteis para ampliar o número de amostras do conjunto de características utilizado neste trabalho. Foi encontrado um banco de dados de imagens mamograficas, disponibilizadas por (SUCKLING et al., 1994), mas estas imagens não apresentam a marcação manuscrita do radiologista, o que impossibilita a aplicação das técnicas de processamento de imagens para a extração das características, como acontece no banco de dados de imagens utilizadas nos experimentos deste trabalho (NCI, 2004). Uma outra razão para se utilizar esta base de dados são as futuras comparações com os resultados obtidos em (ANDRE; RANGAYYAN, 2003; ALTO; 
RANGAYYAN; DESAUTELS, 2005), onde os experimentos também são realizados sobre esta base de dados (NCI, 2004).

AMOSTRAS A SEREM CLASSIFICADAS UTILIZANDO AS CARACTERISTICAS DE FORMA

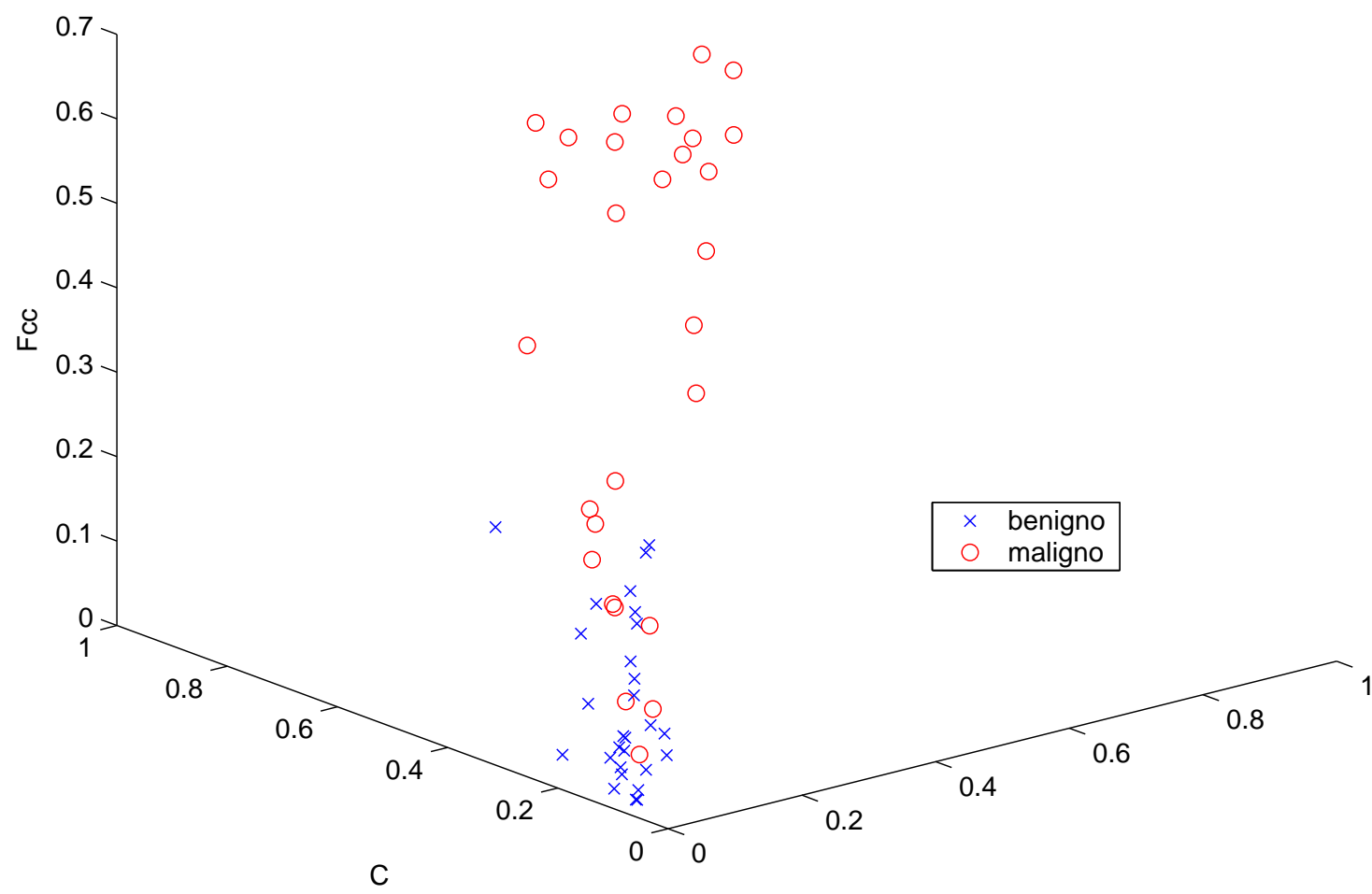

SI

Figura 6.1: Gráfico 3D das características $\left[F_{c c}, S I, C\right]$.

Gráfico $3 \mathrm{D}$ de pontos que correspondem aos valores de $\left[F_{c c}, S I, C\right]$ para as 57 ROIs. Os pontos correspondentes aos nódulos benignos (37) são representados por ' $\mathrm{x}$ ' e os pontos correspondentes aos nódulos malignos (20) são representados por 'o'. Cada característica (feature) está escalada na faixa de [0,1].

Para se ter o conhecimento da distribuição dos conjuntos de características extraídos da forma e da nitidez da borda, foram construídos dois gráficos que possibilitam verificar a distribuição das amostras a serem classificadas no domínio de características. Estes gráficos estão ilustrados na Figura 6.1 e Figura 6.2. A Figura 6.1 ilustra a distribuição no domínio de características de forma $\left[F_{c c}, S I, C\right]$ e a Figura 6.2 ilustra a distribuição no domínio de características de borda $[C V, A$, contraste $]$. 


\section{AMOSTRAS A SEREM CLASSIFICADAS UTILIZANDO AS CARACTERISTICAS DE BORDA}

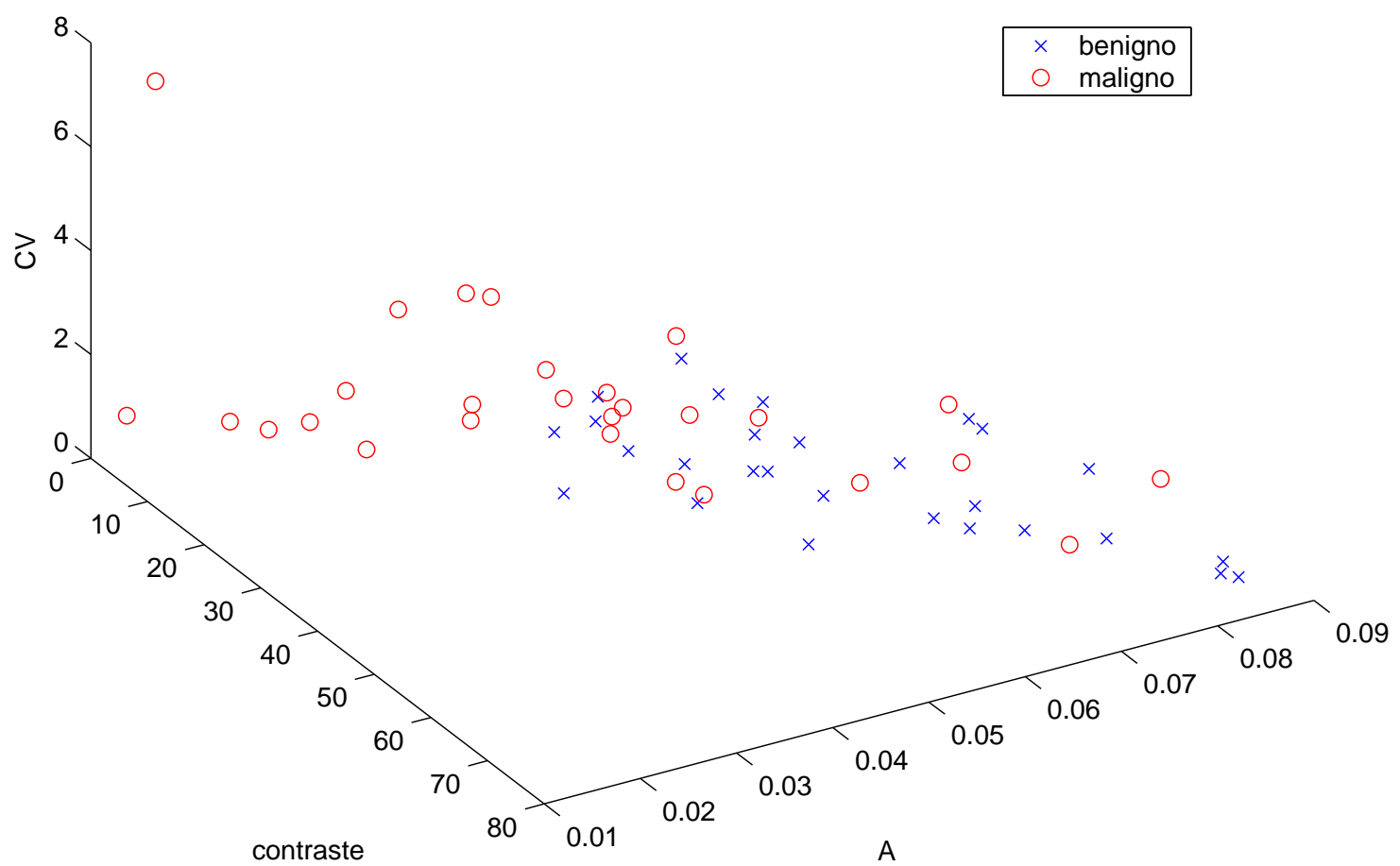

Figura 6.2: Gráfico 3D das características [CV, A, contraste].

Gráfico $3 \mathrm{D}$ de pontos que correspondem aos valores de [CV, $A$, contraste] para as 57 ROIs. Os pontos correspondentes aos nódulos benignos (37) são representados por ' $\mathrm{x}$ ' e os pontos correspondentes aos nódulos malignos (20) são representados por 'o'. Cada característica (feature) está escalada na faixa de $[0,1]$.

Analisando a Figura 6.1 e a Figura 6.2 percebe-se, a partir da posição em que os gráficos estão sendo visualizados, que os conjuntos de características obtidos das medidas de forma e das medidas de nitidez da borda, estão dispostos de maneira diferente.

Na Figura 6.1, as características dos nódulos benignos (representadas por ' $\mathrm{x}$ ') estão, aparentemente, separadas das características dos nódulos malignos (representadas por 'o'). Se essa constatação for verdadeira, o resultado do classificador SLP (classificador linear), medido por $A_{z}$ será alto (próximo de 1). O valor alto de $A_{z}$ significara que as características medidas da forma da borda serão boas 
representações de nódulos benignos e malignos.

Por outro lado, a Figura 6.2 mostra que as características medidas dos nódulos benignos (representadas por ' $\mathrm{x}$ ') estão aparentemente misturados com as características dos nódulos malignos (representadas por 'o'). Sendo está observação verdadeira, o resultado do classificador SLP, medidos por $A_{z}$ não serão altos. O valor baixo de $A_{z}$ significara que as características medidas da nitidez da borda não serão boas representação de nódulos benignos e malignos.

Para verificar os agrupamentos mais representativos de nódulos benignos e malignos que ocasionam em valores altos de $A_{z}$, os experimentos foram realizados combinando em diferentes agrupamentos as características de forma da borda, características de textura e nitidez da borda. Com esse objetivo, foram realizados alguns experimentos usando os conjuntos de características: separados em forma $\left[F_{c c}, S I, C\right]$, textura (14 medidas) e nitidez da borda [CV, A, contraste]; somados $\left[F_{c c}, S I, C, C V, A\right.$, contraste]; individuais, apenas de forma $\left[F_{c c}\right]$ ou $[S I]$, de textura $\left[F_{8}\right]$ ou de nitidez $[$ contraste $]$ ou $[A]$ e também características individuais de forma acoplada com nitidez da borda $\left[F_{c c}, A\right]$ ou $[S I, A]$ ou de forma, textura e nitidez da borda $\left[F_{c c}, A, F_{8}\right]$. Estas combinações, propostas inicialmente por Andre e Rangayyan (2003) e mantidas no trabalho de Alto, Rangayyan e Desautels (2005), foram também mantidas neste trabalho para eventuais comparações dos resultados de classificação e constatações dos agrupamentos de características que melhor representam um nódulo benigno e um nódulo maligno.

As características extraídas dos nódulos das 57 ROIs agrupadas como descrito anteriormente representam as características usadas nos experimentos com o classificador Máquina de Comitê e também nos experimentos dos classificadores MLP e SLP.

Na seção seguinte será explicado, com o auxílio de um experimento, a cons- 
trução da curva ROC e o cálculo sob a sua área $\left(A_{z}\right)$. Na Seção 6.3 será descrito sobre a configuração da Máquina de Comitê assim como, a configuração do MLP e SLP e serão apresentados os resultados de classificação alcançados por cada classificador, expressos em valores de $A_{z}$.

\subsection{Método de Análise de Desempenho - Área Sob a Curva ROC ou $\boldsymbol{A}_{z}$}

O método utilizado para analisar a capacidade do classificador em discriminar um nódulo benigno de um nódulo maligno foi o cálculo da área sob a curva ROC ou $A_{z}$. Lembrando que os detalhes da explicação deste método estão apresentados no Capítulo 5. Nesta seção será ilustrado com um experimento, os passos necessários para a construção da curva ROC e para o cálculo sob a sua área $\left(A_{z}\right)$.

Para explicar o procedimento da construção da curva ROC e do cálculo sob a sua área $\left(A_{z}\right)$, foi considerado o classificador Máquina de Comitê previamente treinado. A Figura 6.3 ilustra o classificador Máquina de Comitê, treinado, recebendo os padrões do conjunto de testes $\left(T t_{N T E \sim D_{N T E}}\right)$ com os devidos pesos probabilísticos $\left(D_{n e}\right)$. A resposta da classificação será dada por $H(x)$. Note que, a explicação detalhada do classificador Máquina de Comitê pode ser encontrada no Capítulo 4 assim como, a explicação dos símbolos $R N_{N T E}, h_{N T E}$ e $\alpha_{N T E}$.

Para a explicação da construção da curva ROC e do $A_{z}$, foi considerado que a resposta dada pelo comitê esteja sendo analisada no combinador de saídas (veja a Figura 6.3), cujos valores apresentados são os apresentados pelos 'x's da Figura 6.4. A resposta da classificação ilustrada pelos ' $\mathrm{x}$ ' são resultados contínuos. O resultado final apresentado por $H(x)$ deverá ser apresentado em valor discreto, -1 (benigno) ou 1 (maligno).

A discretização foi feita em diferentes escolhas de limiares (thresholds) com- 


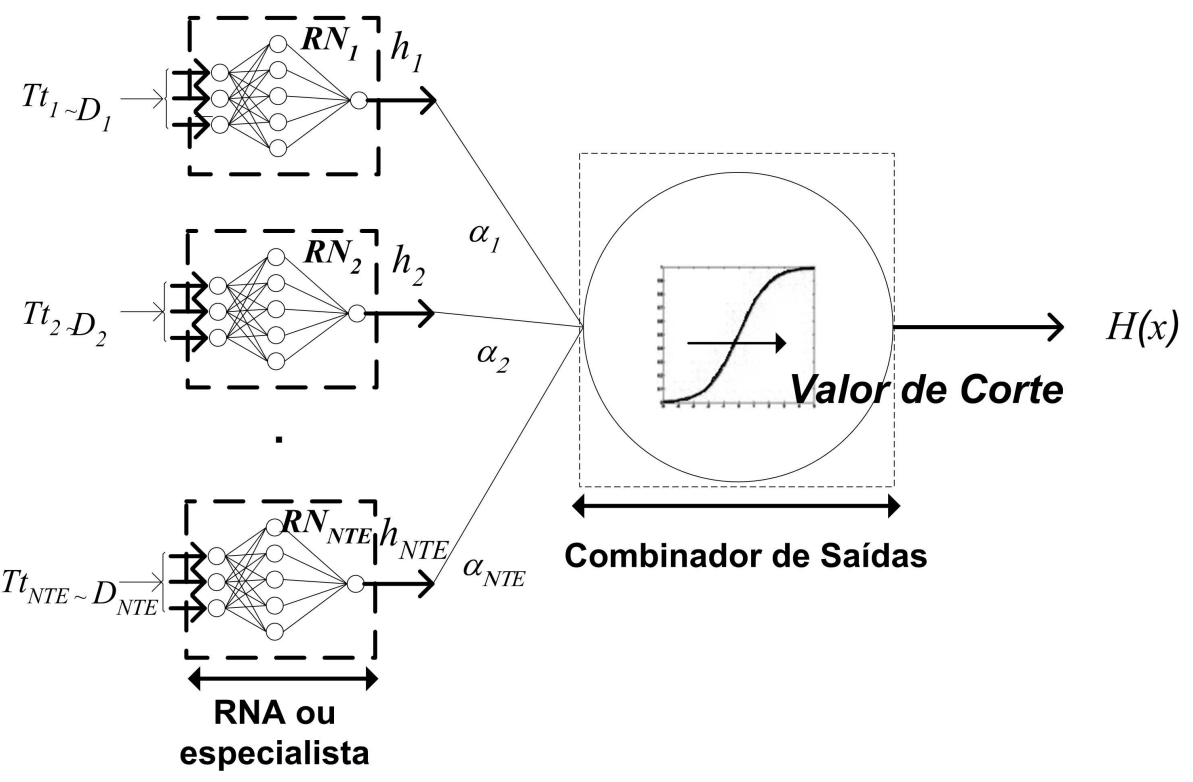

Figura 6.3: Ilustração do teste da Máquina de Comitê.

Ilustração da arquitetura Máquina de Comitê previamente treinada. No combinador de saídas, o operador Valor de Corte é apresentado para explicarmos a construção da curva ROC e conseqüentemente o cálculo sob sua área, o $A_{z}$.

preendidos entre o intervalo -1 e 1. Cada valor do limiar escolhido será nomeado de Valor de Corte. Assim, o valor de ' $\mathrm{x}$ ' abaixo do valor de corte (no exemplo da Figura 6.4, o Valor de Corte atual é 0,1) é forçado para -1 e quando acima do Valor de Corte, o valor de ' $\mathrm{x}$ ' é forçado para 1. Esses resultados forçados (representados por '*' na Figura 6.4) são comparados com os valores desejados (representados por 'o' na Figura 6.4) e nesta comparação é calculado o valor de TFP e TVP, que indica a coordenada de cada ponto da curva ROC (a explicação para este cálculo foi descrita no Capítulo 5). Assim, para cada Valor de Corte definido (Figura 6.4) teremos um ponto da curva ROC (TFP, TVP) (Figura 6.5). Ao final de todos os valores de corte possíveis (dentro do intervalo -1 a 1 no nosso caso) temos um conjunto de pontos, que determinam a curva ROC. O cálculo de $A_{z}$ será dado a partir do cálculo da área sob a curva ROC (veja a Figura 6.5).

Para cada agrupamento das características, serão realizados experimentos com o classificador Máquina de Comitê, como também para os classificadores 
da Máquina de Comitê no Combinador de Saídas

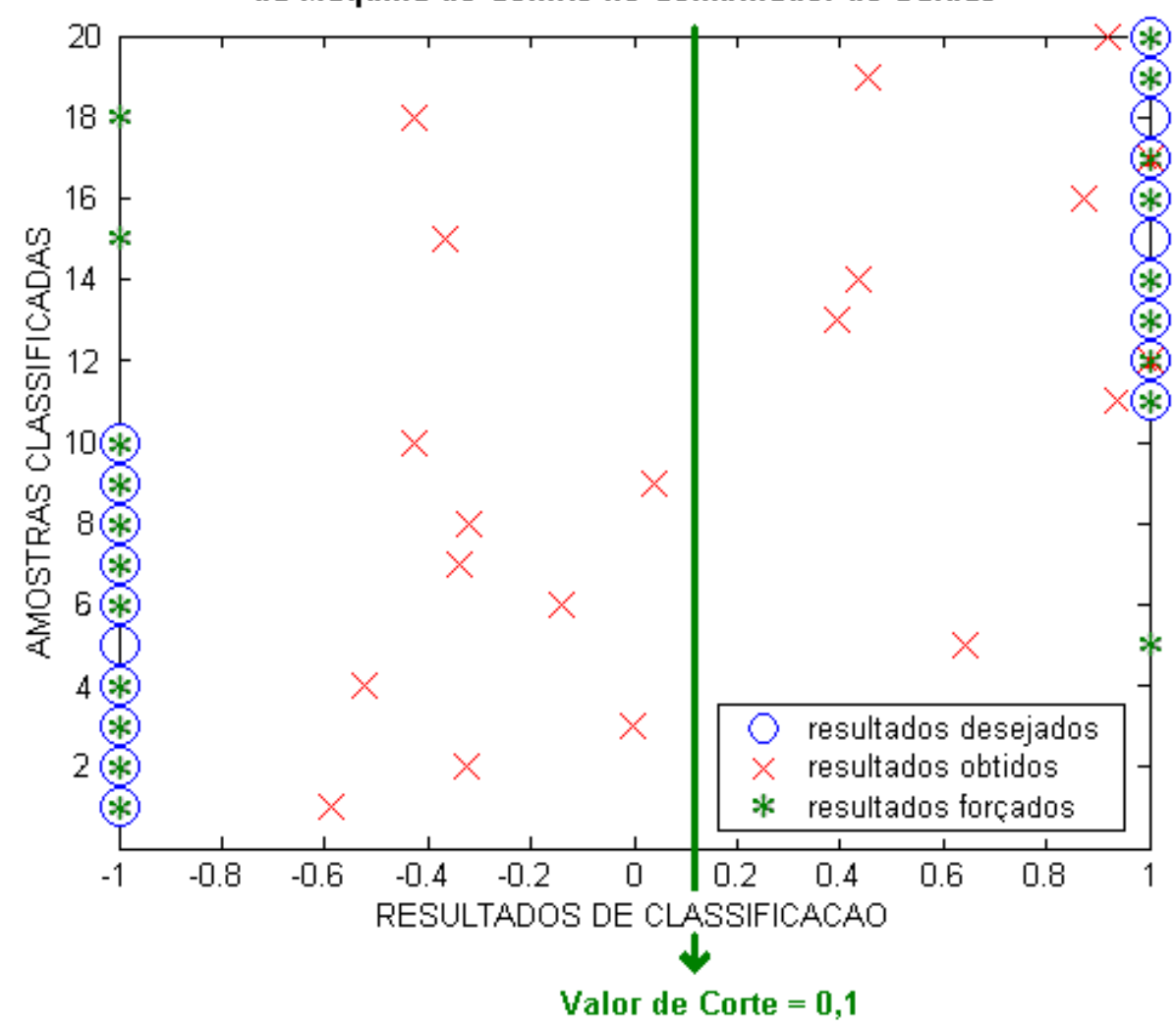

Figura 6.4: Análise dos resultados de classificação da Máquina de Comitê para a construção da curva ROC.

Os ' $\mathrm{x}$ ' representam os resultados dos testes de classificação; os 'o' representam $\mathrm{o}$ diagnóstico real ao qual o conjunto de testes pertence e os ' ${ }^{*}$ ' representam as escolhas forçadas para um Valor de Corte (neste exemplo igual a 0,1). Para estes resultados de exemplo, foram utilizados as características da nitidez da borda $[C V, A$, contraste $]$. No Valor de Corte os valores são forçados para -1 ou 1 e a partir desta escolha forçada é calculado a coordenada (TVP e TFP) de cada ponto da curva ROC.

MLP e SLP, e serão efetuados os respectivos cálculos de $A_{z}$. Os valores de $A_{Z}$ permitem as devidas comparações de desempenho de classificação, como poderá ser observado na próxima seção.

Note que, o cálculo de $A_{z}$ para os classificadores MLP e SLP é realizado de maneira idêntica ao procedimento apresentado anteriormente, quando exemplificado o cálculo de $A_{z}$ para o classificador Máquina de Comitê. É válido destacar que, para o método explicado anteriormente, é necessário se ter um único neurônio de saída, onde se aplicam os possíveis valores de corte. 


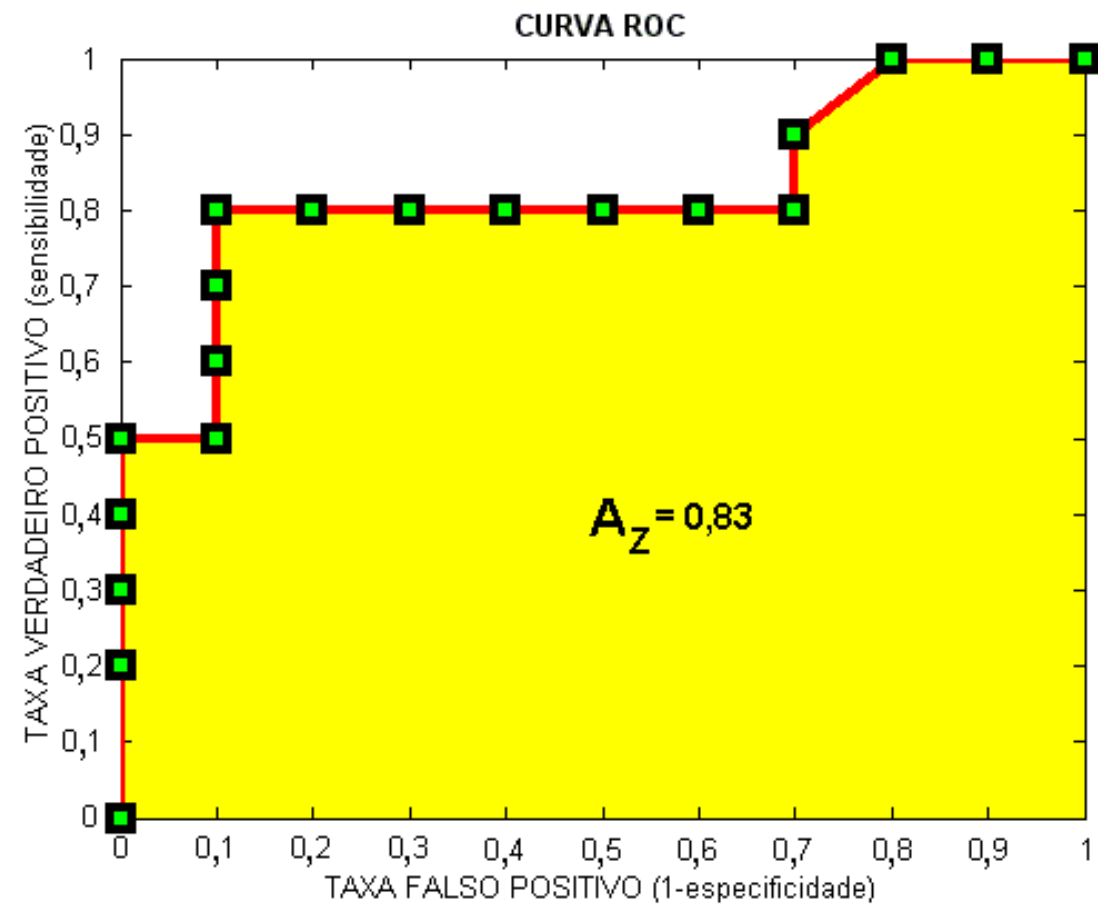

Figura 6.5: Ilustração da curva ROC e do $A_{z}$.

Curva ROC para o resultado de classificação apresentado pela Máquina de Comitê, utilizando as características $[C V, A$, contraste $]$ (características de nitidez da borda ). Para cada ponto da curva ROC um valor de corte foi definido e a partir da escolha forçada, o cálculo de TVP e TFP foi efetuado. A área sombreada ilustra a região onde o cálculo de $A_{z}$ é realizado. O valor de $A_{z}$ mede a capacidade de discriminação do classificador, neste exemplo o valor de $A_{z}$ para o classificador Máquina de Comitê é igual a 0,83 .

Os experimentos realizados e os resultados obtidos são apresentados na próxima seção.

\subsection{Resultados Obtidos}

Como descrito no início deste capítulo, os experimentos realizados envolvem diferentes agrupamentos das características extraídas das 57 ROIs, como pode ser visto na Tabela 6.1.

Para os experimentos realizados, as características usadas nos experimentos foram divididas em: conjunto de padrões de treinamento e conjunto de padrões de teste, separados aleatoriamente e em quantidades diferentes. Foram utilizados 37 
vetores de características (27 benignas e 10 malignas) para o conjunto de padrões de treinamento e 20 (10 benignas e 10 malignas) para o conjunto de padrões de teste. Este processo de divisão é repetido 20 vezes, a partir de escolhas aleatórias. A escolha de 20 experimentos já permite a avaliação razoável das médias de $A_{z}$ dos classificadores, bem como de suas dispersões. Assim, os resultados da Tabela 6.1 mostram o valor médio de $A_{z}$ e o desvio padrão dos 20 resultados apresentados por cada classificador: Máquina de Comitê, MLP, SLP.

\begin{tabular}{|l|c|c|c|c|}
\hline $\begin{array}{l}\text { Características } \\
\text { usadas }\end{array}$ & \multicolumn{2}{|c|}{ Máquina de Comitê } & MLP & SLP \\
\hline & $\begin{array}{c}\text { com } \\
w \text { continuado }\end{array}$ & $\begin{array}{c}\text { sem } \\
\text { continuado }\end{array}$ & & \\
\hline & $A_{z}$ & $A_{z}$ & $A_{z}$ & $A_{z}$ \\
\hline$F_{c c}, S I, C$ & $0,99 \pm 0,02$ & $0,99 \pm 0,01$ & $0,99 \pm 0,01$ & $0,99 \pm 0,04$ \\
\hline$C V, A$, contraste & $0,88 \pm 0,08$ & $0,87 \pm 0,06$ & $0,84 \pm 0,09$ & $0,63 \pm 0,11$ \\
\hline$F_{c c}, S I, C$ & $0,87 \pm 0,08$ & $0,88 \pm 0,07$ & $0,84 \pm 0,09$ & $0,76 \pm 0,07$ \\
$C V, A$, contraste & $0,99 \pm 0,02$ & $0,96 \pm 0,06$ & $0,96 \pm 0,04$ & $0,95 \pm 0,01$ \\
\hline$F_{c c}$ & $0,93 \pm 0,05$ & $0,91 \pm 0,05$ & $0,84 \pm 0,07$ & $0,75 \pm 0,02$ \\
\hline$S I$ & $0,78 \pm 0,07$ & $0,79 \pm 0,07$ & $0,70 \pm 0,07$ & $0,69 \pm 0,10$ \\
\hline$A$ & $0,68 \pm 0,09$ & $0,69 \pm 0,11$ & $0,66 \pm 0,10$ & $0,58 \pm 0,16$ \\
\hline contraste & $0,97 \pm 0,05$ & $0,98 \pm 0,02$ & $0,97 \pm 0,04$ & $0,99 \pm 0,01$ \\
\hline$F_{c c}, A$ & $0,92 \pm 0,05$ & $0,93 \pm 0,04$ & $0,90 \pm 0,05$ & $0,86 \pm 0,02$ \\
\hline$S I, A$ & $0,66 \pm 0,02$ & $0,68 \pm 0,04$ & $0,63 \pm 0,15$ & $0,52 \pm 0,22$ \\
\hline textura & $0,69 \pm 0,07$ & $0,69 \pm 0,08$ & $0,66 \pm 0,02$ & $0,56 \pm 0,07$ \\
\hline$F_{8}$ & $0,98 \pm 0,03$ & $0,99 \pm 0,00$ & $0,99 \pm 0,03$ & $0,99 \pm 0,01$ \\
\hline$F_{c c}, A, F_{8}$ & & & \\
\hline
\end{tabular}

Tabela 6.1: Tabela de resultados.

Resultados da área sob a curva ROC - $A_{z}$ para diferentes classificadores (Máquina de Comitê, MLP e SLP) obtidos utilizando diferentes combinações de características: forma, textura e nitidez da borda.

\subsection{Configuração dos Classificadores para a Ob- tenção dos Resultados}

Quanto à topologia do classificador MLP, seguimos a seguinte configuração: número de neurônios na camada de entrada $\left(N e_{m}\right)$ igual ao número de características usadas, por exemplo, características de forma $\left(N e_{m}=3\right)$, características de textura 
$\left(N e_{m}=14\right)$ e características de nitidez da borda $\left(N e_{m}=3\right)$; quanto aos neurônios na camada oculta, experimentos para verificar as curvas de aprendizagem das características de forma, textura e nitidez da borda foram realizados. As Figuras 6.6, 6.7 e 6.8 mostram os resultados do aprendizado (erro médio quadrático por número de iterações) para diferentes quantidades de neurônios na camada oculta $\left(N o_{n}=5 / 10 / 15 / 20 / 30\right)$. A partir destes experimentos, percebe-se que quando foi utilizado $N o_{n}=30$, as curvas de aprendizado, para todos os conjuntos de características, apresentam resultados satisfatórios (erro médio quadrático menor ou próximo ao desejado e pouco número de iterações). Com esta constatação, decidimos utilizar 30 neurônios na camada escondida $\left(N o_{n}=30\right)$, para todos os experimentos do MLP, com os diferentes agrupamentos; Na camada de saída foi usado apenas 1 neurônio (benigno ou maligno). Assim, a topologia do MLP foi $N e_{m}=3 / 14 / 3$ (dependendo do número de medidas de cada característica), $N o_{n}=30$ e $N s_{1}=1\left(N e_{m}: 30: 1\right)$. O erro quadrático máximo permitido foi de 0,2 e o número máximo de iteração foi de 10.000 .

Como discorrido no Capítulo 4, o classificador Máquina de Comitê utiliza como especialistas o MLP. A topologia do MLP especialista é diferente do MLP utilizado na comparação. Enquanto na topologia do MLP foi considerado para a escolha do número de neurônios da camada escondida o menor erro médio quadrático (Figuras 6.6, 6.7 e 6.8) no MLP especialista, além do erro médio quadrático foi considerado para a escolha do número de neurônios na camada escondida o número de iterações. Assim, foi escolhido a quantidade de 10 neurônios para a camada escondida $N o_{n}=10$.

No treinamento da Máquina de Comitê, utilizamos o MLP configurado com a topologia $\left(N e_{m}: 10: 1\right)$, pelas razões discutidas anteriormente. Para o treinamento do MLP membro do comitê (especialista), o erro médio quadrático máximo permitido foi de 0,35. Na Tabela 6.2 está descrito o número de especialistas en- 
volvidos no processo de treinamento da Máquina de Comitê.

\begin{tabular}{|l|c|c|}
\hline $\begin{array}{l}\text { Características } \\
\text { usadas }\end{array}$ & \multicolumn{2}{|c|}{ Máquina de Comitê } \\
\hline & $\begin{array}{c}\text { com } \\
\text { continuado }\end{array}$ & $\begin{array}{c}\text { sem } \\
\text { continuado }\end{array}$ \\
\hline & número de especialistas \\
\hline$F_{c c}, S I, C$ & 30 & 30 \\
\hline$C V, A$, contraste & 200 & 200 \\
\hline$F_{c c}$, SI, C,CV, A, contraste & 200 & 200 \\
\hline$F_{c c}$ & 30 & 30 \\
\hline$S I$ & 30 & 30 \\
\hline$A$ & 100 & 100 \\
\hline contraste & 300 & 300 \\
\hline$F_{c c}, A$ & 30 & 30 \\
\hline$S I, A$ & 30 & 30 \\
\hline textura & 300 & 300 \\
\hline$F_{8}$ & 200 & 200 \\
\hline$F_{c c}, A, F_{8}$ & 30 & 30 \\
\hline
\end{tabular}

Tabela 6.2: Número de especialistas usado no comitê.

Para a arquitetura SLP, é realizado um treinamento para que o número máximo de iteração fosse 10.000 ou que um erro mínimo de 0,2 fosse atingido.

Os experimentos referentes à Máquina de Comitê envolveram duas diferentes configurações da arquitetura original, uma denominada de "sem $w$ continuado" e a outra "com $w$ continuado". Nos experimentos realizados com a configuração "sem w continuado", consideramos em cada iteração (en, vide Capítulo 4), uma nova inicialização dos pesos sinápticos $(w)$ e um novo processo de aprendizado das redes MLP (Perceptron de Múltiplas Camadas). Por outro lado, a configuração da Máquina de Comitê denominada "com $w$ continuado" é desenvolvida diferentemente da configuração anterior, pois aqui procura-se não desprezar o conhecimento obtido pelo especialista da iteração anterior $\left(R N_{e n-1}\right)$, o w (matriz de pesos sinápticos). Assim, o $w$ conseguido pelo especialista na iteração en $\left(R N_{e n}\right)$ será usado como parâmetro inicial, ou conhecimento inicial do próximo 


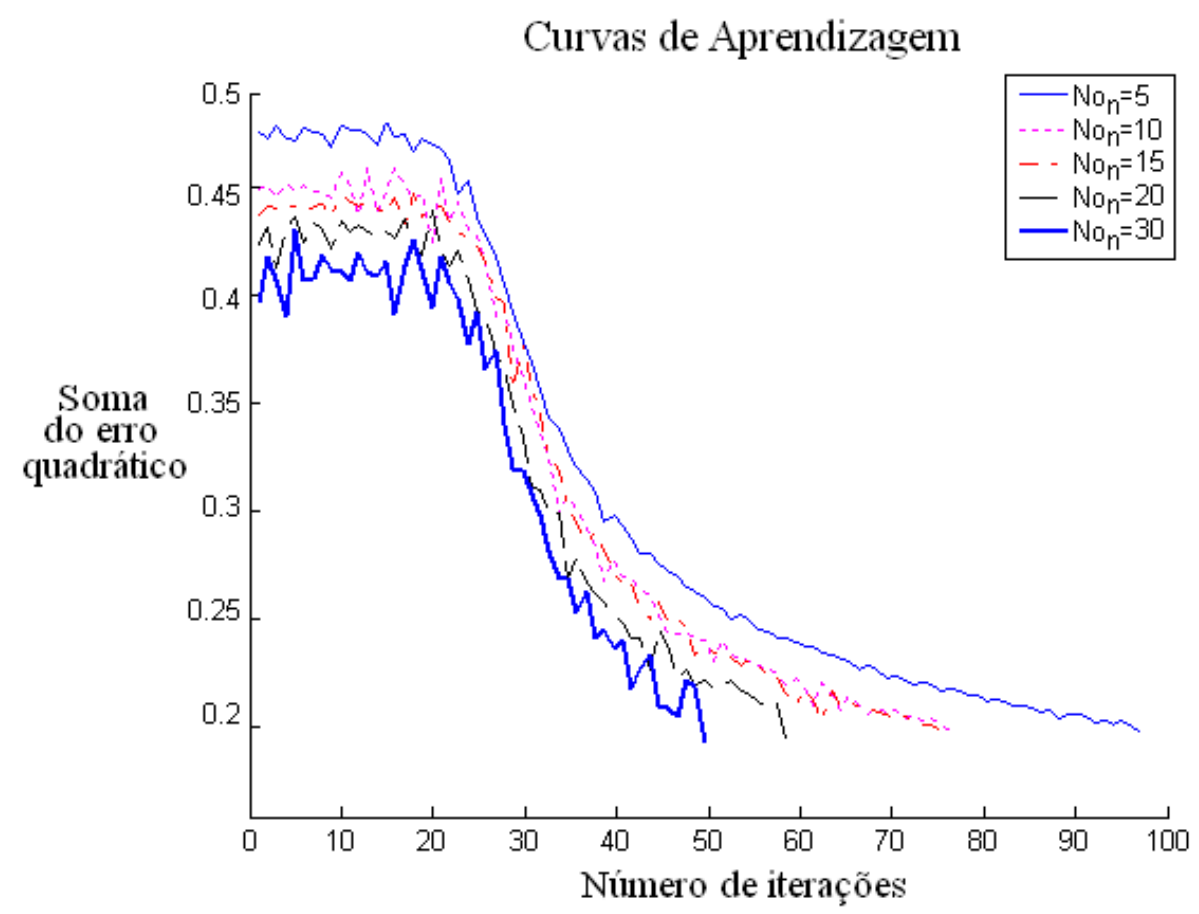

Figura 6.6: Curvas de Aprendizagem para as características $\left[F_{c c}, S I, C\right]$. Verificação do número de neurônios na camada oculta $N o_{n}$ do MLP para as características de forma $\left(\left[F_{c c}, S I, C\right]\right)$.

\section{Curvas de Aprendizagem}

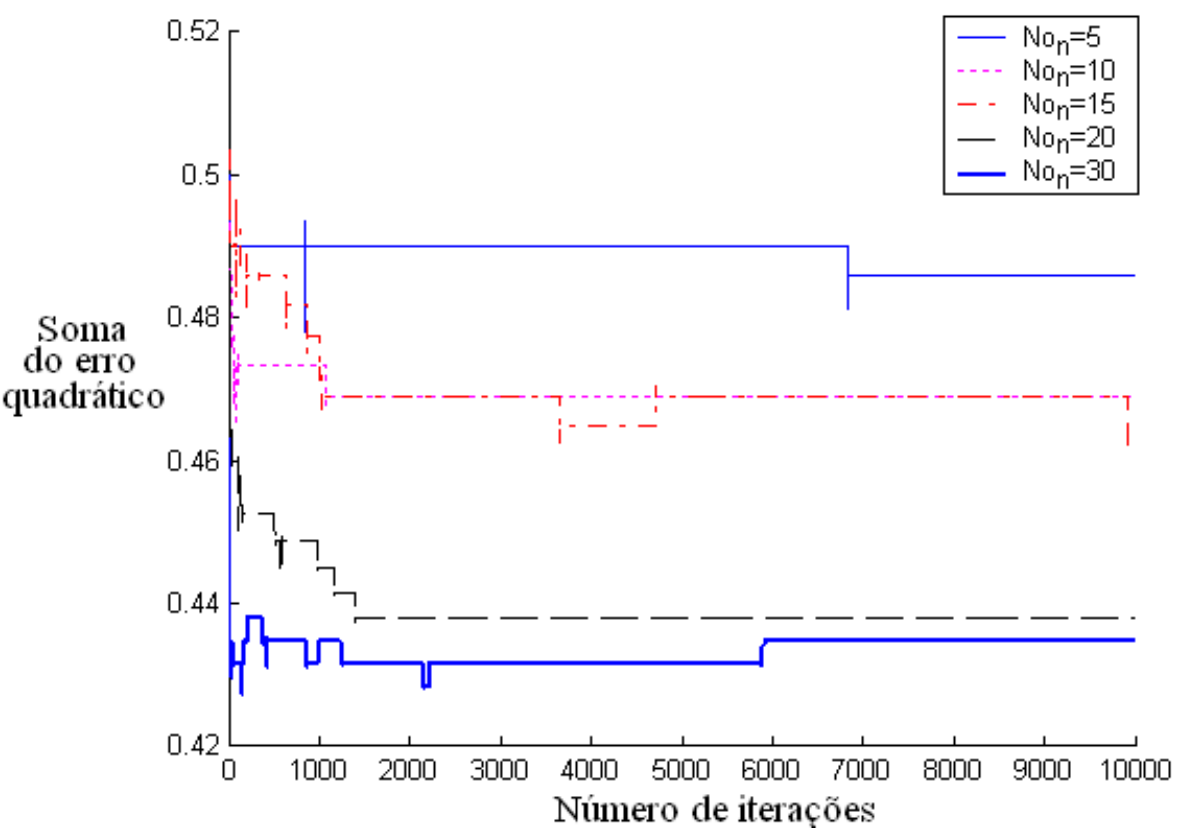

Figura 6.7: Curvas de Aprendizagem para as características de textura. Verificação do número de neurônios na camada oculta $N o_{n}$ do MLP para as 14 características de textura. 


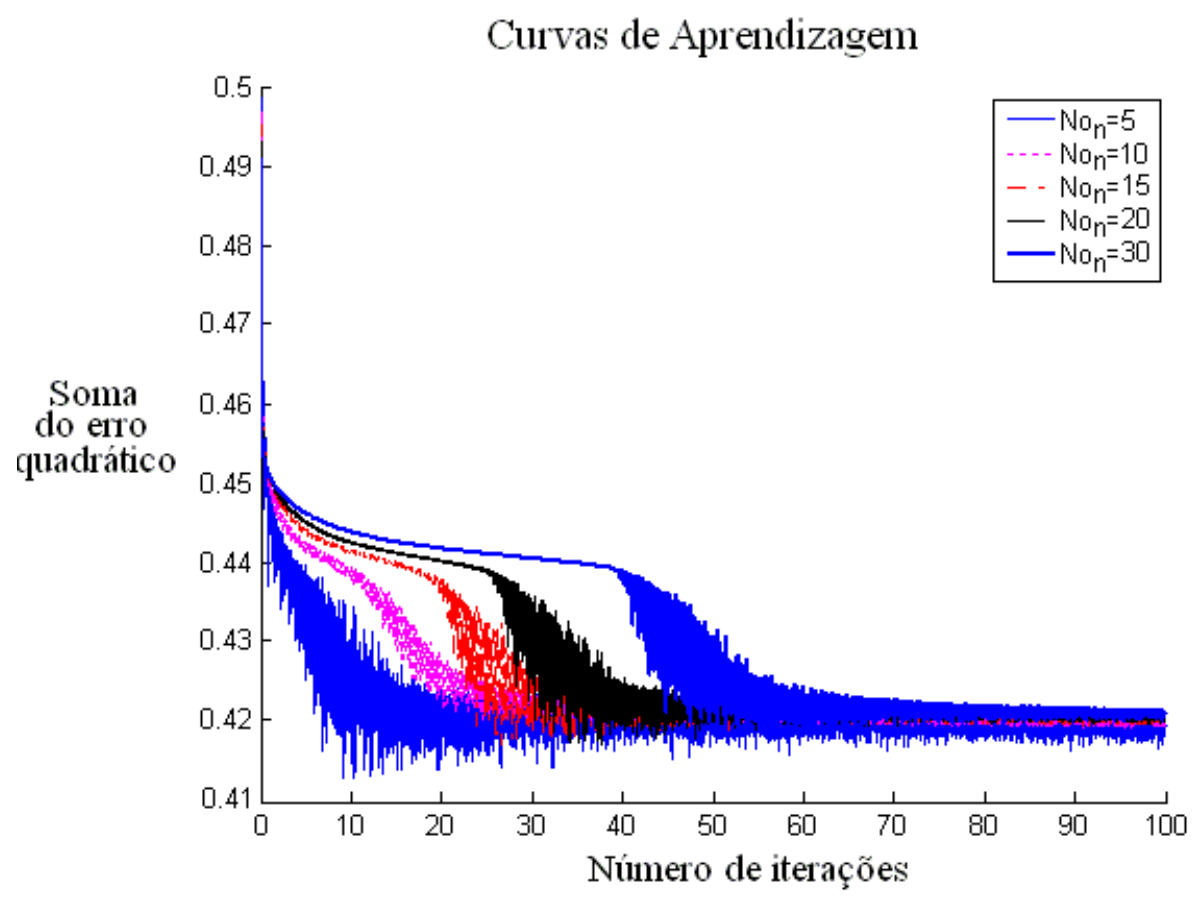

Figura 6.8: Curvas de Aprendizagem para as características [CV, A, contraste]. Verificação do número de neurônios na camada oculta $N o_{n}$ do MLP para as características de nitidez da borda ([CV, A, contraste $])$.

especialista $\left(R N_{e n+1}\right)$. Experimento semelhante a este utilizando a configuração "com o w continuado" foi tentado por Murphey et al. (MURPhEY; CHEN; FELDKAMP, 2001, 2002) utilizado para a solução de problema de diagnóstico de falha em aparelhos.

O objetivo de realizar os experimentos com diferentes configurações na arquitetura da Máquina de Comitê, foi o de procurar reduzir o custo computacional do modelo Máquina de Comitê configurada com a arquitetura "sem $w$ continuado" porém, mantendo ou então melhorando o valor de $A_{z}$.

O tempo gasto no processo de aprendizado dos classificadores seguem a seguinte sequência em ordem decrescente (mais tempo desprendido no processo de aprendizado para menos tempo): Máquina de Comitê, MLP e SLP. Uma vez treinados os classificadores, o tempo gasto para a classificação, no caso do classificador Máquina de Comitê que gastou mais tempo de aprendizado foi da ordem 
de segundos.

\subsection{Análises Realizadas}

Analisando a Tabela 6.1 é possível perceber alguns comportamentos que chamam a atenção, como por exemplo a redução do valor de $A_{z}$ quando conjugamos mais características. Esse efeito pode estar sendo causado pelo problema da dimensionalidade, assunto melhor discutido a seguir em 6.4.1.

Uma outra análise que será realizada é quanto à forma de apresentação dos resultados de $A_{z}$. Como eles são indicados pela média e desvio padrão de 20 experimentos aleatórios, os resultados expressos nessa forma não permitem em vários casos concluir de imediato se o resultado obtido pelo classificador Máquina de Comitê difere do classificador MLP, por exemplo. Isto será analisado no item 6.4.2 lançando-se mão do teste de hipóteses.

\subsubsection{O problema da Dimensionalidade}

O problema da dimensionalidade também conhecido como curse of dimensionality e como comportamento de curva 'U', é um fator relevante que deve ser considerado quando se deseja decidir o número de elementos de cada amostra (vetor) do conjunto de padrões treinamento e de teste a ser utilizado em um problema de reconhecimento de padrões.

Segundo (JAIN; DUIN; MAO, 2000) existem casos onde o número de amostras do conjunto de treinamento requerido para que o classificador apresente bom desempenho é uma função monotonicamente crescente da dimensão do espaço de características (quantidade de elementos de cada amostra). Em alguns casos, pode-se mostrar que essa função é exponencial (CAMPOS, 2001) e (JAIN; DUIN; MAO, 2000). 
Nos resultados obtidos, percebe-se que em alguns casos, o valor de $A_{z}$ diminui com a adição de características sem adicionar mais exemplos de treinamento (por exemplo, observe as linhas da Tabela 6.1 onde a característica $S I$ é utilizada). Talvez isso esteja ocorrendo pelo fato do número de exemplos de treinamento não ser grande o suficiente em relação ao número de características. Esse efeito é conhecido como fenômeno do pico (peaking phenomena), é uma conseqüência do problema da dimensionalidade.

Outros fatores como a complexidade do classificador e o número de classes também podem prejudicar o desempenho. Segundo (JAIN; DUIN; MAO, 2000) deve-se utilizar um número de amostras de treinamento por classe dez vezes maior que a dimensionalidade.

Porém, em nosso caso, percebe-se que a complexidade do classificador talvez não seja um fator a ser considerado na redução do desempenho de classificação quando se aumenta a dimensão, pois perceba que o efeito da adição de característica e redução de $A z$ ocorre com todos os classificadores da Tabela 6.1.

A curva apresentada na Figura 6.9 ilustra o efeito da dimensionalidade. Nesta curva temos três regiões no eixo da dimensionalidade com efeitos diferentes.

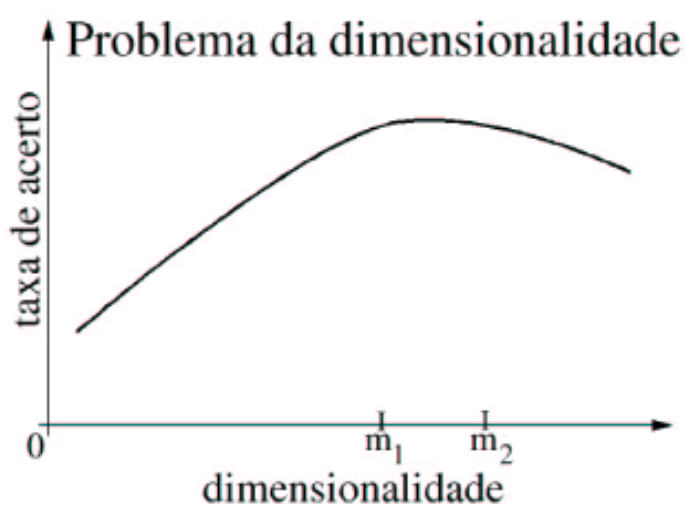

Figura 6.9: Efeito do problema da dimensionalidade. (Fonte (CAMPOS, 2001))

1. Na primeira região entre 0 e $m 1$, ocorre o comportamento mais intuitivo, 
a taxa de erro diminui com o aumento das características. Isso se deve ao fato de espaços com dimensões muito pequenas não possuírem informações suficientes para a distinção dos nódulos malignos e nódulos benignos. Com isso, a adição de novas características melhora o resultado de $A_{z}$.

2. Na segunda região entre $m 1$ e $m 2$ acontece uma estabilização da taxa de erro. Neste caso, seria a melhor escolha da dimensão.

3. A última região, após $m 2$ é onde ocorre de fato o problema da dimensionalidade. Note que o aumento no número de características aumenta a taxa de erro.

Neste trabalho não foi feita uma investigação para verificar qual a dimensão dos conjuntos de padrões de treinamento e de teste que resulta em melhor resultado de classificação. A estratégia de trabalhos anteriores (ANDRE; RANGAYYAN, 2003; ALTO; RANGAYYAN; DESAUTELS, 2005) de investigar quais as características ou as melhores combinações de características apresentam melhor resultados

de $A_{z}$, foi mantida neste trabalho. Trabalhos de extensão para a redução de dimensionalidade e estratégias de tentativa e erro em relação à dimensionalidade para saber se o número de características e a dimensão são suficientes para o classificador apresentar resultados satisfatórios de discriminação, podem ser realizados.

\subsubsection{Análise dos Resultados com o Teste de Hipóteses}

Neste trabalho foi apresentado o classificador neural do tipo Máquina de Comitê como uma proposta de melhorar o resultado de discriminação entre nódulos benignos e nódulos malignos, ou seja, aumentar o valor de $A_{z}$ em relação aos classificadores neurais MLP e SLP estudados anteriormente (YU; GUAN, 2000; HALKIOTIS; MANTAS; BOTSIS, 2002, 2002; ANDRE; RANGAYYAN, 2003). 
Dos resultados obtidos, apresentados na Tabela 6.1, percebe-se em alguns casos (como: $\left[F_{c c}, S I, C\right],[C V, A$, contraste $],\left[F_{c c}\right],[$ contraste $],[S I, A],\left[F_{8}\right] \mathrm{e}$ $\left.\left[F_{c c}, A, F_{8}\right]\right)$ que, se comparar os valores apresentados pela Máquina de Comitê (em ambas configurações: "com $w$ continuado" ou "sem $w$ continuado") com os valores apresentados pelo MLP, não fica evidente qual o classificador que apresenta melhor resultado.

Os resultados expressos pelo cálculo da média de $A_{z}$ e do desvio padrão não permitem tirar boas conclusões para a comparação de resultados entre os classificadores. O cálculo do desvio padrão é uma maneira de indicar a dispersão dos resultados de $A_{z}$ sobre uma média de 20 resultados, o que indicara quanto os resultados de $A_{z}$ são dependentes do conjunto de padrões de treinamento.

Para concluir sobre os resultados obtidos nos experimentos foi realizado o teste de hipóteses utilizando a distribuição de Student $t$, assunto detalhado no Anexo A. Para a realização do teste, considere $\mu_{1}$ como sendo a média de $A_{z}$ apresentada por um classificador (por exemplo, Máquina de Comitê) e $\mu_{2}$ como sendo a média da classificação dada por outro classificador (por exemplo MLP). Ambos classificadores testados sob o mesmo conjunto de teste escolhido aleatoriamente das 57 ROIs. Assim, precisa-se decidir entre duas hipóteses:

- $H_{0}: \mu_{1}=\mu_{2}$, se não há diferença significativa no resultado entre os classificadores.

- $H_{1}: \mu_{1} \neq \mu_{2}$, se há diferença significativa no resultado entre os classificadores.

Com base em um teste bilateral, no nível de significância $0,05, H_{0}$ é rejeitado quando $t_{\text {calc }}$ estiver fora do intervalo de $-t_{0,975}$ a $t_{0,975}$, o qual para $N_{1}+N_{2}-2$, ou seja, 38 graus de liberdade, é o que vai de $-2,02$ a 2,02. Por conseguinte, qualquer 
valor que estiver fora deste intervalo, rejeitar-se-ia $H_{0}$, ou seja, os resultados diferem significantemente (ou o resultado entre os classificadores é diferente).

Os testes de hipóteses serão aplicados para verificar se o classificador Máquina de Comitê apresenta resultados de $A_{z}$ significantemente melhor que os classificadores MLP e SLP. Dessa maneira, apresentaremos os resultados dos testes comparando os valores médios de $A_{z}$ entre o:

- classificador Máquina de Comitê configurado "sem w continuado" e o classificador Máquina de Comitê configurado "com w continuado", os quais serão representados por '\#', Figura 6.10;

- classificador Máquina de Comitê configurado "sem w continuado" e o classificador MLP, cujos resultados serão representados por ‘*', Figura 6.11;

- classificador Máquina de Comitê configurado "sem w continuado" e o classificador SLP, cujos resultados serão representados por '十', Figura 6.12;

- classificador Máquina de Comitê configurado "com $w$ continuado" e o classificador MLP, os quais serão representados por ' $\mathrm{x}$ ', Figura 6.13;

- classificador Máquina de Comitê configurado "com $w$ continuado" e o classificador SLP, resultados representados por 'o', Figura 6.14;

Os resultados dos testes são apresentados nas Figuras 6.10, 6.11, 6.12, 6.13, 6.14 mostradas a seguir. São considerados resultados que não diferem significantemente (não tem diferença no resultado de classificação), as marcações que estiverem dentro do intervalo que vai de $-2,02$ até 2,02 , região destacada pelo retângulo com listras. Conseqüentemente, são considerados resultados que diferem significantemente (existem diferenças nos resultados dos classificadores), aqueles cujas marcações estiverem fora da região destacada. 


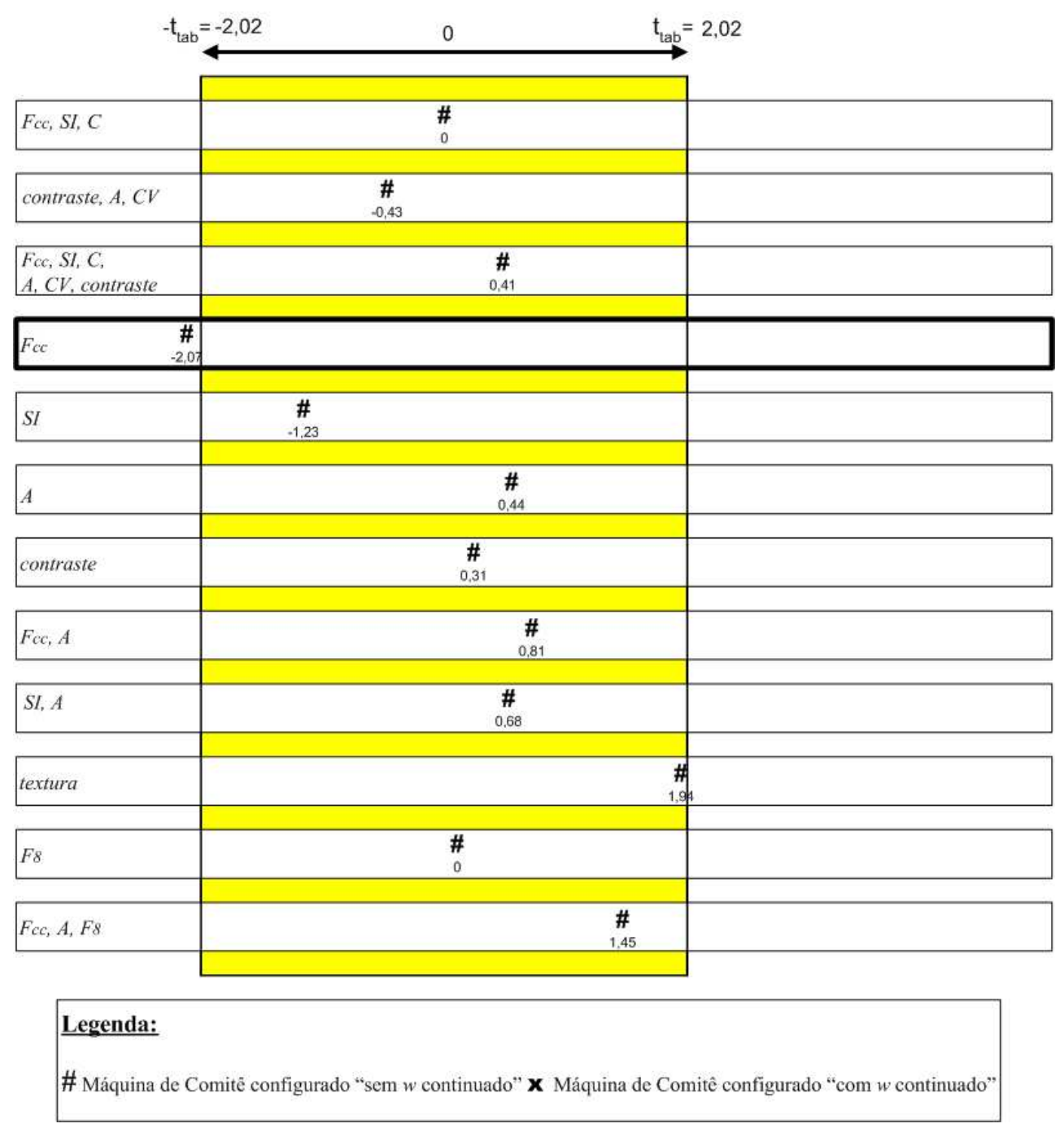

Figura 6.10: Comparação entre o classificador Máquina de Comitê configurado "sem $w$ continuado" e "com $w$ continuado".

Dos resultados apresentados, conclui-se que:

As marcações '\#' mostradas na Figura 6.10 representam as comparações entre os classificadores Máquina de Comitê configurado "sem $w$ continuado" e o classificador Máquina de Comitê configurado "com w continuado". Percebe-se que para todas as características utilizadas, exceto para a característica $F_{c c}$, os resultados de $A_{z}$ não diferem significantemente. Isso significa que quando utilizar a característica $F_{c c}$ o classificador Máquina de Comitê configurado "com $w$ continuado" é o mais apropriado entre as duas configurações. Do contrário, ambas 
configurações podem ser utilizadas.

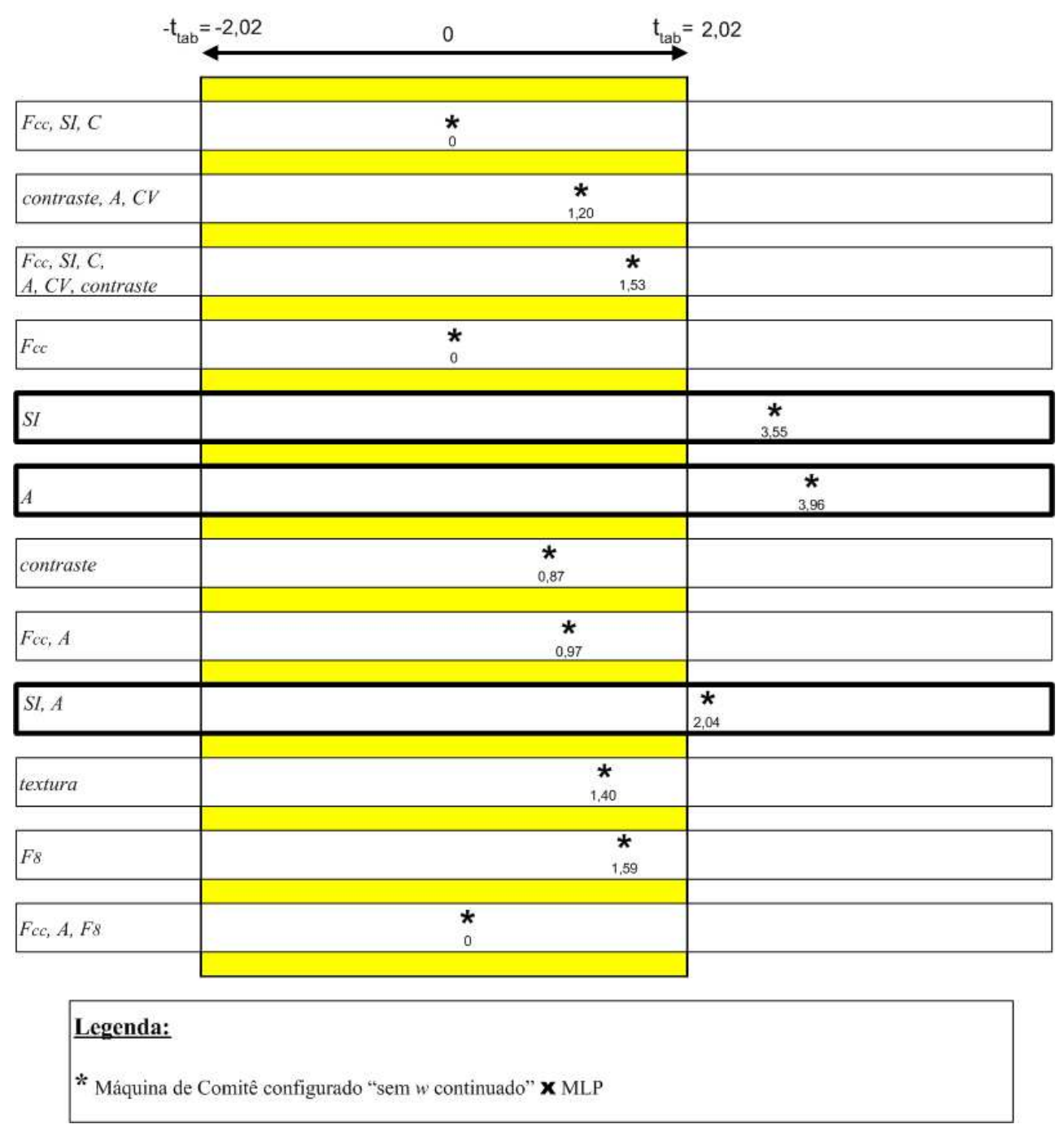

Figura 6.11: Resultados da comparação entre o classificador Máquina de Comitê configurado "sem $w$ continuado" e o classificador MLP.

As marcações '*' mostradas na Figura 6.11 representam a comparação entre o classificador Máquina de Comitê configurado "sem $w$ continuado" e o classificador MLP. Os resultados diferem significantemente quando utilizadas as características: $[S I],[A]$ e $[S I, A]$. Dessa maneira, quando utilizadas estas características, deve-se decidir pela escolha do classificador Máquina de Comitê configurado "sem w continuado" ao classificador MLP.

As marcações '+' mostradas na Figura 6.12 representam as comparações entre 


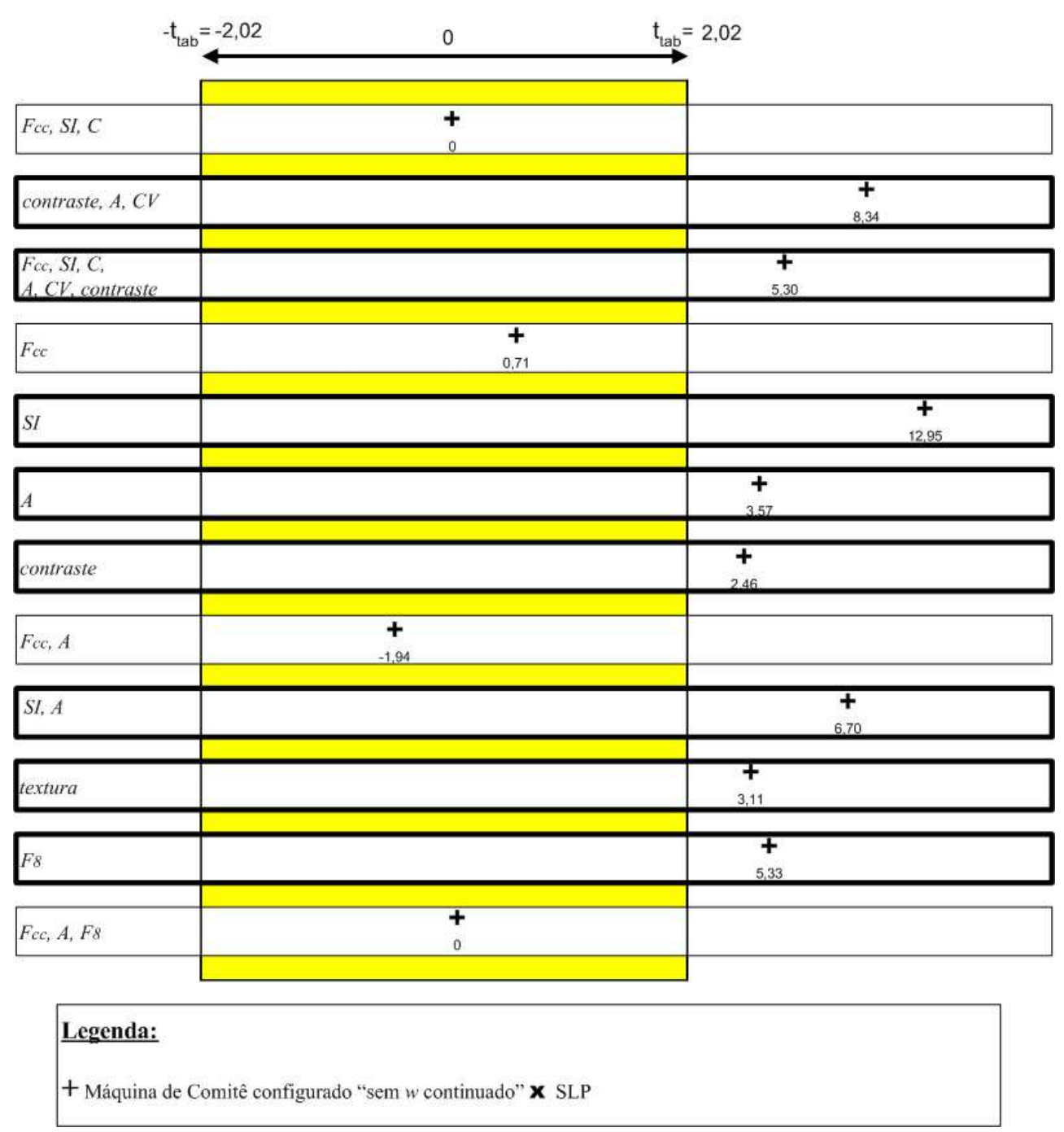

Figura 6.12: Resultados da comparação entre o classificador Máquina de Comitê configurado "sem $w$ continuado" e o classificador SLP.

o classificador Máquina de Comitê configurado "sem w continuado" e o classificador SLP. Nota-se que em grande parte dos casos, os resultados de $A_{z}$ diferem significantemente. Assim, quando utilizar as características: [contraste, $A, C V]$, $\left[F_{c c}, S I, C\right.$, contraste, $\left.A, C V\right],[S I],[A],[$ contraste $],[S I, A],[$ textura $]$ e $\left[F_{8}\right]$ devese decidir pelo uso do classificador Máquina de Comitê configurado "sem $w$ continuado" ao classificador SLP.

As marcações 'x' mostradas na Figura 6.13 representam as comparações entre o classificador Máquina de Comitê configurado "com w continuado" e o classifi- 


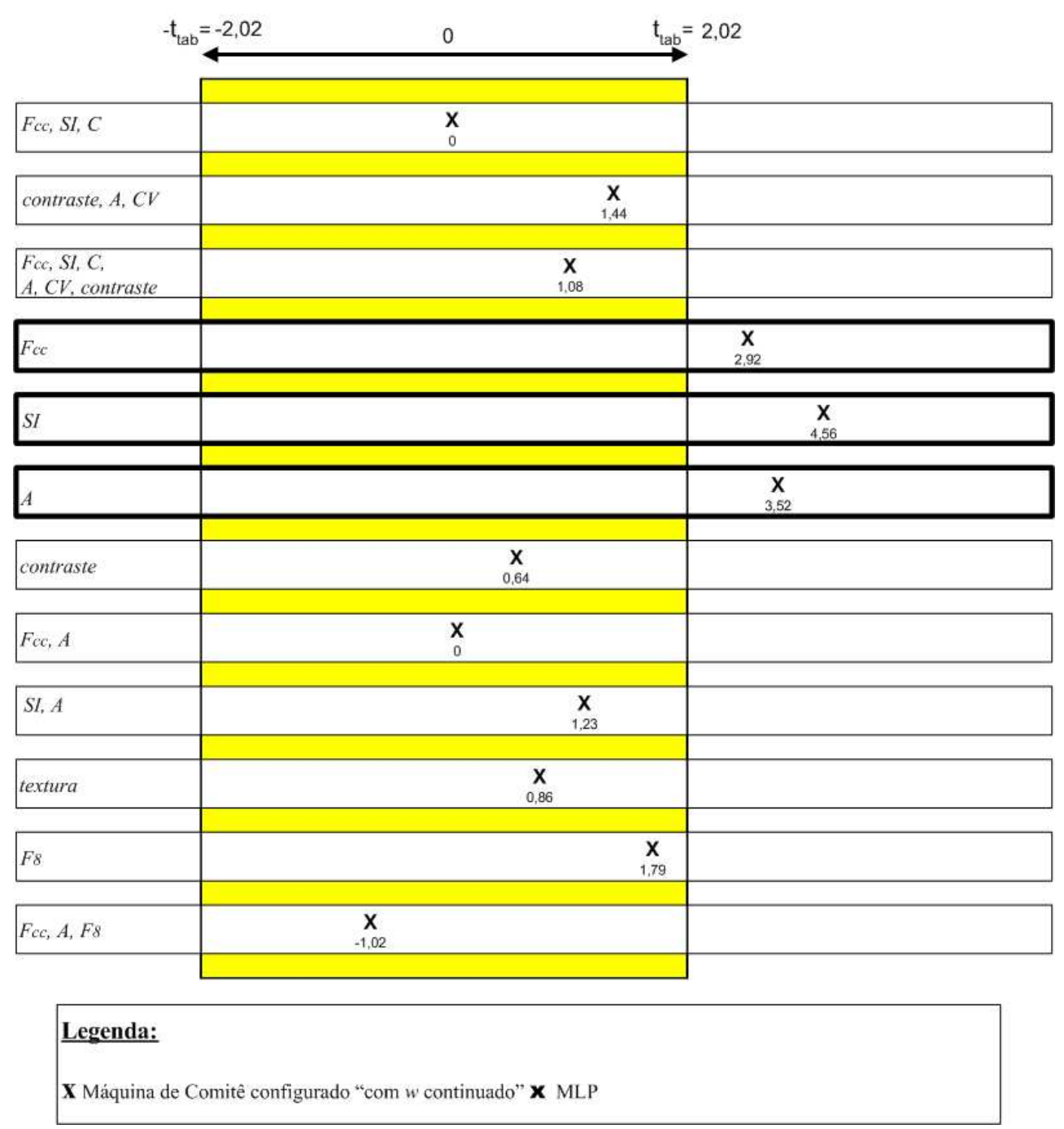

Figura 6.13: Resultados da comparação entre o classificador Máquina de Comitê configurado "com $w$ continuado" e o classificador MLP.

cador MLP. Percebe-se que, os resultados de $A_{z}$ diferem significantemente para as características $\left[F_{c c}\right],[S I]$ e $[A]$. Assim, quando utilizadas estas características, deve-se decidir por usar o classificador Máquina de Comitê configurado "com $w$ continuado" ao MLP.

As marcações 'o' mostradas na Figura 6.14 representam as comparações entre o classificador Máquina de Comitê configurado "com w continuado" e o classificador SLP. Percebe-se que para grande maioria dos casos, os resultados de $A_{z}$ diferem significantemente. Assim, para as características [contraste, $\left.A, C V\right]$, 


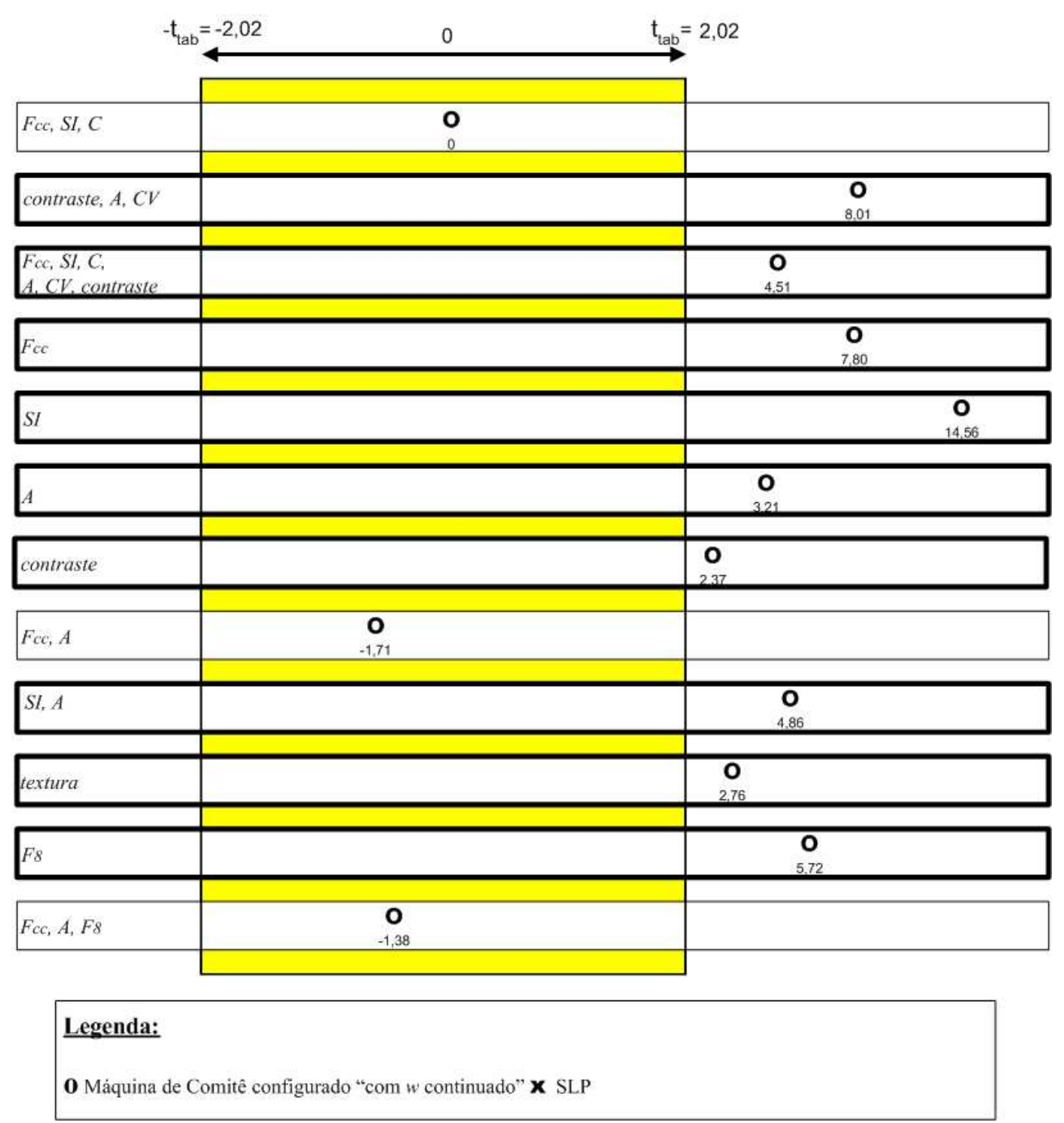

Figura 6.14: Resultados da comparação entre o classificador Máquina de Comitê configurado "com $w$ continuado" e o classificador SLP.

$\left[F_{c c}, S I, C\right.$, contraste, $\left.A, C V\right],\left[F_{c c}\right],[S I],[A],[$ contraste $],[S I, A],[$ textura $\left.]\right]$ e $\left[F_{8}\right]$ deve-se decidir pelo uso do classificador Máquina de Comitê configurado "com $w$ continuado" ao SLP.

Com estes resultados, podemos verificar com um certo grau de precisão (95\%) que o classificador Máquina de Comitê (considerando as duas configurações) apresentou melhor resultados de classificação quando comparado com o classificador MLP, para as características: $\left[F_{c c}\right],[S I],[A]$ e $[S I+A]$, veja na Figura 6.15 as regiões destacadas por linhas pontilhadas. Por outro lado, quando foi 
comparado o classificador Máquina de Comitê com o classificador SLP, os resultados foram melhores para as seguintes características: [contraste, $A, C V$ ], $\left[F_{c c}, S I, C\right.$, contraste, $\left.A, C V\right],\left[F_{c c}\right],[S I],[A],[$ contraste $],[S I, A],[$ textura $\left.]\right] \mathrm{e}$ $\left[F_{8}\right]$, veja na Figura 6.15 as regiões destacadas por linhas pontilhadas e não pontilhadas. 


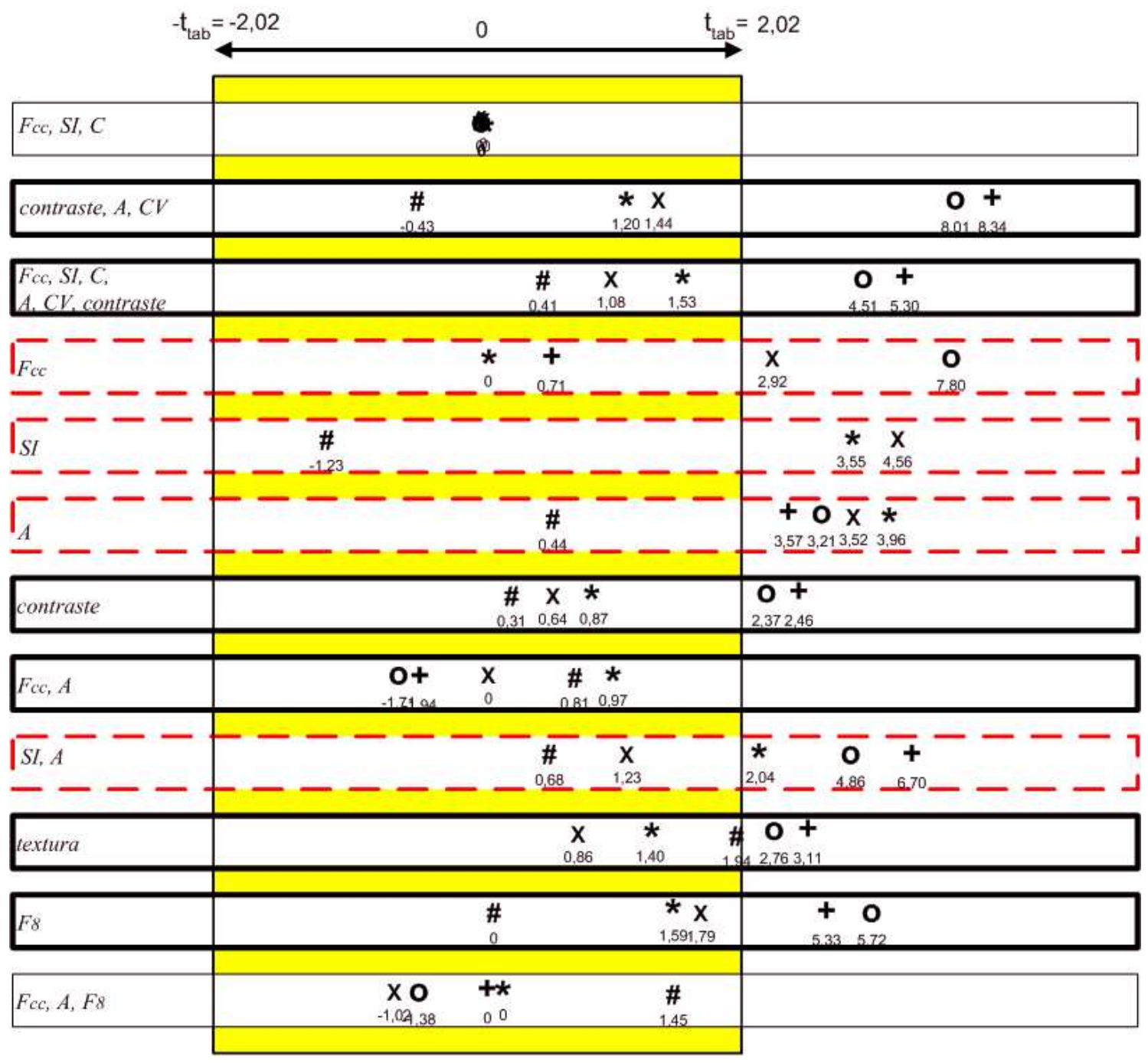

Legenda:

\# Máquina de Comitê configurado "sem $w$ continuado" $\mathbf{x}$ Máquina de Comitê configurado "com $w$ continuado" * Máquina de Comitê configurado "sem w continuado" $\mathbf{X}$ MLP

+ Máquina de Comitê configurado "sem $w$ continuado" $\mathbf{x}$ SLP

$\mathbf{X}$ Máquina de Comitê configurado "com $w$ continuado" $\mathbf{X}$ MLP

$\mathbf{0}$ Máquina de Comitê configurado "com $w$ continuado" $\mathbf{X}$ SLP

Figura 6.15: Todos os resultados de comparações. 


\section{Conclusão e Trabalhos Futuros}

Na Seção 6.1 as análises pertinentes utilizando o teste de hipóteses foram realizadas. Estas análises permitem concluir quais combinações de caracaterísticas usadas e com qual classificador, os resultados de $A_{z}$ são melhores. Além destes resultados experimentais, neste trabalho foi apresentada uma técnica de redes neurais artificiais utilizada como classificador de nódulos de mama não palpáveis identificados na imagem de mamografia pelo radiologista. Para a representação de um nódulo benigno ou maligno utilizamos uma série de conjuntos de características (características de foma, textura e nitidez da borda do nódulo) extraídas com base na marcação do radiologista, através de técnicas de processamento de imagens.

Dissertou sobre o problema do câncer de mama no Brasil e no mundo assim como a tendência da doença para os próximos anos assim como foi apresentado quais os fatores que aumentam o risco do desenvolvimento do câncer.

Como ainda não há um método para a prevenção da doença, foi discorrido sobre a mamografia, que é a melhor maneira para a detecção precoce da doença em estágios iniciais, antes mesmo que o nódulo se torne palpável. Seguiu-se a apresentação dos problemas encontrados na interpretação de um nódulo ainda em seu estágio inicial (não palpável) em uma imagem de mamografia pelos radiologistas, que cometem erros que comprometem o paciente e o sistema de saúde. Por isso surgiram pesquisas para o desenvolvimento de sistemas de auxílio ao diagnóstico 
por computador (CAD). Como estes sistemas utilizam-se de duas técnicas complementares, processamento de imagens e inteligência computacional, foi discorrido sobre as principais técnicas aplicadas neste contexto. Quanto as técnicas de processamento de imagens, estas são aplicadas com base no procedimento clínico do radiologista com o objetivo de extrair as características que melhor representam um nódulo benigno e maligno. Com as características extraídas, utiliza-se das arquiteturas de Redes Neurais Artificiais para realizar a classificação. Os resultados de classificação são analisados por método sob a curva ROC proposto para aplicações de classificadores neurais na medicina, como visto nas referências bibliográficas estudas. Finalmente, apresentamos os procedimentos dos experimentos realizados, os resultados contrastados entre outro classificadores e as análises pertinentes dos resultados obtidos com o teste de hipótese utilizando a distribuição de Student $t$, que permite comparar os resultados da média de $A_{z}$ obtidos pelos classificadores e concluir se os resultados diferem significantemente ou não diferem significantemente.

A utilização de redes neurais no auxílio a classificação de nódulos mamográficos, as técnicas desenvolvidas neste trabalho, os estudos realizados para o desenvolvimento do trabalho e a seleção das referências bibliográficas permitem mais uma colaboração para o entendimento do problema de classificação de nódulos mamográficos e desenvolvimento de novas soluções.

Um outro resultado importante deste trabalho, refere-se às características que melhor descrevem um nódulo benigno de um nódulo maligno. Dessa maneira, é possível elencar quais as características ou quais os conjuntos de características que devemos utilizar no caso de um classificador automático ou no caso de um Atlas indexado por conteúdo. Assim, esse trabalho também pode ser utilizado como uma ferramenta para grupos de estudos que trabalham com técnicas de processamento de imagens de mamografia para avaliar, se determinadas carca- 
terísticas extraídas de nódulos são capazes de diferenciar um nódulo benigno de um nódulo maligno.

Quanto aos trabalhos de extensão, podemos sugerir alguns como:

- Utilizar informações clínicas do paciente (fatores de risco, como mostrado no Capítulo 2) além das características extraídas dos exames mamográficos na classificação, para tentar maximizar a capacidade de discriminação do classificador, em nódulo maligno ou benigno.

- Verificar o problema da dimensionalidade aplicando técnicas para extrair redundâncias, como por exemplo a técnica conhecida como Análise de Componentes Principais (HAYKIN, 1999) e também procurar incorporar mais casos à base de dados para aumentar a quantidade de características.

- Fazer diferentes experimentos com a Máquina de Comitê visando melhorar a capacidade de classificação de nódulos mamográficos, como: utilizar outros conjuntos de características; ou utilizar outros classificadores neurais como especialistas do comitê; ou extrapolar alguns parâmetros da Máquina de Comitê, como o número máximo permitido de especialistas NTE e o erro máximo tolerável ( erromax $_{\max }$. 


\section{Anexo A - Teste de Hipóteses utilizando a distribuição de Student $t$}

A distribuição $t$ de Student nos permite fazer a inferência da média populacional em intervalos de confiança para uma população nas quais não se conhece o desvio padrão populacional, a partir de até 30 amostras $(\mathrm{n}<30)$, mas segundo Spiegel essa inferência pode ser estendida para casos com mais de 30 amostras desde que sejam realizadas as modificações convenientes.

A teoria permite a determinação de valores de $t$ para médias populacionais em função da média amostral, do desvio padrão amostral, dos graus de liberdade da amostra e do intervalo de confiança desejado. O grau de liberdade normalmente representado por $(\nu)$ varia com a quantidade de amostras utilizadas nos experimento. Para amostras menores que 30 (também chamado de pequenas amostras), o intervalo de confiança é considerado como sendo N-1, ou seja o número de amostras menos 1 e para amostras maiores que 30 (também chamado de grandes amostras) o grau de liberdade é considerado com sendo N. O nível de confiança é o percentual de probabilidade com relação à população que o intervalo de confiança estimara a média. Com o modelo $t$ de Student baseia-se na distribuição de probabilidade normal (ou de Gauss), um nível de confiança de $95 \%$ para as duas caudas da curva de probabilidade normal, por exemplo, significa que a média populacional (todos os casos de $A_{z}$ ) encontra-se dentro dos limites do intervalo, com probabilidade de $95 \%$. Dos $5 \%$ relativo ao provável erro, 
o valor da média teria $2,5 \%$ de probabilidade de estar acima do limite superior do intervalo de confiança e 2,5\% de estar abaixo do limite inferior (SPIEGEL, 1993). No Apêndice A encontram-se os valores de $t$, em função de graus de liberdade e de confiança. Em geral, podem-se representar os limites de confiança para as médias por:

$$
\mu= \pm t_{0,975} \frac{s}{\sqrt{N-1}}
$$

Onde $t_{0,975}$ é a constante de Student, $s$ o desvio padrão e $N$ o número de amostras.

Para o processo de decisão, ou seja, verificar se a média do resultado apresentado por um classificador difere significantemente da média do resultado apresentado por um outro classificador é necessário definir duas hipóteses:

- $H_{0}$ que é a hipótese nula geralmente indica rejeição, ou no nosso caso, o resultado de um classificador não difere do outro, e

- $H_{1}$ hipótese alternativa, ou em nosso caso, o resultado dos classificadores diferem significantemente ao outro.

Assim para um processo de decisão é feita uma comparação entre o $t$ calculado, que representaremos por $t_{\text {calc }}$ e o t tabelado (Apêndice A), representado pelo $t_{t a b}$. Para verificarmos os resultado entre $t_{c a l c}$ e $t_{t a b}$ definimos duas hipóteses $\left(H_{0}\right.$ e $H_{1}$ ), como definida anteriormente, que nos permite verificar a significância das médias de $A_{z}$ apresentadas pelos diferentes classificadores. Como descrito anteriormente, para a escolha do $t_{t a b}$ é necessário considerar o intervalo de confiança e o grau de liberdade.

Os experimentos serão realizados da seguinte maneira. Para exemplificar a explicação, imaginemos que queiramos comparar os resultados da média de $A_{z}$ 
apresentado pela Máquina de Comitê com o apresentado pelo MLP. Seja $\mu_{1}$ e $\mu_{2}$ a média de $A_{z}$ apresentado por cada um dos classificadores, devemos decidir pelas hipóteses:

- $H_{0}: \mu_{1}=\mu_{2}$, não há diferença entre o resultado apresentado pelos classificadores e

- $H_{0}: \mu_{1} \neq \mu_{2}$ há diferença significativa entre os resultados apresentados pelos classificadores

Estas comparações são feitas para um nível de significância igual a 0,05 $(97,5 \%)$.

Assim calculamos o $t_{\text {calc }}$ conforme Eq. A.2 e esse resultado será comparado com $t_{t a b}$ obtido pela tabela de distribuição t (Apêndice A).

$$
t_{\text {calc }}=\frac{\bar{X}_{1}-\bar{X}_{2}}{\sigma \cdot \sqrt{1 / N_{1}+1 / N_{2}}}
$$

Em que $\sigma$ é

$$
\sigma=\sqrt{\frac{N_{1} \cdot s_{1}^{2}+N_{2} \cdot s_{2}^{2}}{N_{1}+N_{2}-2}}
$$

O grau de liberdade $(\nu)$ é calculado por: $\mathrm{N} 1+\mathrm{N} 2-2=20+20-2=38$. Sendo N1 e N2, o número de amostras.

Assim para o nível de significância igual a $0,05 t_{0,975}=2,02$. 


\section{Referências Bibliográficas}

ALBERTA-CANCER-BOARD. Screen test: Alberta program for the early detection of breast cancer. 2099-01 Biennial Report, Edmonton, Alberta, Canada, 2001.

ALTO, H.; RANGAYYAN, R.; DESAUTELS, J. Content-based retrieval and analysis of mammographic masses. to appear in Journal of Electronic Imaging, 2005.

ANDRE, T.; RANGAYYAN, R. M. Classification of tumors and masses in mammograms using neural networks with shape and texture features. 25th Annual International Conference of the IEEE Transactions on Engineering in Medicine and Biology Society, p. 17-21, September 2003.

ARAUJO, S. D. T. de. Mortalidade por câncer de mama, com idade igual ou superior a 50 anos, estado de são paulo 1979-1997. tese de mestrado apresentada à Universidade de São Paulo, Dezembro 2000.

BAEG, S.; KEHTARNAVAZ, N. Texture based classification of mass abnormalities in mammograms. Proceedings of the 13th IEEE Symposium on Computer-based Medical Systems, v. 1, p. 163-168, 2000.

BERGADANO, F.; CUTELLO, V. Probably approximately correct learning in fuzzy classification systems. IEEE Transaction on Fuzzy Systems, v. 3, p. 473-478, November 1995.

CAMPOS, T. E. Técnicas de seleção de características com aplicações em reconhecimento de faces. dissertação de mestrado apresentada ao Instituto de Matemática e Estatística da Universidade de São Paulo, Maio 2001.

CHAN, H. P.; WEI, M. A. H. D.; SAHINER, B. S.; ADLER, D. D.; GOODSITT, M. M.; PETRICK, N. Computer-aided classification of mammographic masses and normal tissue: linear discriminant analysis in texture feature space. Physics in Medicine and Biology, v. 40, p. 857-876, 1995.

CLARIDGE, E.; RICHTER, J. H. Characterization of mammographic lesions. Proc. 2nd Int. Workshop on Digital Mammography, p. 241-250, July 1994.

DELEO, J. M. Measuring classifier intelligence. Proceedings of the 2002 PerMIS Workshop, p. 26-31, 2002. 
DELEO, J. M.; CAMPBELL, G. Receiver operating characteristic (roc) methodology in artificial neural network with biomedical applications. Proc. World Congress on Neural Networks, v. 2, p. 735-740, 1995.

DUDA, R.; HART, P.; STORK, D. Pattern Classification and Scene Analysis. Wiley, NY: John Wiley Professio, 2000.

FERRARI, R. J.; RANGAYYAN, R. M.; DESAUTELS, J. E. L.; FRERE, A. F. Analysis of asymmetry in mammograms via directional filtering with gabor wavelets. IEEE Transactions on Medical Imaging, v. 20, p. 953-964, September 2001.

FREUND, Y.; SCHAPIRE, R. E. Experiments with a new boosting algorithm. Machine Learning: Proceedings of the Thirteenth International Conference, v. 1, p. $148-156,1996$.

FREUND, Y.; SCHAPIRE, R. E. A decision-theoretic generalization of on-line learning and an application to boosting. Journal of Computer and Systen Sciences, v. 1, p. 119-139, December 1997.

GOH, W. Y.; LIM, C. P.; PEH, K. K. Predicting drug dissolution profiles with an ensemble of boosted neural networks: A time series approach. IEEE TRANSACTIONS ON NEURAL NETWORKS, v. 14, p. 459-463, March 2003.

HALKIOTIS, S.; MANTAS, J.; BOTSIS, T. Computer-aided detection of clustered microcalcifications in digital mammograms. Special Issue: Proceedings of the fifth European Systems Science Congress, v. 2, October 2002.

HALL, M.; STORELlA, J. M.; SILVERSTOND, D. Z.; WYSHAK, G. Nonpalpable breast lesions: Recommendations for biopsy based on suspicion of carcinoma at mammography. Radiology, v. 167, p. 353, 1988.

HARALICK, R.; SHANMUGAM, K.; DINSTEIN, I. Textural features for image classification. IEEE Transactions on Systems, Man, and Cybernetics, SMC-3, p. 610-621, 1973.

HAYKIN, S. Neural networks: A comprehensive foundation. Upper Saddle River, NJ: Prentice Hall, 1999.

HERMANN, G.; JANUS, C.; SCHWARTZ, I. S.; KRIVISKY, B.; BIER, S.; RABINOWITZ, J. G. Nonpalpable breast lesions: Accuracy of prebiopsy mammographic diagnosis. Radiology, v. 165, p. 323-326, 1987.

HERNANDEZ-AGUIRRE, A. The probably approximately correct (pac) population size of a genetic algorithm. IEEE, p. 199-202, 2000.

HOLDEN, S. B.; RAYNER, P. J. W. Generalization and pac learning: Some new results for the class of generalized single-layer networks. IEEE Transaction on Neural Networks, v. 6, p. 368-380, March 1995. 
HU, Y. H.; HWANG, J.-N. Handbook for Neural Network Signal Processing. [S.l.]: CRC Press, 2001.

INCA. Instituto nacional do câncer - falando sobre câncer de mama. Ministério da Saúde. Secretaria Nacional de Assistência à Saúde., 2002.

INCA. Instituto nacional do câncer - estimativa 2005: Incidência de câncer no brasil. Ministério da Saúde. Secretaria Nacional de Assistência à Saúde., 2004.

JACOBSON, H. G.; EDEIKEN, J. Biopsy of occult breast lesions: Analysis of 1261 abnormalities. J. Am. Math. Assoc., v. 263, p. 2341-2343, 1990.

JAIN, A. K.; DUIN, R. P.; MAO, J. Statistical pattern recognition: a review. IEEE Transactions on Pattern Analisys and Machine Intelligence, v. 22, p. 4-37, 2000

JIANG, J. L.; LOE, K. F. S-adaboost and pattern detection in complex environment. IEEE Computer Society Conference on Computer Vision and Pattern Recognition, v. 1, p. I-413 - I-418, June 2003.

KOVACS, Z. L. Redes neurais artificiais : fundamentos e aplicações, um texto básico. São Paulo, SP: Collegium Cognitio, 1996.

KRAUS, J. E.; PISANESCHI, J. Disponível em http://atlasveg.ib.usp.br/indice/pare.html. Acessado em 16 de Agosto, 2004

MAVROFORAKIS, M. E.; GEORGIOU, H. V.; CAVOURAS, D.; DIMITROPOULOS, N.; THEODORIDIS, S. Mammographic mass classification using textural features and descriptive diagnostic data. Proceedings of the 14th IEEE International Conference on Digital Signal Processing, v. 1, p. 461-464, 2002.

MUDIGONDA, N. R.; RANGAYYAN, R. M.; DESAUTELS, J. E. L. Gradient and texture analysis for the classification of mamographic masses. IEEE Transactions on Medical Imaging, v. 20, p. 1032-1043, October 2000.

MURPHEY, Y. L.; CHEN, Z.; FELDKAMP, L. Neural learning using adaboost. Proceedings of the 2001 International Joint Conference on Neural Networks, 2001.

MURPHEY, Y. L.; CHEN, Z.; FELDKAMP, L. Incremental neural learning using adaboost. Proceedings of the 2002 International Joint Conference on Neural Networks, 2002.

NACAPAN. Disponível em http://www.napacan.com.br/manual/manual3.asp?pag $=3$. acessado em 16 de Agosto, 2004.

NCI, N. C. I. Disponível em http://cancernet.nci.nih.gov/statistics/. Acessado em, 2004. 
PARKIN, D. Cancer burden in the year 2000. the global picture. European Journal of Cancer, v. 37, p. $4-66,2000$.

PAUlinelli, R. R.; JúNIOR, R.; CURADO, M. P.; SOUZA, A. A. e. Breast cancer in goiás, in brazil and in the world: current incidence and mortality rates. Revista Brasileira de Saúde Materno Infantil, v. 3, p. 14 - 24, Março 2003.

Petrosian, A.; CHAN, H. P.; HELVIE, M. A.; GOODSITT, M. M.; ADLER, D. D. Computer-aided diagnosis in mammography: classification of mass and normal tissue by texture analysis. Physics in Medicine and Biology, v. 39, p. 2273-2288, 1994.

RANGAYYAN, R. M.; EL-FARAMAWY, N. M.; DESAUTELS, J. E. L.; ALIM, O. A. Measures of acutance and shape for classification of breast tumors. IEEE Transactions on Medical Imaging, v. 16, p. 799-810, 1997.

RANGAYYAN, R. M.; MUDIGONDA, N. R.; DESAUTELS, J. E. L. Boundary modelling and shape analysis methods for classification of mammographic masses. Medical and Biological Engineering and Computing, v. 38, p. 487-495, May 2000.

RAO, N. S. V.; OBLOW, E. M. Majority and location based fusers for systems of pac concept learners. IEEE Transaction on Systems, Man and Cybernetics, v. 24, p. 713-727, May 1994.

ROCKIT. Disponível em http://www.radiology.uchicago.edu/krl/krl roc/software index.htm. Acessado em 16 de Março, 2004.

ROMERO, E.; ALQUEZAR, R. Maximizing the margin with feedforward neural networks. Neural Networks, 2002. Proceedings of the 2002 International Joint Conference (IJCNN), v. 1, p. 743-748, May 2002.

SAHINER, B.; CHAN, H.; PETRICK, N.; HELVIE, M.; GOODSITT, M. Computerized characterization of masses on mammograms: The rubber band straightening transform and texture analysis. Medical Physics, v. 25, p. 516-526, 1998.

SAHINER, B.; CHAN, H.; PETRICK, N.; HELVIE, M.; HADJIISKI, L. Improvement of mammographic mass characterization using spiculation measures and morphological features. Medical Physics, v. 28, p. 1455 - 1465, 1998.

SAHINER, B.; CHAN, H. P.; PETRICK, N.; HELVIE, M. A.; HADJIISKI, L. M. Improvement of mammographic mass characterization using spiculation measures an morphological features. Medical Physics, v. 28, p. 1455-1465, July 2001.

SANTOS, V. T. Segmentação de imagens mamograficas para detecção de nódulos em mamas densas. tese de mestrado apresentada à Universidade de São Paulo, Novembro 2002. 
SAUDE, A. Disponível em:

http://www.agendasaude.com.br/enciclo.asp?mostrar=neoplasias. Acessado em 16 de Agosto, 2004.

SCHAPIRE, R. E. A brief introduction to boosting. Proceedings of the Sixteenth International Joint Conference on Artificial Intelligence, p. 1-6, July 1999.

SCHAPIRE, R. E. The boosting approach to machine learning: An overview. MSRI Workshop on Nonlinear Estimation and Classification, p. 1-23, December 2002 .

SCHWENK, H. Using boosting to improve a hybrid hmm/neural network speech recognizer. Acoustics, Speech, and Signal Processing, 1999. ICASSP '99. Proceedings., 1999 IEEE International Conference on, v. 2, p. 1009-1012, March 1999.

SHEN, L.; RANGAYYAN, R. M.; DESAUTELS, J. E. L.; FRERE, A. F. Application of shape analysis to mammographic calcifications. IEEE Transactions on Medical Imaging, v. 13, p. 263-274, June 1994.

SILVA-FILHO, A. C. R. Disponível em http://neuron.ffclrp.usp.br/ disciplinas/ informatica/ raciocinio-probabilistico2.pdf. acessado em 17 de Agosto, 2004.

SILVA, L. A.; DEL-MORAL-HERNANDEZ, E.; RANGAYYAN, R. M. Classificação de tumores e massas de mama utilizando máquinas de comitê. Proceedings of the International Federation for Medical and Biological Engineering: Proceedings of the III Latin American Conference on Biomedical Engineering, João Pessoa, Paraíba, Brazil, v. 5, p. 935-938, Setembro 2004.

SILVA, L. A.; DEL-MORAL-HERNANDEZ, E.; RANGAYYAN, R. M. Classification of breast masses using a committee machine of neural networks. to appear in International Conference on Biomedical Engineering - BioMED 2005, IASTED, Innsbruck, Austria, February 2005.

SOUZA, J. W. M. de. Disponível em http://www.geocities.com/hotsprings/1613. Acessado em 07 de Janeiro, 2005.

SPIEGEL, M. R. Estatística. São Paulo, SP: Makron Books, 1993.

SUCKLING, J.; PARKER, J.; DANCE, D. R.; ASTLEY, J. H. S.; DOGGIS, C. R. M.; RICKETTS, I.; STAMATAKIS, E.; CERNEAZ, N.; KOK, S. L.; TAYLOR, P.; BETAL, D.; ; SAVAGE, J. The mammographic image analysis society digital mammogram data-base. Proc. 2nd Int. Workshop Digital Mammography, p. 375-378, 1994.

TAPE, T. G. Disponível em http://gim.unmc.edu/dxtests/roc1.htm. acessado em 02 de Julho, 2004.

VIOLA, P.; JONES, M. Fast and robust classification using asymmetric adaboost and a detector cascade. MIT Press, Cambridge, MA, 2001. 
WOODS, K.; BOWYER, K. Generating roc curves for artificial neural networks. IEEE Transactions on Medical Imaging, v. 13, p. 329-337, June 1997.

YU, S.; GUAN, L. A cad system for the automatic detection of clustered microcalcifications in digitized mammogram films. IEEE Transactions on Medical Imaging, v. 20, p. 115-126, February 2000. 
Apêndice A - Tabela da Distribuição de Student $t$. 


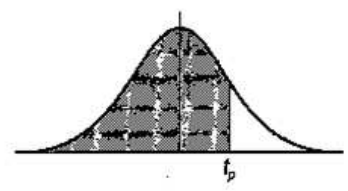

\begin{tabular}{|c|c|c|c|c|c|c|c|c|c|c|}
\hline$v$ & $t_{\theta, 995}$ & $t_{\theta, 99}$ & $t_{0,975}$ & $t_{0,95}$ & $t_{0,9 \theta}$ & $t_{0,8 \theta}$ & $t_{\theta, 75}$ & $t_{0,70}$ & $t_{0,60}$ & $t_{0,55}$ \\
\hline I & 63,66 & 31,82 & {$[2,71$} & 6,31 & 3,08 & 1,376 & 1,000 & 0,727 & 0,325 & 0,158 \\
\hline 2 & 9,92 & 6,96 & 4,30 & 2,92 & 1,89 & 1,061 & 0,816 & 617 & 289 & 142 \\
\hline 3 & 5,84 & 4,54 & 3,18 & 2,35 & 1,64 & 0,978 & 0,765 & 584 & 277 & 137 \\
\hline 4 & 4,60 & 3,75 & 2,78 & 2,13 & 1,53 & 0,941 & 0,741 & 569 & 271 & 134 \\
\hline 5 & 4,03 & 3,36 & 2,57 & 2,02 & 1,48 & 0,920 & 0,727 & 0,559 & 0,267 & 0,132 \\
\hline 6 & 3,71 & 3,14 & 2,45 & 1,94 & 1,44 & 906 & 718 & 553 & 265 & 131 \\
\hline 7 & 3,50 & 3,00 & 2,36 & 1,90 & 1,42 & 896 & 711 & 549 & 263 & 130 \\
\hline 8 & 3,36 & 2,90 & 2,31 & 1,86 & 1,40 & 889 & 706 & 546 & 262 & 130 \\
\hline 9 & 3,25 & 2,82 & 2,26 & 1,83 & 1,38 & 883 & 703 & 543 & 261 & 129 \\
\hline 10 & 3,17 & 2,76 & 2,23 & 1,81 & 1,37 & 879 & 700 & 542 & 260 & 129 \\
\hline 11 & 3,11 & 2,72 & 2,20 & 1,80 & 1,36 & 876 & 697 & 540 & 260 & 129 \\
\hline 12 & 3,06 & 2,68 & 2,18 & 1,78 & 1,36 & 873 & 695 & 539 & 259 & 128 \\
\hline 13 & 3,01 & 2,65 & 2,16 & 1,77 & 1,35 & 870 & 694 & 538 & 259 & 128 \\
\hline 14 & 2,98 & 2,62 & 2,14 & 1,76 & 1,34 & 868 & 692 & 537 & 258 & 128 \\
\hline 15 & 2,95 & 2,60 & 2,13 & 1,75 & 1,34 & 866 & 691 & 536 & 258 & 128 \\
\hline 16 & 2,92 & 2,58 & 2,12 & 1,75 & 1,34 & 865 & 690 & 535 & 258 & 128 \\
\hline 17 & 2,90 & 2,57 & 2,11 & 1,74 & 1,33 & 863 & 689 & 534 & 257 & 128 \\
\hline 18 & 2,88 & 2,55 & 2,10 & 1,73 & 1,33 & 862 & 688 & 534 & 257 & 127 \\
\hline 19 & 2,86 & 2,54 & 2,09 & 1,73 & 1,33 & 861 & 688 & 533 & 257 & 127 \\
\hline 20 & 2,84 & 2,53 & 2,09 & 1,72 & 1,32 & 860 & 687 & 533 & 257 & 127 \\
\hline 21 & 2,83 & 2,52 & 2,08 & 1,72 & 1,32 & 859 & 686 & 532 & 257 & 127 \\
\hline 22 & 2,82 & 2,51 & 2,07 & 1,72 & 1,32 & 858 & 686 & 532 & 256 & 127 \\
\hline 23 & 2,81 & 2,50 & 2,07 & 1,71 & 1,32 & 858 & 685 & 532 & 256 & 127 \\
\hline 24 & 2,80 & 2,49 & 2,06 & 1,71 & 1,32 & 857 & 685 & 531 & 256 & 127 \\
\hline 25 & 2,79 & 2,48 & 2,06 & 1,71 & 1,32 & 856 & 684 & 531 & 256 & 127 \\
\hline 26 & 2,78 & 2,48 & 2,06 & 1,71 & 1,32 & 856 & 684 & 531 & 256 & 127 \\
\hline 27 & 2,77 & 2,47 & 2,05 & 1,70 & 1,31 & 855 & 684 & 531 & 256 & 127 \\
\hline 28 & 2,76 & 2,47 & 2,05 & 1,70 & 1,31 & 855 & 683 & 530 & 256 & 127 \\
\hline 29 & 2,76 & 2,46 & 2,04 & 1,70 & 1,31 & 854 & 683 & 530 & 256 & 127 \\
\hline 30 & 2,75 & 2,46 & 2,04 & 1,70 & 1,31 & 854 & 683 & 530 & 256 & 127 \\
\hline 40 & 2,70 & 2,42 & 2,02 & 1,68 & 1,30 & 851 & 681 & 529 & 255 & 126 \\
\hline 60 & 2,66 & 2,39 & 2,00 & 1,67 & 1,30 & 848 & 679 & 527 & 254 & 126 \\
\hline 120 & 2,62 & 2,36 & 1,98 & 1,66 & 1,29 & 845 & 677 & 526 & 254 & 126 \\
\hline$\infty$ & 2,58 & 2,33 & 1,96 & 1,645 & 1,28 & 842 & 674 & 524 & 253 & 126 \\
\hline
\end{tabular}

Figura A.1: Valores dos percentis $\left(t_{p}\right)$ da distribuição de Student $t$ com $\nu$ graus de liberdade (área sombreada $=p$ ). Fonte: (SPIEGEL, 1993). 